\title{
Indigent Care in Texas: A Study of Poor Farms and Outdoor Relief
}

Martha Doty Freeman

Follow this and additional works at: https://scholarworks.sfasu.edu/ita

Part of the American Material Culture Commons, Archaeological Anthropology Commons, Environmental Studies Commons, Other American Studies Commons, Other Arts and Humanities Commons, Other History of Art, Architecture, and Archaeology Commons, and the United States History Commons

Tell us how this article helped you.

This Article is brought to you for free and open access by the Center for Regional Heritage Research at SFA ScholarWorks. It has been accepted for inclusion in Index of Texas Archaeology: Open Access Gray Literature from the Lone Star State by an authorized editor of SFA ScholarWorks. For more information, please contact cdsscholarworks@sfasu.edu. 


\section{Indigent Care in Texas: A Study of Poor Farms and Outdoor Relief}

\section{Licensing Statement}

This is a work for hire produced for the Texas Department of Transportation (TxDOT), which owns all rights, title, and interest in and to all data and other information developed for this project under its contract with the report producer. The report may be cited and brief passages from this publication may be reproduced without permission provided that credit is given to TXDOT and the firm that produced it. Permission to reprint an entire chapter, section, figures or tables must be obtained in advance from the Supervisor of the Archeological Studies Branch, Environmental Affairs Division, Texas Department of Transportation, 125 East 11th Street, Austin, Texas, 78701. 


\title{
INDIGENT CARE IN TEXAS: A STUDY OF POOR FARMS AND OUTDOOR RELIEF
}

\author{
by \\ Martha Doty Freeman \\ Principal Investigator: Douglas K. Boyd
}

TECHNICAL REPORTS NO. 79

Prewitt and Associates, Inc.

Cultural Resources Services

Austin, Texas

ARCHEOLOGICAL STUDIES PROGRAM, REPORT NO. 111

Archeological Studies Program

Environmental Affairs Division

Texas Department of Transportation

Austin, Texas

CSJ No. 0015-14-109

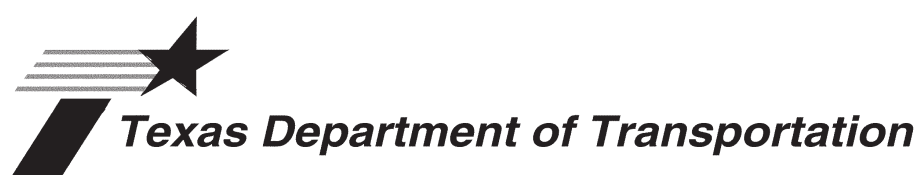

August 2008 


\title{
INDIGENT CARE IN TEXAS: A STUDY OF POOR FARMS AND OUTDOOR RELIEF
}

\author{
COPYRIGHT @ 2008
}

Texas Department of Transportation (TxDOT) and Prewitt and Associates, Inc. (PAI)

TxDOT and PAI jointly own all rights, title, and interest in and to all data and other information developed for this project under Contract 577XXSA001, Work Authorization

57704SA001. Brief passages from this publication may be reproduced without permission provided that credit is given to TxDOT and PAI. Permission to reprint an entire chapter, section, figures or tables must be obtained in advance from the Supervisor of the Archeological Studies

Program, Environmental Affairs Division, Texas Department of Transportation, 125 East 11th Street, Austin, Texas, 78701.

\author{
jointly published by the \\ Texas Department of Transportation \\ Environmental Affairs Division \\ Archeological Studies Program \\ Scott Pletka, Ph.D., Supervisor, Archeological Studies Program
}

Archeological Studies Program, Report No. 111

CSJ No. 0015-14-109

Al McGraw, Series Editor

and

Prewitt and Associates, Inc.

Cultural Resources Services

Austin, Texas

PAI Project No. 207020

Technical Reports, Number 79

Printed by Morgan Printing in Austin, Texas

ISBN 1-930788-80-0 


\section{TABLE OF CONTENTS}

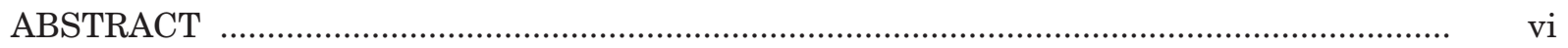

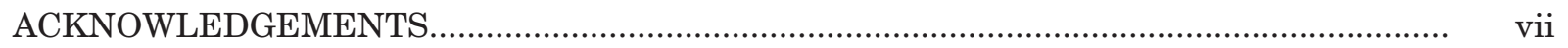

PROJECT BACKGROUND AND SCOPE OF WORK …...................................................... 1

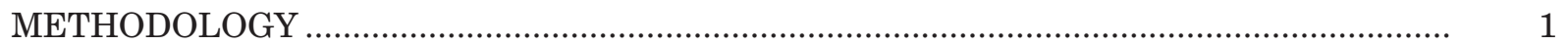

HISTORICAL LANGUAGE ASSOCIATED WITH PAUPER CARE ..................................... 2

REVIEW OF CONTEXTUAL LITERATURE ABOUT PAUPER CARE................................. 4

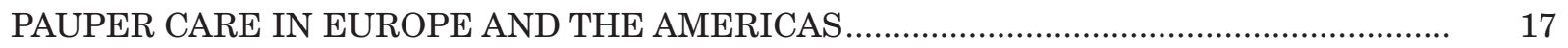

PAUPER CARE IN TEXAS ....................................................................................... 30

PAUPER CARE IN BELL COUNTY, TEXAS, 1850S-1969..................................................... 49

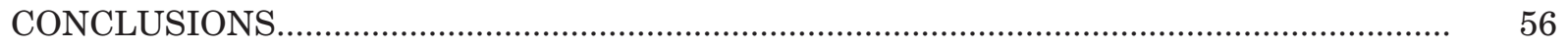

PRELIMINARY INVENTORY AND ASSESSMENT OF THE $1898-1912$

BELL COUNTY POOR FARM ............................................................................ 58

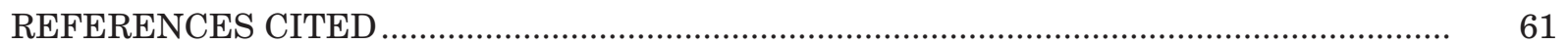




\section{LIST OF FIGURES}

1. Numbers of native- and foreign-born paupers supported by counties, $1850 \ldots \ldots \ldots \ldots \ldots \ldots \ldots . . . . . . . .31$

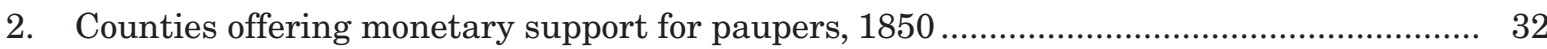

3. Numbers of native- and foreign-born paupers supported by counties, $1860 \ldots \ldots \ldots \ldots \ldots \ldots \ldots . . . . . . . . . .33$

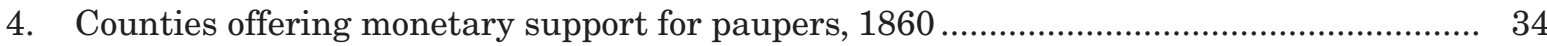

5. Numbers of native- and foreign-born paupers supported by counties, $1870 \ldots \ldots \ldots \ldots \ldots \ldots . . . . . . . .37$

6. Counties offering monetary support for paupers or levying a special tax

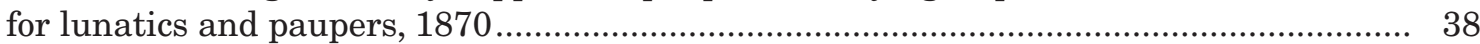

7. Counties with poorhouses and numbers of paupers and indigents in institutions,

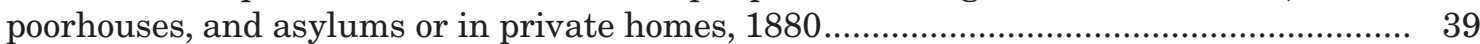

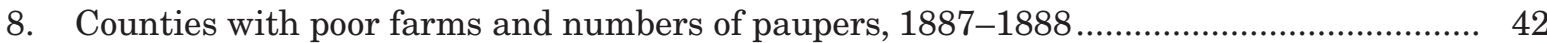

9. Counties having a county poorhouse, city poorhouse, almshouse, or poor farm and numbers of paupers in almshouses, 1890

10. Counties having a county poorhouse, city poorhouse, almshouse, or pauper farm, 1903-1904

11. Counties having poor farms or other institutions for housing paupers, 1910

12. Counties having poor farms or poorhouses, numbers of insane on poor farms, and numbers of feebleminded in jails and on poor farms,1911-1912

13. Modern aerial photograph showing Interstate Highway 35, the Bell County Pauper Cemetery on Pepper Creek, and the complex of historic buildings and features on the 1898-1912 Bell County Poor Farm property

14. Map of historic resources located on the 1898-1912 Bell County Poor Farm property west of Interstate Highway 35. 


\section{LIST OF TABLES}

1. Summary of Texas Department of Transportation work authorizations issued to Prewitt and Associates, Inc., for historical research and archeological investigations pertaining to the Bell County Pauper Cemetery on Pepper Creek (41BL1201) and the 1898-1912 Bell County Poor Farm

2. Inventory of existing and possible historical resources on the 1898-1912

Bell County Poor Farm property 


\begin{abstract}
Indigent Care in Texas: A Study of Poor Farms and Outdoor Relief was prepared by Prewitt \& Associates, Inc., for the Archeological Studies Program, Environmental Affairs Division, Texas Department of Transportation (TxDOT), as one of a series of investigations concerning pauper cemeteries and poor farms. The investigations are an outgrowth of planning for road improvements to Interstate Highway 35 between Belton and Temple that has been ongoing since 2002. The purpose of this most recent investigation has been to provide context for properties associated with pauper care in Texas and to present the findings of a preliminary field investigation of one such property in Bell County. The author concluded that indigent care in Bell County occurred most frequently outside of institutions, but that the poor farm model was an important one in the history of pauper care in Texas and the United States. Standing structures and the records associated with poor care in Texas are rare, making the surviving examples of both unusually noteworthy.
\end{abstract}




\section{ACKNOWLEDGMENTS}

The rarity of physical remains associated with poor farms in Bell County and Texas meant that the authors were particularly dependent on firsthand accounts and individuals who had taken on the subject of pauper care as something of interest. Joy Worley, granddaughter of the owners of the Bell County Poor Farm property, and her husband, Carl, met the principal investigator and the author at the poor farm site and generously spent several hours pointing out site features. Her childhood memories of the property were helpful in locating now-demolished buildings that might have been associated with Bell County pauper care between 1898 and 1912. Her relatives, Charles Ruble of San Antonio and Joanne Ruble Miller of Centerville, had less-detailed memories of the property in the 1930s and 1940s, but they generously shared what details occurred to them.

Principal investigator Douglas Boyd shared articles, books, correspondence, and online information that he collected in the time between different phases of the project. In particular, the information he received from Patricia Benoit of Temple and Linda Crannell, who has established

a website about poor relief, included data from local records and obscure publications that were of great assistance in providing a state and nationwide context.

A chance conversation with an acquaintance, Susan Cotton, led to her donation of a 1926 master's thesis by Mary McKenney Nelson. That thesis, in turn, referenced primary documents in the Legislative Reference Library and Center for American History that appeared in no other scholarly treatments of indigent care in Texas.

Employees of the Bell County Clerk's office were helpful to a fault, as were librarians at the Belton Public Library and the University of Mary Hardin-Baylor. In Austin, the staffs of the Legislative Reference Library, Texas State Library and Archives Commission, and Center for American History at The University of Texas at Austin filled the same functions, while the librarians at the Perry-Castañeda Library at The University retrieved historic texts that had been sent to storage. Michelle Mears, archivist at the University of North Texas, made portions of a master's thesis available, and friends at Lopez Garcia, a design and engineering firm in Dallas, went far beyond the author's requests to try to make a hard-to-find and impossible-to-copy text available. Sandra Hannum provided her usual help in producing illustrations for the report, which editor Elaine Robbins capably produced. 


\section{PROJECT BACKGROUND AND SCOPE OF WORK}

As part of the continuing historical and archeological investigations of 41BL1201, the Bell County Pauper Cemetery on Pepper Creek, the project historian completed historical research and limited field investigations pertaining to the associated Bell County Poor Farm. The goals of the research and investigations were: (1) to complete historical narratives about the cemetery and the associated Bell County Poor Farm at its pre-1913 location; (2) to clarify the location and extent of historical remains that were or may have been associated with the 1898-1912 Bell County Poor Farm; and (3) to compile archival and field research into a historical narrative that considered the relationships among the Pepper Creek Pauper Cemetery, the various Bell County poor farms and county home, and the broader historical context of the Texas system of poor farms and county homes as they relate to national, state, and local indigent care policies.

This project was completed for the Archeological Studies Program, Environmental Affairs Division, Texas Department of Transportation (TxDOT). The author, an independent consultant, conducted the work for Prewitt and Associates, Inc., under TxDOT Work Authorization No. 57704SA006. This project is the eleventh in a series of tasks authorized and funded by TxDOT since 2002 (Table 1). These studies were initiated because of planning for road improvements to Interstate Highway 35 between Belton and Temple (TxDOT CSJ No. 0015-14-109). This road improvement project is still in the planning stages, and no final decisions have been made regarding construction details. Consequently, the potential impacts of this project on the historical resources in question-which include certain structures and features associated with the 1898-1912 Bell County Poor Farm west of IH 35 and the Bell County Pauper Cemetery on Pepper Creek just east of IH 35-are not known.

\section{METHODOLOGY}

Work on the project started with a field visit to the site of the 1898-1912 Bell County Poor Farm by principal investigator Doug Boyd of Prewitt and Associates, Inc.; Joy Riley Worley, the granddaughter of H. R. and Minnie Pearl Smith, who owned the property from 1929 to 1959; and the author. Mrs. Worley's husband, Carl Worley, also was present. Worley identified and described numerous features on the site but, with the exception of a jail structure, was unable to verify the functions or ages of other buildings. Other individuals interviewed included Charles Ruble of San Antonio and Joanne Ruble Miller of Centerville, who were related to Minnie Smith and visited the Smith property in the 1930s and 1940s. Neither Ruble (2008) nor Miller (2008) was knowledgeable about buildings on the property that might have been associated with its use as a poor farm.

Archival research consisted of the completion of an annotated bibliography and acquisition of additional contextual information. The historian focused particularly on acquiring information from a variety of Internet sites about other poor farms in Texas and from the Texas Historical Commission about poor farms that had been listed in the National Register of Historic Places or designated as Registered Texas Historical Landmarks. Because Texas was a part of Spain and, later, of Mexico, the author also collected supplemental information about pauper care in European countries relatively unaffected by the Reformation and about the traditions of poor care in Latin America, Mexico, and Mexican Texas. Late in the project, a chance conversation with an individual unrelated to the project resulted in the acquisition of a previously unknown M.A. thesis that described poor care in Texas through the 1920s. The thesis bibliography included references to several early twentieth-century studies of pauper care in Texas that the historian had not seen cited in any other scholarly works.

Completion of the research phase resulted in a review of current scholarship about the precedents for pauper care in the United States and Latin America. A focus on poor care in Texas included broad studies about legislation, the locations of pauper facilities, and public policy governing care of indigent classes, as well as narrowly focused studies of facilities in Anderson, Bell, Bexar, Bowie, Cass, Collin, Dallas, El Paso, Ellis, Fannin, Galveston, Grayson, Harris, Hill, Hunt, Hutchinson, Kaufman, Milam, Navarro, Parker, Tarrant, 


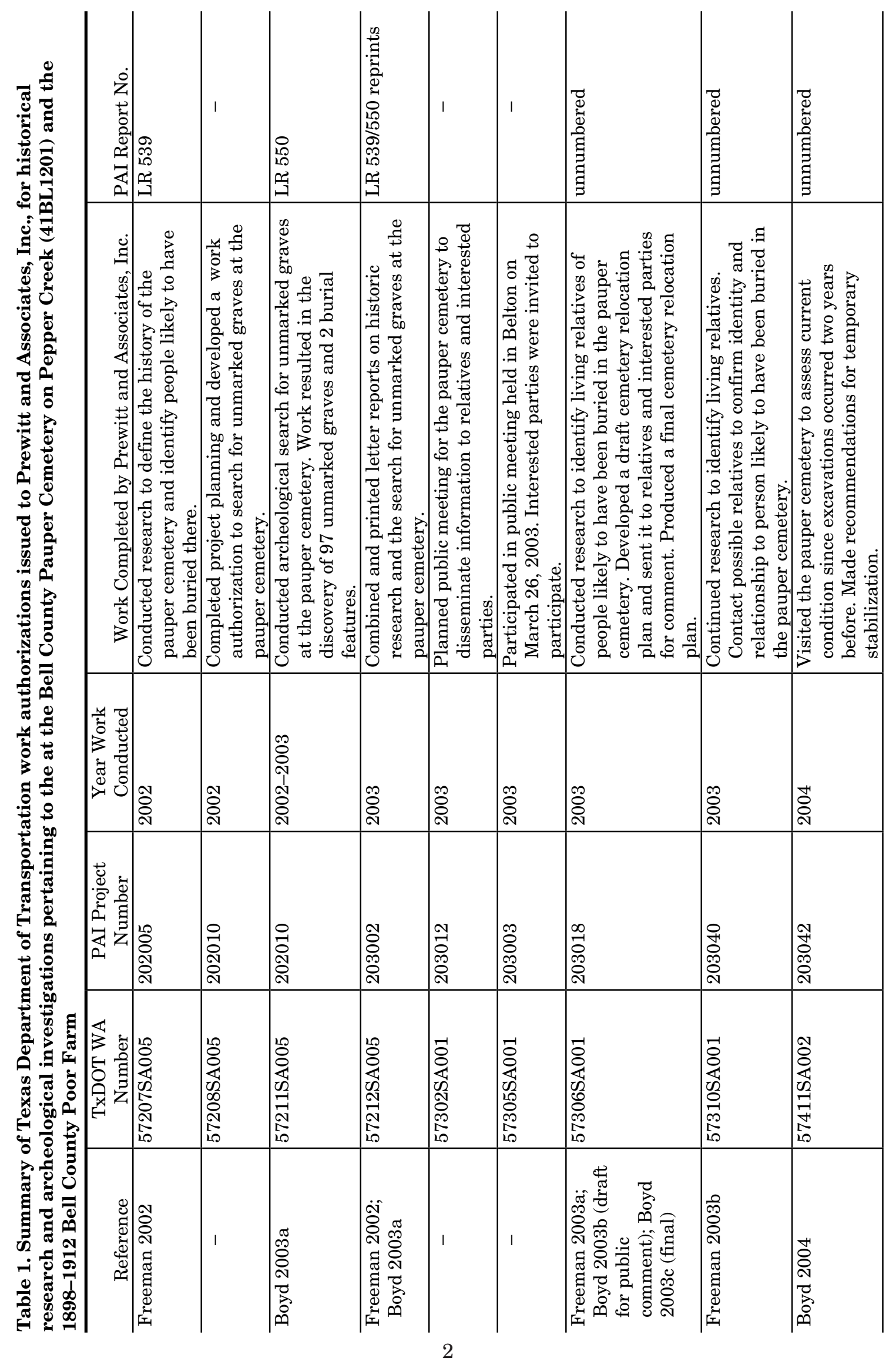




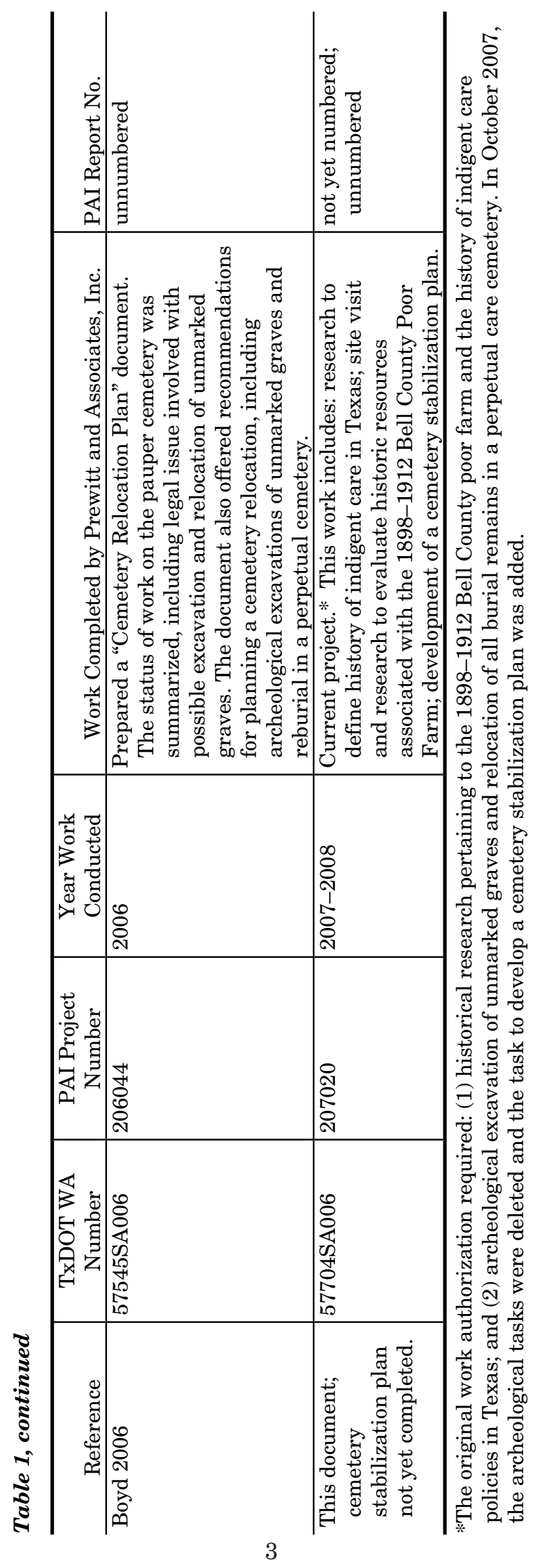


and Travis Counties. Finally, primary source materials, consisting largely of census data, provided information about pauper care both nationally and in Texas.

The research does not purport to be exhaustive. Study of scholarship about the history of pauper care was limited by the publications available at The University of Texas at Austin, where the Perry-Castañeda Library included nineteenth- and twentieth-century primary and secondary texts about pauper care in the United States, Latin America, and Europe. Collections at the university's Center for American History, the Legislative Reference Library of Texas, and the Texas State Library and Archives Commission all had primary and secondary materials that pertained to indigent care in Texas.

\section{HISTORICAL LANGUAGE ASSOCIATED WITH PAUPER CARE}

Prior to the early twentieth century, society at large and public officials interested in policies supporting pauper care developed language that was used to describe and classify individuals who were members of the indigent class and to explain the structures of public and private care that evolved to meet their needs. Many terms used historically, particularly those that described various medical and nonmedical conditions that afflicted certain classes of people, sound harsh to twenty-firstcentury sensibilities.

However, in the interest of conveying the sense, as well as the historical facts, associated with the history of indigent care, the author has retained much of the language contained in historical literature that described various indigent classes. Some historical terminology is still used in current literature. Other terminology has been changed to reflect changes in public and professional attitudes. Terms that appear in the body of the report include the following:

Auctioning off the poor: Sometimes, the poor were auctioned off to the lowest bidder, who then used the labor of the individual pauper. In turn, the bidder was expected to provide board, nursing care, and clothing; doctor's bills and funeral charges were extra. In the eighteenth century, auctioning off was seen as a way to avoid the public expenses that accompanied housing the indigent in institutions (Wagner 2005). Beginning in the nineteenth century, paupers in poor farm settings were, in effect, auctioned off as a group when the facility itself was auctioned off by the county to the highest bidder.

Blind: Federal censuses enumerated paupers who were both totally blind and semiblind, but not any individual who could see well enough to read. Blind persons could be self-supporting or partly self-supporting. Those who were totally blind were "unable to distinguish forms or colors; the partially blind [could] distinguish forms or colors, but [could not] see to read, or at least not without such effort as to making reading practically impossible" (U.S. Bureau of the Census 1880). Like deaf mutes, idiots, and the insane, blind individuals sometimes became part of the pauper class and, thus, part of the population of poor homes and pauper farms.

Boarding out: By at least the eighteenth century, the old, ill, poor youth, and disabled individuals having a "strong back and weak mind" who could do farm and other work were boarded out to households who were paid by a town or county to take care of the indigent (Wagner 2005:8).

Deaf mutes: Census enumerators were cautioned to identify within this category only those who could not speak because they could not hear well enough to learn to speak, and to differentiate them from semi-mutes and semideaf individuals. Enumerators were told to take particular pains to identify those deaf mutes who had suffered the condition from birth as opposed to those who had become deaf mute at a later age. Pains also were taken to identify all deaf mutes within a given community, a task that was relatively simple because "The class feeling of the deaf and dumb, arising from their isolated state, is so great that they seek each other out for the sake of companionship, and ordinarily know every deaf-mute for miles around" (U.S. Bureau of the Census 1880).

Homeless children: Children in institutions "designed for the care of poor or homeless children, or in any poor-house or other asylum for the destitute" were of particular interest to census enumerators. Enumerators were requested to ask questions about children's "antecedents" that were "designed to bring out 
the proportion of children in institutions who belong to the respectable and to the vicious classes severally" (U.S. Bureau of the Census 1880).

Idiots: The word "idiot" had a special meaning and referred to a person whose mental facilities were arrested in infancy or childhood, or a person who had become idiotic as a result of scarlet fever, measles, meningitis, a blow to the head, a fall or fright, or some other event. Such a person was different from demented or insane individuals who might display some signs of apparent idiocy because their mental powers had deteriorated as a result of insanity. Idiots could be self-supporting, partly selfsupporting, or not self-supporting at all. They might be maintained or treated in an institution at their own expenses, or at the expense of a town, county, institution, or state agency. As with deaf mutes, the government in 1880 was particularly interested in identification of individuals who had been idiots from birth (U.S. Bureau of the Census 1880).

Indoor relief: Indoor relief was relief provided to an indigent individual in the context of an institution such as a poorhouse, workhouse, or poor farm (Wagner 2005:8).

Insane: According to the 1880 census, forms of insanity included "mania, melancholia, paresis (general paralysis), dementia, epilepsy or dipsomania." Insane persons could have multiple attacks of insanity, and enumerators were instructed to determine how old the individual was when the first attack occurred, how many attacks he had suffered, and how long the most recent attack had lasted. They also were to describe the ways in which insane individuals were cared for and restrained, whether in an institution or at home (U.S. Bureau of the Census 1880).

Legal settlement: Also known as settlement, legal settlement was the requirement that an individual seeking assistance from a county be able to prove that he or she had lived there for a set period of time, the length of which was established by the town, county, or state. Some states required that individuals pay taxes before receiving aid. A few states had no requirements, and one county would accept indigent individuals from another county. According to Wagner (2005:153 n10), the principle of settlement was not overturned until the 1960s, when the Supreme Court ruled that "extensive residency laws for the purpose of welfare and other benefits violated the Constitution."

Occasional or temporary poor: This class was comprised of individuals who were supported sporadically, often during times of bad weather or economic distress. Such individuals often cycled in and out of institutions and usually were physically capable of working.

Outdoor relief: Outdoor relief was care provided outside of a community-, county-, or state-owned facility that required no removal from the home and placement in an institution. Often public funds were given to an individual who continued to live in his own home, or to a family member or acquaintance who then housed and cared for the pauper.

Permanent poor: The permanent poor were those who were regularly supported on a longterm basis at public expense. Typically, these individuals were children or the elderly or were physically or mentally afflicted in some way that precluded their working.

\section{HISTORIOGRAPHY OF CONTEXTUAL LITERATURE ABOUT PAUPER CARE}

Literature about the history and character of pauper care and public policy consists of primary and secondary source materials that are organized geographically from the national to the local levels and chronologically from the Middle Ages through the Reformation, the American colonial period, and industrialization and urbanization that occurred during the nineteenth and early twentieth centuries. Additionally, the literature discusses the religious, philosophical, political, and sociological underpinnings of pauper care that had an impact on public and professional perceptions of the pauper class and resulted in the formulation of theory and legislation that directly impacted poor care.

As early as the 1820 s in the eastern United States, officials responsible for or interested in poor care visited almshouses to collect information about the buildings that housed paupers of all types, the policies and laws that governed their care, and the governmental structure associated with each institution (Philadelphia Board of Guardians 1827). Perhaps the bestknown of these studies was that of John Yates, 
New York Secretary of State, who reviewed the laws governing and expenses associated with poor relief in New York, Massachusetts, Rhode Island, Connecticut, New Hampshire, Delaware, Pennsylvania, Illinois, Virginia, Vermont, New Jersey, Maryland, North Carolina, South Carolina, Georgia, and Alabama. He classified the poor, stating that the permanent poor were those "regularly supported, during the whole year, at the public expense." This class included idiots, lunatics, the blind, extremely aged and infirm, lame or those incapable of labor, children, and men and women who could not earn a living. According to Yates, the second class of poor were the occasional, or temporary, poor who received relief sporadically, usually in the fall or winter. Yates concluded that the greatest number of both classes were found in large cities, villages, and towns because of the density of population and their proximity to commercial and navigational facilities. He remarked on the impact of alcohol on individual paupers and their families, and he analyzed the pauper class by sex and place of origin, noting that 52 percent were female and 48 percent male, and a disproportionate number (27 percent) were either aliens or naturalized foreigners. A very large number (about 40 percent) were children younger than 14 , and Yates introduced a theme that became pervasive in literature about poverty: uneducated children would one day "form a fruitful nursery for crime." Finally, Yates touched on laws that pertained to residency as a requirement for receiving care, on the high proportion of paupers in Europe (10 percent of the total population), and on the virtues of the poorhouse system, which had a history of diminishing "the evils and expenses of pauperism" (Yates 1971:939-1111).

The studies of the 1820s were followed in the 1830 s and 1840 s by a report by Samuel Chipman and increasing numbers of comments by members of Congress, who were concerned about the potential annexation of slave states. Chipman's study of poorhouses, jails, and other public institutions in the Middle Atlantic and New England states highlighted links among intemperance, poverty, and criminality. While he described his work as the first to systematically classify paupers and criminals, his emphasis on the effects of alcohol overrode all other explanations for the existence of a pauper class (Chipman 1834). Remarks by politicians prior to the annexation of Texas by the United States were similarly weighted to a particular point of view. Commentary by the Honorable William Lowndes Yancey of Alabama, for example, pointed out that the "proportion of colored prisoners and paupers to the entire colored population" was larger in Boston, New York City, and Philadelphia and progressively smaller in Richmond and Charleston. He believed that statistics showed that "bond and free negroes stand higher, physically, and morally, in the slave, than they do in the free, States" (Yancey 1845:14). Theodore Sedgwick also presented statistics that showed a lower proportion of dependent classes in the slaveholding versus the non-slaveholding states. He concluded, however, that a slave, "for all intents and purposes" was "but a pauper-fed by another, clothed..." (Sedgwick 1844:43).

A last pre-Civil War study by Thomas R. Hazard (1851) identified four systems for poor relief: parceling the poor out to the lowest bidder, contracting with a committee for their maintenance, placing them in a town-owned asylum, and providing what was called outdoor relief (outside of a community-owned facility) (Hazard 1851:85). While Hazard's classification system focused on Rhode Island paupers, it was, in fact, broadly representative of care systems throughout the eastern half of the United States at mid-century.

Hazard also attempted to identify the causes of poverty, and he listed a broad range of situations that included both conditions over which an individual theoretically had some control (disagreements with a husband; intemperance; and insanity due to high temper, immorality, impurity, and use of opium), and those for which an individual might not be responsible (intemperance by others, ill treatment, imbecility, insanity due to heredity, loss of an industrious husband, loss of property through fraud, old age, and ill health) (Hazard 1851:10-11, 15, 32). Hazard recognized the variety and complexity of factors that might result in a condition of pauperism, and he identified tools developed by communities to deal with that heterogeneous population.

Intemperance remained a theme throughout the nineteenth century, but its identification as a cause of pauperism was not without detractors. G. Thomann (1884:3-5), for example, disputed prohibitionists' arguments that inebriety 
was the condition most responsible for insanity, pauperism, and crime. Rather, he pointed to theories that the use of new steam manufacturing processes in factories and on farms had "created an army of involuntary idlers" and that overproduction and over-speculation, accompanied by lockouts, strikes, and financial crises, were root causes of pauperism (Thomann 1884:40). He pointed out that many theorists believed that abuse of alcohol was "not the cause, but an effect of poverty." Thus, "[i]n reality, intemperance is quite often the effect; poverty the cause, and pauperism the ultimate result" (Thomann 1884:43). He pointed to Europe, where humanitarians were trying to improve living conditions for the poor, and he concluded that, "aside from physical ailment, and the results of economic evils and scant natural resources, indolence and improvidence are the chief sources of pauperism...." To support his theory, he pointed to one New York poorhouse where 68 percent of the indigent males were disabled, 15 percent had no work, and 11 percent were intemperate. Of the last class, 53 percent were from Ireland and 39 percent from the United States (Thomann 1884:40-41, 45, 47).

While statistics for pauperism were recorded in every U.S. census beginning in 1850 , and the 1880 census provided detailed data about the condition of every individual receiving public assistance, the 1890 census was the first to be accompanied by specific studies by the federal government (U.S. Department of the Interior, Census Office 1895; 1896). These studies dealt with paupers who were residents of almshouses and with inmates of benevolent institutions, some portion of whom were "objects of charity" or had some connection with the pauper class. The analyses performed on the collected data for both classes sought to answer questions about the number of female residents who had borne children, the causes of pauperism or other dependence, the type of institutional support offered, the number of residents who had relatives in the same institutions, educational opportunities for inmates younger than 16 years old, the number of illegitimate children, the number of children born in an institution, the number of children with living parents, the number of children surrendered to the institution, foundlings, and the number of able-bodied inmates (U.S. Department of the Interior, Census Office 1896:1-3).
Based on collected statistics, the census office concluded that from greatest to least the assigned cases of pauperism in almshouses (where men were in the majority) and benevolent institutions (where women were in the majority) were: want of any other home; old age and infirmity; being crippled, diseased (rheumatism, paralysis, epilepsy, and syphilis), deformed, or bedridden; and being a tramp. The exception to the similar lists was the condition of lying in, which was more prevalent in benevolent institutions (U.S. Department of the Interior, Census Office 1896:302, 355).

The growing interest in statistical data about the poor was reflected in studies of specific populations, such as that by Mary Roberts Smith, who studied 228 women in the San Francisco, California, almshouse in 1892-1894 (Smith 1896), and other studies by the federal government. In 1904, the Bureau of the Census examined paupers in almshouses and focused on an enumeration of poor laws passed by state legislatures. Specifically, the bureau was interested in the kind and extent of outdoor relief, how a person qualified for outdoor relief, the classes of people who were entitled to aid, how almshouses were administered and governed, treatment of destitute children, and extent of state supervision of almshouses (U.S. Department of Commerce and Labor, Bureau of the Census 1906:41).

In Texas, Dr. M. L. Graves, superintendent of the Southwestern Insane Asylum in San Antonio, turned his attention to the percentages of the insane in Texas as a proportion of the general population, critiqued the state lunacy laws, analyzed the cases of insanity (with special emphasis on heredity), and concluded that the burden of taxation would become insupportable if the root causes of mental defectiveness were left untreated. Touching on a topic that would become widely discussed by World War I, Graves lamented the lack of consideration given to inappropriate breeding and its inevitable impacts on heredity (Graves 1905:3-16).

Six years later, in 1910, the federal government again studied the pauper population in almshouses, which it defined as "an institution supported or controlled by town, municipal, county, or state authorities and used for the shelter of persons who are without means for self-support and who have no relatives 
able and willing or legally bound to aid them" (Harris 1915:11). The report's author pointed to changes in general trends, such as the decreasing use of almshouses to house tramps and petty criminals and to house women and children, for whom there were more care options available (Harris 1915:11). He noted that not only had the percentage of paupers within the general population declined in every census since 1880 , but that almshouse paupers were a "rapidly shifting group," moving in and out of almshouses relatively quickly (Harris 1915:9). He also summarized state laws that indicated that the preponderance of care was offered on a county level and supervised by county commissioners, supervisors, or the county court. However, in some cases, care was provided by towns. In general, there was a trend for states increasingly to supervise charities (Harris 1915:12).

Harris summarized a number of national patterns, noting that the greatest number of paupers per 100,000 population was in New England and the smallest number was in the West South Central division, which included Texas. Statistics pertaining to age demonstrated that about one-third of paupers were younger than 55 , another one-third were ages 55-69, and the final one-third were 70 and older. A full 1 out of 60 individuals over the age of 79 were in almshouses. On the other hand, the proportion of paupers younger than 50 had declined in every census. The ratio of men to women during the same period had increased steadily (Harris 1915:9).

Nationally, the ratios of whites and Negroes relative to general population were roughly equivalent, but foreign-born individuals were disproportionately represented (Harris 1915:9-10). Paupers also were more likely to be single and illiterate. Men were most likely to have been unskilled laborers and women to have been domestic servants. In 1910, about 80 percent were either unable to do any work or had diminished capacity. Almost 64 percent were physically or mentally defective, but the number of insane and feebleminded was declining in almshouses due to the establishment of special institutions for their care. A relatively high percentage died each year, with the leading cause of death being tuberculosis (Harris 1915:9-10).

Harris noted that the length of stay in an almshouse depended on whether the individual was what he defined as one of the larger group of "temporary inmates, who come in times of misfortune or unemployment and generally leave within a year" or the smaller group of "permanent paupers, who have definitely failed in the economic struggle and who go to the almshouse to spend their declining days" (Harris 1915:10). The size of the first group probably accounted for the statistics that enumerated large turnovers within the space of a single year. He concluded from that pattern that "paupers in almshouses are an unstable, rapidly shifting, group..." Indeed, many of them were "not paupers at all in the generally accepted sense of the word 'pauperism,' which usually implies a permanent condition of indigence as contrasted with 'poverty,' which may be temporary" (Harris 1915:12).

Harris's study supplemented a study (U.S. Department of Commerce, Bureau of the Census 1914) of state laws that pertained to dependent classes and noted changes that had occurred in perceptions and treatments of those classes. According to the federal study, public and government agencies no longer considered the insane, feebleminded, epileptic, leprous, and inebriated to be "drags upon the community, who must somehow be taken care of," but rather "unfortunates to whom the community owes relief and support" (U.S. Department of Commerce, Bureau of the Census 1914:6). Traditional language itself was thought to be changing, so that "pauper" had been replaced by "poor," "indigent," and "dependent"; "pauper asylum" and "poorhouse" were being replaced by "infirmary," "hospital," and "home for the aged and infirm"; "insane asylum" was being replaced by "state hospital"; and "charity" by "aid." Simultaneously, the structure of aid was becoming more centralized, so that care previously provided by local authorities was shifting to the state, which increasingly oversaw private as well as public care institutions (U.S. Department of Commerce, Bureau of the Census 1914:5-7).

Analysis by the federal government was paralleled by state-level studies in the early twentieth century, including one by the Kansas Board of Control. That state's poor relief through county almshouses began in the early 1860 s and was regulated by state legislation. Although the state had established specialized 
institutions to house special classes of people, the county almshouse persisted as a refuge (albeit humiliating) for the destitute aged (Kansas Board of Control 1908:255-256).

In Texas, C. S. Yoakum discussed the cases of feeblemindedness, the place of defectives in society, the benefits of segregating defectives by means of state care, the proper care and treatment of the insane, and changes in public policy that needed to occur in Texas. He provided examples of public institutions that cared for defectives, including jails and poor farms. A recurrent theme in his study was the need to prevent the growth of defective populations through sterilization and other methods to end their reproduction while providing them with "the highest degree of training, protection, care, and enjoyment, of which they are capable" (Yoakum 1914).

George Warfield (1915) conducted an examination of outdoor relief in Missouri that urged reform and struck a different tone from the earlier study by the Department of Commerce. Warfield criticized those responsible for overseeing local relief because they were not properly trained and gave monetary relief in such a way that it tended to encourage various forms of immoral behavior. Echoing an increasingly common theme, Warfield pointed to the tendency of the feebleminded to propagate and noted that many who received relief were related by blood or marriage: "So striking was this fact that it raises a question whether the dependent element of the population, and, from many indications, the defective and criminal elements also, do not belong to a comparatively small number of families in which degeneracy is marked." Warfield then strongly urged that Missouri through its board of State Charities maintain county records of outdoor relief, investigate those requesting aid, authorize the board to act as the coordinator of the various public and private charities, and develop "a system of county or district asylums on the cottage plan" to provide appropriate custodial care for "indigent defectives, especially the mental defectives..." (Warfield 1915:iv-v).

These state-level studies were accompanied in the first two decades of the twentieth century by broad studies concerning the history of poor care, evolving policies, attempts to define the types of individuals in need of care, and even an investigation of appropriate archi- tecture for poor farms and poor homes. Written primarily by a new vanguard of reformers, the publications included Alexander Johnson's analysis of almshouse construction and management. Johnson, who was General Secretary of the National Conference of Charities and Correction, sounded the then-common alarm against outdoor relief because he believed that it was the system most likely to be abused (Johnson 1911:2-3). On the other hand, institutions that were overly large usually resulted in aggravation of underlying problems and encouraged the multiplication of degenerate populations such as those in Great Britain, where the sheer number of "defectives" threatened the country's "national existence" (Johnson 1911:46). Johnson advocated the care of paupers in relatively small units that would facilitate the simultaneous care for and control of "defective inmates" (Johnson 1911:5-6).

Johnson addressed several topics that were key to the appropriate housing and care of paupers. The location of facilities should be in the country, but proximate to population centers. A country setting allowed for the cultivation of an institutional food supply and disposal of waste from the kitchen and dining room. The setting also provided opportunities for beneficial labor (Johnson 1911:8-10).

An appropriate site should be accessible and it should include a good supply of potable water. The site should have both well-drained soils and soils that were in good enough condition to farm. It was useful to have a wood lot for fuel and for its aesthetic and recreational attributes. An additional plus for any site was its natural beauty, which could be enjoyed by inmates having few other pleasures. An almshouse constructed on such a site should be organized with specific points in mind: the appropriate classification of the various classes of paupers according to their conditions, absolute segregation of the sexes, abundance of fresh air and light, adequate floor space for various uses, accessibility of every part of the facility to the administration, and "the comfort and convenience of all the inmates" (Johnson 1911:11-13, 16). Johnson then provided certain standardized plans for facilities that incorporated specific planning principles.

Johnson's analysis of almshouse architecture included a number of appendices that consisted of short studies concerning the draw- 
backs of mingling different classes of paupers in a single institution, the roles of county hospitals, systems to classify paupers in Great Britain and Denmark, the persistence of the concept that some almshouses should also serve as houses of correction, and problems associated with imbeciles and feebleminded individuals. The appendices also investigated the roles that public relief and private philanthropy play in the perpetuation of indigency, the need for control of the population, advice to superintendents, appropriate work for defectives, the need to restrain "vagrant and degraded women" who frequently became mothers of illegitimate paupers, examples of the ill treatment of insane paupers, and a discussion of plans for model institutions.

One appendix concerning the function of the almshouse was a paper given to the National Conference of Charities and Correction that summarized changes that had occurred to the institution. Stating that almshouses were characterized by their individuality because they represented different stages of development in the care of the dependent class, the author maintained that earliest almshouses were "public dumping ground[s] for all classes of dependents and defectives and for some classes of delinquents." These classes included children, idiots, epileptics, insane and feebleminded individuals, deaf and dumb, blind, sick, tramps, criminals, and "the respectable aged poor." Over time, some of these dependent classes were removed in part or whole to specialized institutions (Johnson 1911:171-172). The author enumerated factors that determined how effective an almshouse could be: the character of the head public figures in positions of authority, the extent to which almshouses were open institutions whose inmates were relatively free to come and go, and the numbers of individuals who could reasonably and economically be cared for.

About the first factor, the author concluded that, because people in charge of almshouses tended to be elected or appointed officials with no scientific skills specific to the defective classes, those dependents who required "special scientific treatment" were not "proper almshouse inmates."

About the second factor, the author believed that individuals such as prisoners or other delinquents who must be kept under lock and key were not appropriate residents in an institution that was relatively open. Finally, city almshouses tended to be large, but the vast majority were relatively small institutions that served fewer than 100 inmates. Therefore, "[a]ny classes of dependents...who cannot properly and economically be cared for in small numbers, are not suitable almshouse inmates" (Johnson 1911:173-174). In conclusion, the author stated that classes such as children; and the blind, deaf and dumb, idiotic, feebleminded, insane, epileptic, consumptive, acutely diseased, and pregnant did not belong in almshouses due to the specialized care they required. Rather, appropriate residents were "those aged and infirm persons who are unable to support themselves and are without relatives to support them." For that population, an institution "something between a hospital and a home" was most appropriate (Johnson 1911:174-180).

In 1916, Edward Devine applied scientific principles to the analysis of pauperism. Unlike other authors who categorized members of the pauper class itself, Devine created two broad categories of condition: 1) poverty, which he believed was "the larger and more important problem" with links to economic reform, health, housing, and the administration of justice and capable of being reduced by "economic, sanitary and social reforms, public hygiene and social insurance, effective organization of charity and the development of educational measures..."; and 2) pauperism, which was distinguishable from poverty because it consisted of "the habitual receipt of public relief" and of the habit of making little rather than needing much (Devine 1916:3-4). He distinguished his classification system from the legal concept that underlay English and North American poor laws, "recognize[d] a legal right to relief [and] create[d] an elaborate machinery for the administration of this poor relief" with the almshouse, poorhouse, poor farm, or county home at its center. He also distinguished the North American classification system from the religious concepts that underlay the charity of Catholic countries in Central and South America, where benefaction was "a means of spiritual edification of the giver..." Its central feature was the "privilege of giving" rather than the "right to relief." Devine's "new" view of poverty and pauperism, the "natural view," held 
that it was possible to abolish poverty and pauperism by providing for the "segregation and humane care of the feeble-minded, the prevention of alcoholism, and the development of social insurance against sickness." Fundamental to achieving abolition were professional sanitarians in the public health service and the "professional and technical training of social workers for the tasks of relief and prevention" (Devine 1916:6-8, 18-19).

Like many others of his generation, such as Margaret Sanger, ${ }^{1}$ and contrary to the conclusions drawn by the U.S. Department of Commerce (1914), Devine was a proponent of eugenics, the science of racial improvement. $\mathrm{He}$ believed that pauperism was a "distinct hygienic problem," one primarily of "mental defect," and that it could be controlled or eliminated by the "segregation and humane treatment of individuals and the gradual elimination of defective strains..." (Devine 1916:5). He maintained that, while the mentally defective were unfit for parenthood, they were people "whose minds cannot be cured but who can transmit their defect, with its strains of pauperism, prostitution, criminality, and other grievous consequences" (Devine 1916:11-12). He suggested that the scientific community distinguish between pauperism, which was a "mental disease or mental defect" capable of being eliminated or relieved "by eugenic and sanitary measures"; and poverty, which was an "economic and social condition" that could be eliminated or mitigated by economic progress and social reform..." (Devine 1916:5).

Three years after Devine's study, Frederick Hoffman concentrated on one aspect of pauper life-the issue of burial in large cities. His book was largely an advertisement for industrial insurance, life insurance offered to less prosperous wage earners on an "industrial" or weekly payment plan and often used to pay burial expenses. Hoffman identified the disfavor with which pauper burials were viewed and the impact that industrial insurance had in the United States beginning in 1875. He maintained that the availability of such insurance had dramatically reduced the rate of pauper

${ }^{1}$ Sanger, founder of the American Birth Control League, particularly emphasized the need to prevent the feebleminded, physically unfit, materially poor, racially inferior, and mentally incompetent from propagating. burial between 1880 and 1918, but that the potter's field remained "a relic of barbarism and a disgrace to modern civilization" (Hoffman 1919:10-12, 93).

The 1920s saw a reexamination of the subject of paupers on a national scale by the federal government, which published its study of paupers in almshouses in 1923 and a followup study of the cost of American almshouses in 1925. The first study omitted recipients of outdoor relief and inmates of other institutions, focusing instead on those poor who lived in almshouses. It defined the almshouse as "an institution supported or controlled by town, municipal, county, or State authorities and used for the shelter of persons who are without means of support and who have no relatives able and willing or legally bound to aid them" (U.S. Department of Commerce, Bureau of the Census 1925:2).

One of the most important contributions of the 1925 analysis was that it looked back at the statistics from the 1850, 1860, 1870, 1880, 1890, 1904,1910 , and 1923 censuses of paupers and drew certain conclusions. First, in the United States generally and most states individually there had been a marked decrease in the number of almshouse paupers between 1880 and 1923 and a particularly large decrease between 1904 and 1922. Exceptions to this pattern occurred in the West North Central, West South Central, and Mountain divisions; the states comprising the West South Central division (Arkansas, Louisiana, Oklahoma, and Texas) increased, and in Texas, the numbers doubled from 1880 to 1904 and declined only slightly in the 1910 and 1923 censuses. However, at no time did the numbers of almshouse paupers in Texas exceed 27.2 per 100,000 population, or .027 percent (U.S. Department of Commerce, Bureau of the Census 1925:6-7, 9). Another important contribution of the study was its conclusion that "paupers in almshouses are a rapidly shifting group and...many of them are not paupers at all in the sense of being permanently indigent" (U.S. Department of Commerce, Bureau of the Census 1925:3). This conclusion confirmed that of Harris (1915:12) a decade earlier.

A second government study, this one by Estelle Stewart in 1925, traced the origins of the American almshouse and workhouse (including poor farms) to English poor law, and she compared the almshouse system from state 
to state. She noted that in 40 of 47 states, almshouses were run by the county, while in the remainder, paupers were cared for on a town or township level or through outdoor relief. Only 1 state (Michigan) had a state department with powers to enforce recommendations and administer state laws. Thirteen out of 48 states had agents of state boards who made yearly inspections of almshouses. She provided state-specific statistics for the numbers of institutions, inmates by sex, numbers of acres held by institutions, monetary values of assets, numbers of inmates per institution, and the cost per inmate of support. She also summarized state laws governing almshouses (Stewart 1925).

Stewart sharply criticized small almshouses, which she characterized as being dilapidated, inadequate, and indecent (Stewart 1925:41). She also referenced the contemporaneous and even more critical study undertaken by the Bureau of Labor Statistics in cooperation with fraternal organizations. Written by Harry C. Evans and describing 2,183 almshouses in 48 states, The American Poorfarm and Its Inmates (1926) was a scathing indictment of the poor farm system. Evans argued strongly for the abolition of poor farms, listing 13 conditions or practices that he believed argued for abolition of the system. He provided summaries of the financial and social conditions at poor farms in each state (Evans 1926:3, 6-20, 21-92). Then, in a chapter entitled "The American Pauper-His Ancestry and Progeny," Evans presented his own conclusions about the identity of the American pauper. Echoing the ideas of Thomas Robert Malthus, Margaret Sanger, and Edward Devine, Evans concluded that the vast majority of American paupers were feebleminded, and he believed that the disproportionate number of foreignborn paupers had, through their children, "added to the pollution of American Society" (1926:93-94). He wrote allegorically of the principle of cleansing life, refining, casting out the dross, and maintaining purity. He wrote more directly of the need to eliminate "the sources that pollute life" and advocated not just placing "mental defectives" in the permanent custody of the state but also making sure that they were prevented from "leaving a progeny of their own kind to take their place." Using terms such as "final solution," Evans eventually used the term "sterilization" and posited that biological poverty could only be countered by an increase in "superior stock" (Evans 1926:93-99).

The philosophies of eugenics and nativism implicit in arguments by Evans and others during the first two decades of the twentieth century, as well as criticism of state- and locally run pauper care, appear to have spurred a number of state-specific studies. Among the first was a study by the Texas Eleemosynary Commission. Created by the state legislature through H.C.R. No. 15, which was approved on June 23,1923 , the commission was charged with making a statewide study of dependents and "unfortunates"; considering ways to prevent insanity, feeble-mindedness, and other conditions; examining the custody and care of the criminally insane; and reviewing and revising laws pertaining to inmates of state eleemosynary institutions. Commission members hired experts to conduct surveys of institutions, including 18 almshouses and poor farms, which they recommended should be abolished because they were filled with a heterogeneous mixture of dependent classes, were providing no useful service, and were not only a waste of public money but also "relics of medieval ignorance..." (Texas Eleemosynary Commission 1925:3-8). The commission's call for specialized mental and occupational therapy and for the involvement of psychiatric-social workers reflected the increasingly important and visible role those professionals were assuming in the United States. Their conclusion that nothing would work in the long term unless steps were taken, perhaps through sterilization and marriage laws, to prevent the propagation of mental defectives (Texas Eleemosynary Commission 1925:12-13,15) reflected mainstream thought within the professional and charitable communities interested in the care of dependent classes.

Arthur James's The Disappearance of the County Almshouse in Virginia: Back from "Over the Hill" (1926) echoed Evans's criticism of the almshouse system. James characterized the county-run poorhouse as "an institution symbolic of the uttermost despair of mankind, a word to connote poverty, neglect, disease, filth, loneliness and death itself...[and] a conspicuous example of inefficient and reactionary government" (James 1926:3). He also linked county almshouses and the problem of poverty 
and poor relief, concluding that the perpetuation of the almshouse system was contributory to poverty (James 1926:22).

At the same time, James was critical of Evans's work, asserting that Evans had pointed out "a few of the worst institutions" and described "the conditions in the worst almshouses and the worst aspects of the system as a whole," while failing to describe the "improved places" that showed "the recent and present change and development in the system."Further, Evans's publication had left without comment "some splendid successes in alleviating the very conditions it exposes" (James 1926:5). ${ }^{2}$ Specifically, Virginia was changing its system by reestablishing a system of child placing; replacing the older practice of providing doles with "family aid and individual pensions under trained, welfare workers"; abolishing individual county-level almshouses with regional "hospital homes"; establishing hospitals for the care of the insane, deaf, blind, feebleminded, and epileptic; subsidizing hospitals that cared for the indigent; and establishing a government for the care of dependent and neglected children (James 1926:16). As a result of these changes and a county system of outdoor relief, the pauper population now consisted primarily of the indigent poor. Supervisors had been able to close some county institutions so that the 96 county and 12 city and town almshouses active in 1909 numbered 65 and 10 in 1926. James admitted that the existence of some "unplaceable" individuals meant that almshouses might persist, and he urged the establishment of district or regional homes because they would be more economically viable (James 1926:16, 22).

Two years later, Roy Brown described North Carolina's system of public poor relief. He outlined the history of pauper care in England, where specific important principles developed concerning the law of legal settlement, which entities should be fiscally responsible for the poor, and how children and other classes should be treated (Brown 1928:2-7). He traced the history of poor relief in North Carolina to the early eighteenth century and the beginnings of legislation to 1749 , and he identified 1785 as the year when the North Carolina legislature

2 This criticism of Evans's work was echoed more than 70 years later by Tuten (1999:48), who pointed out numerous inaccuracies in Evans's work as it pertained to Jefferson County, Alabama. empowered wardens in seven counties to purchase land and build almshouses for the poor and those generally "deprived of their senses." The idea, which spread to other counties and evolved during the nineteenth century, eventually encompassed the practice of farming operations in connection with almshouses. As Brown summarized the philosophy, the idea developed that "the poor might be supported wholly or mainly by their own labor or by their labor supplemented by that of certain classes of misdemeanants" (Brown 1928:10-19, 26-29, 32-33).

The mid-nineteenth century represented something of a turning point for pauper care in North Carolina in several respects. The public accepted the idea of taxing itself to provide for pauper care, officials identified the education of both whites and African-Americans as a method to help prevent poverty, and the state established and opened a hospital for the insane (Brown 1928:67-68, 94-95), thus providing an early mechanism for segregating at least one particular class of paupers. After the Civil War, North Carolina's new 1868 constitution transferred control of county affairs, including poor care, to boards of county commissioners while simultaneously making care of the insane, blind, and deaf mutes the responsibility of the state (Brown 1928:69, 95). Despite these changes, Brown described county homes in early twentieth-century North Carolina as being "dumping ground[s] for the wrecks of every type" (Brown 1928:98, 125).

Charitable work was reorganized in North Carolina in 1917-1919, when care was organized on a county basis and each county had a local board and superintendent of public welfare. On the state level, a new Board of Charities and Public Welfare was reorganized and charged with supervision of charitable organizations. Nonetheless, Brown saw little to recommend the system in the $1920 \mathrm{~s}$ : in 1922, 94 counties owned poor farms, which were poorly equipped and run as a tenant farm would be; supervision and the quality of superintendents were inadequate; the system of outdoor relief was rife with the potential for graft; and inmates of poor farms remained a heterogeneous group, despite actions taken by the state to remove certain classes of inmates to specialized institutions. Interestingly, Brown noted that the population of needy and dependent individuals was shrinking, and that the 
numbers in county homes by the 1920 s were so small that it made classification impracticable (Brown 1928:100, 109, 113-114, 118-119, 125, 132-135, 164, 171-173).

The depression of the 1930s increased the population of the poor, and the University of Minnesota began a study in the early thirties to identify types of individuals who might benefit by settlement on farms. ${ }^{3}$ Proposals by congressmen and others had provided for "the settlement of the unemployed on subsistence farms, and R.W. Murchie suggested the establishment of relief farms where single unemployed men and marginal workers would live and work on a supervised colony farm (Murchie 1933:5-8, 24). Studies by other state committees and scholars, however, continued to emphasize the persistence of poorhouses and poor farms as central features in efforts to provide relief and care. Studies of the institution and state policies in Kansas, for example, reviewed the English roots of poorhouses, the trend to establish state-run institutions, the impact of the Social Security Act, the growing trend to provide outdoor relief, and the lack of caretakers who were properly trained (Kansas Emergency Relief Committee 1935:v, 1-2, 31-32). They also summarized the state's laws that provided for a plethora of public welfare programs and institutions on state and county levels (Lowe and Staff 1937).

Studies of state-level public assistance programs persisted during World War II and after. Paul Stafford's study of poor care in New Jersey summarized the history of public assistance from the establishment of workhouses and efforts to care for orphans in the late $1600 \mathrm{~s}$, the creation of mechanisms for public funding, and the establishment of outdoor relief as the principal form of assistance during the eighteenth century (Stafford 1941:25, 27, 31). In the late eighteenth century, the New Jersey legislature created a new structure in the form of county poorhouses or almshouses for all classes of the poor, and county workhouses for offenders who were incarcerated (Stafford 1941:26-27). The nineteenth century was characterized by the further development of the almshouse system in preference to outdoor relief, an emphasis on

3 The author, R. W. Murchie, and others noted that between 1930 and 1932 there was a "decided reversal of the rural-urban population movement in the United States, and in those two years over a million people had been added to the farm population" (Murchie 1933:28). public institutions, and the establishment of institutions to care for special classes, such as the indigent insane and children. Simultaneously, the number of poor farms or almshouse farms increased. By the early 1940s, New Jersey still had a complicated system that consisted of institutions on the municipal, county, and state levels, with almshouses being one component of the system (Stafford 1941:48-49, 51, 53-56, 59-63, 74, 164-167).

By the 1960s, with the disappearance of most county farms and homes, studies of poorhouses, poor farms, and pauper care had become scholarly investigations that emphasized the history of poor care in specific cities, states, and regions of the United States, and in other countries. Ethel McClure's study of the development of poor farms and homes for the aged in Minnesota (1968) reiterated the English roots of poor laws; described the origins of New World systems and institutions; identified key national events that impacted pauper populations such as the panics of 1857,1873 , and 1893, and passage of the Social Security Act of 1935; and discussed the impacts of lengthened life spans, shifts of population from rural to urban settings, and changing attitudes on the part of a youth-centered society concerning care for elderly parents. She also identified the studies of the $1920 \mathrm{~s}$, that were largely critical of poor farms, as helping to further the nascent movement for state and federal programs, including pensions and social security.

Other narrowly focused studies of the midto-late twentieth century included Woodrow Borah's assessment (1966) of social welfare and obligation in New Spain, its roots in preReformation Spain, and the continuing influence of the Catholic Church, which had retained the property and endowments necessary to provide relief to all classes. Borah traced the transfer of that system to Latin America and Mexico, where associations of the pious, hospitals, and church and civil authorities combined with help within extended families to create a network of care. The extension of that network through law and community practice into Spanish Texas, as well as its persistence during the Mexican period, is described in De la Teja and Wheat (1985:7-34). The best-recorded efforts at providing charity and welfare were those undertaken in Bexar in the 1820 s and early 1830 s, when a citizens' board provided food for destitute soldiers who 
were sometimes left without pay or supplies. Individual families sometimes took in citizens left homeless by epidemics and floods.

Priscilla Clement's study (1985) of welfare and the poor focused on Philadelphia in the first half of the nineteenth century but asserted that the policies, concerns, and institutions that developed in that one city were typical of a broader region since the study of pre-twentiethcentury public assistance was a study of local history, most poor relief programs being locally administered. She described poor relief as it was practiced in Philadelphia and then drew broad conclusions about the practice of welfare in America during the nineteenth century. She described the motivations of both those who sought assistance and those who provided it, identifying factors that have guided the creation and administration of welfare programs.

A similar study by Robert Cray, Jr. (1988), focused on paupers and poor relief in New York City and the surrounding area from 1700 to 1930. He concluded that "civil officials had to balance a sense of compassion with a sense of economy" (Cray 1988:4). In the eighteenth century, it was not necessary to build and support poorhouses in rural areas and small villages because there were so few poor, and they were readily accommodated by local officials, family, and church-based charity. With time, however, transportation linked cities to rural areas, which made them vulnerable to transients and new ideas about economic development. Increasingly, rural areas and villages came to favor poorhouses and pauper auctions, and they also came to view poor people as costly burdens rather than as objects of charity (Cray 1988:50-53, 84). By the early nineteenth century, both urban and rural populations favored the use of almshouses because they believed that they could be used to reduce expenditures on poor relief, and because poor people were safer in an institution, where they could be required to work (Cray 1988:50-53, 84).

A number of master's theses and scholarly articles written in the mid- to late twentieth century have summarized the history of pauper care in Texas. A thesis by Velma Lee Cathey (1949) outlined the history of institutional care in Texas from the mid-nineteenth through the mid-twentieth centuries. Cathey also identified three general phases of welfare legislation:
1856-1919, when the state emphasized institutional care; 1919-1939, when public welfare was organized under the board of control; and 1939-1949, when the state decentralized its public welfare services. Cathey's work was followed by Ruth Whiteside's study (1973) of the impact of the Texas Constitution on welfare. She identified the articles within the Constitution of 1876 that required counties to provide manual labor poorhouses and farms, and she discussed the impact of the Congressional acts of 1972 that resulted in a welfare system that was fully federalized. Finally, Debbie Cottrell's review of the county poor farm system in Texas (1989:169-190) examined three county poor farms in depth and provided a historical context for the system in English poor laws and in the 1869 and 1876 state constitutions. She emphasized that poorhouses and poor farms were attractive to public officials who believed them to be more cost-effective than outdoor relief, and she maintained that the typical "frontier Texan" considered relief to be a responsibility of relatives, but not the government, which used poorhouses as "dumping grounds for society's outcasts."

A regional view was provided by Elna Green (1999), who edited 11 articles about social welfare practices in the South from 1830 to 1930. Green pointed to the English antecedents to southern colonial social welfare policy, and noted the ways in which southern policies differed from those practiced in the North, at least until the twentieth century, when progressive southerners looked northward for reform models. Outdoor relief prevailed until the nineteenth century, when poorhouses became common. However, as specialized state institutions for special dependent classes proliferated, almshouses were increasingly used to house the elderly (Green 1999:vii-xviii). An article in Green's volume by James Tuten (Green 1999:40-57) focused more narrowly on the operations of one institution in Alabama, the Jefferson County Poor Farm. Tuten characterized the Jefferson County institution as one which never attained agricultural self-sufficiency. $\mathrm{He}$ also tracked changes in the poor farm population, concluding that only onequarter of inmates were there because of their financial condition, the balance being orphans, the sick, and the insane. Increasingly, however, as children were excluded and other options for 
care became available, the mean age and death rate of the population increased. He pointed out inaccuracies in Evans's highly critical 1926 publication and then noted the impact of the Social Security Act of 1935, which he characterized as constituting a return to outdoor relief. Nonetheless, a few Alabama counties continued to operate poor farms until after World War II.

Michael Katz's social history of welfare (1986) purported to treat care in the United States, but actually focused on large, urban poorhouses in the East Coast region with a strong emphasis on New York. He organized his study chronologically, identifying an era when poorhouses were the preferred response to poverty, but outdoor relief persisted. He also asserted that poorhouse culture fostered the development of specialized institutions. He discussed the era from the 1890s through the 1930 s, when a reform movement focused on children, when individuals who were specially trained (social workers and public welfare officials) became involved in reform, and when the New Deal completed the emergence of the welfare state. He then traced the relation of social welfare to the post-World War II experience, which resulted in federal programs such as the War on Poverty and Great Society (Katz 1986:xii-xv).

Finally, David Wagner's study of American poorhouses provided a national historic context, discussing European antecedents and the various philosophies of care for the poor in colonial and nineteenth-century America. He described the intense opposition to outdoor relief by social reformers and its reappearance late in the nineteenth century when special classes began to receive pensions. Like Katz, Wagner concluded that poorhouses and pauper care were characterized by institutional complexity and served a variety of purposes and roles that were as widely varying as social control and altruism (Wagner 2005:4-9, 20). He also remarked on the persistence of the poorhouse, an institution that found a role in both pre-industrial and industrial societies (Wagner 2005:45-46) and existed as late as the 1960s, largely because significant numbers of individuals were not covered by Social Security until 1956 and later (Wagner 2005:132-133).

A sampling of literature about pauper care in Europe and the Americas highlights trends in the history of theory about indigent care:
- Early nineteenth-century authors were interested in analyzing almshouse populations in order to effect reform. There was an early emphasis on the supposed effects of alcohol and the potential threat of immigrants, who were believed to represent a disproportionately large percentage of the total pauper population in North America.

- Early nineteenth-century authors were concerned for the effects of almshouses on children, who might become more inclined to crime because of their exposure to undesirable elements of society in institutions.

- By the mid-nineteenth century, there was some recognition of the complexity of the causes of poverty and a continuing emphasis on intemperance as a leading cause.

- In 1880, the United States government began to study pauper populations in detail, creating special censuses. Conclusions drawn by government studies about causes of pauperism (want of other home, old age, infirmity, disease, etc.) increasingly differed from those of social scientists who emphasized the genetic causes and advocated eugenic solutions.

- Beginning in the $1880 \mathrm{~s}$, discussions about the causes of pauperism became more nuanced and statistics for larger populations more readily available. The impact of change from a predominantly agrarian society to one in which industry played a role was examined, and some scholars concluded that an industrial revolution had left numerous members of the agricultural class involuntarily unemployed. Disability continued to be a strong prognosticator of poverty.

- The genetic roots of pauperism remained a dominant theory between ca. 1900 and 1930 . The theory was used as a primary attack on poorhouses and poor farms, which were considered to be breeding grounds of inferior human stock due to inbreeding, lack of external controls, and mixing of sexes and different types of indigent populations. 
- State and federal agencies during the first quarter of the twentieth century emphasized the responsibility of the community to provide relief and began to change the language traditionally used to describe certain classes of indigents as well as the names of public institutions.

- Both federal- and state-level agencies issued studies of poor relief programs and attempted to define different classes of indigents.

- During the first quarter of the twentieth century, some reformers discussed physical changes to pauper facilities, such as poorhouses and poor farms, that might effect positive changes in care.

- Increasingly, the role of professionals in the care of defectives and dependents was emphasized. Such professionals considered abolition of poverty and pauperism to be dependent on the work of professional sanitarians in the public health service and of social workers.

- In 1900-1930, descriptions of the degraded state of poorhouse and poor farm inhabitants and the anonymity of pauper burial emphasized the horrors of pauperism.

- State-sponsored studies of the 1920s were uniformly critical of the quality of care provided to mentally impaired paupers when administered outside of specialized state institutions.

- State-level studies of systems and institutions used to deliver relief continued after 1930 but were considerably less critical of poorhouses and poor farms than in the past. The concept of eugenics as a mechanism for the control and eradication of defectives became less prevalent, and the associated language all but disappeared.

- With the disappearance of county homes and farms in the $1960 \mathrm{~s}$, scholars began to study the history of poor care in specific cities, states, and regions of the United States. There was increasing interest in the indigent care systems of other countries, including
Latin America and Mexico. Scholars also emphasized the development of public policy on the state and local levels.

\section{PAUPER CARE IN EUROPE AND THE AMERICAS}

The poor have been a part of the human landscape for millennia. The Greeks referred to the pauper class as one comprised of individuals who were not so much indigent as inefficient, and they suggested that the condition of poverty was that of making little as opposed to needing much. The associated Latin word "pauper" meant "simply poor, without means of support" (Devine 1916:3-4).

Medieval European ideas about the pauper class recognized what were identified as the "impotent poor" as a distinct class (Brown 1928:3-4). While assistance was available in the forms of alms and almshouses, which were made available to both poor people and wanderers (Wagner 2005:4), English law in the late 1300 s provided that beggars who were impotent to work should continue to live in the cities and towns where they were then situated or withdraw to the towns where they were born. This "law of legal settlement" was intended to restrict the movement of beggars and to fix in law the residence of laborers (Brown 1928:2-4).

The law of legal settlement was accompanied by attempts to identify beggars by including them in a census and licensing those poor people who local officials decided should be allowed to beg. Implicit in these early actions were certain principles: 1) the community was obligated to relieve the suffering of the poor; 2) the impotent poor would be provided for through voluntary alms collected by the church; 3) no one should be compelled to beg, and no one should beg openly; 4) poor who returned to their place of settlement should be received charitably; and 5) individuals identified as "sturdy vagabond[s] and valiant beggars" should have to work for a living (Brown 1928:4).

According to Borah (1966:45-46, 48), many European countries began to organize systems of social welfare during the fifteenth century; Spain, on the other hand, continued to practice relief based on a Middle Ages social structure 
that emphasized "the obligations and rights of the various classes...." As long as the lower classes "kept to their place," they were to be given access to aid and justice by nobles, the wealthy, and the monarch. Widows, orphans, and other needy classes, such as the sick, aged, and hungry, were provided assistance through the community, the church, and endowed charities, many of which were under church control. Guilds, cofradias (associations of pious people), and entities such as hospitals (institutions that cared for the sick and insane) joined with extended families to create an effective network of aid in fifteenth-century Spain.

Until the Reformation, the church was largely responsible for poor relief in England, as well, and monasteries became centers for maintaining the idle poor (Brown 1928:4-5). The Reformation passed Spain by, so the Catholic Church retained its endowments and with them an intact system for providing aid (Borah 1966:45). The suppression of monasteries in England during the reign of Henry VIII, however, resulted in an increase in the number of vagabonds and wandering beggars, and the government subsequently both suppressed begging and idleness through laws and provided for the establishment of almshouses. According to Brown (1928:45), local authorities were authorized to provide "tenantries, cottages, and other convenient housing for the lodging of the impotent." Wagner interpreted the post-1500 English revolution in poor care as being more punitive, blaming Protestantism for the "harsher treatment of the poor and those who were deemed unproductive ('indolent' or 'vicious')." He identified what he called a "new concensus [sic]," and where Brown saw almshouses, Wagner identified workhouses, correctional institutions meant to impose discipline on the unworthy poor, those "men of working age, who were vagrants, beggars, 'indolent,' petty criminals, or intemperate" (Wagner 2005:4-5).

The conquest of New Spain brought with it pre-Reformation, church-based institutions typified by organized aid for the needy provided by endowments and supplemented by ecclesiastical and civil funds. The overarching institution was the hospital or hospice, which included groups of volunteer workers and other supporters. As they had done in Spain, such hospitals and hospices cared for lepers; the sick; the aged, infirm, and needy; and even travelers. The general order for the Indies promulgated in 1541 by Charles V required all towns of Spanish and Indians to have hospitals, of which he was the patron. In the sixteenth, seventeenth, and eighteen centuries, care for the ill, insane, and aged was provided by hospital orders, and those workers were assisted by cofradias. Church and civil authorities also carried on a wide range of welfare activities. In the case of the church, those activities were supported by revenues that were distributed to the poor and used for good works at the discretion of the clergy. Convents served as places where the needy were fed, clothed, and sometimes lodged; in some cases foundlings and orphans were taken in and reared. Civil officials in Mexico City created an institution in the late 1500s that guaranteed a supply of basic grains to the poor at the lowest possible price. In other cases, towns made special provisions for legal assistance to the poor, including those in jail, and to widows and minors (Borah 1966:46-51).

Absent the traditional role of the Catholic Church in caring for the poor, England continued to develop a substitute system during the reigns of Henry VIII (1509-1547), Edward VI (1547-1553), and Elizabeth I (1558-1603). An overriding and increasingly important principle was that the poor should be supported by taxation. Initially, a person appointed by town officials and the church asked townspeople to make donations for the support of the poor. Failure of this approach inevitably led to the recognition, in 1572, of the principle that the poor would have to be supported through a tax levy imposed by justices of the peace. The money collected then would be administered by overseers of the poor, who were appointed by the justices and kept a register (Brown 1928:5-6).

Development of civil structures during the reign of Elizabeth I was followed by the act of "43 Elizabeth" in 1604 that left the main administrative power with annually appointed parochial authorities. The act required children whose parents could not work and other married or unmarried persons who did not have an occupation to work. It provided relief to the lame, impotent, and blind and those unable to work, defined as the impotent poor. As the foundation of English poor law until the nineteenth 
century, 43 Elizabeth also defined three classes of poor-the impotent poor, dependent children, and the able-bodied, the last of whom worked in houses of correction. Two to four selected householders served with church wardens in every parish as overseers of the poor, and they also raised relief funds by taxation. The justices of the peace were authorized to commit poor people who refused to work to houses of correction or jails (Brown 1928:7).

Between ca. 1600 and the 1790s, England saw the development of a "network of law and practice which...had become entwined in the fabric of society and the economic system" (Poynter 1969:xi). It was a network or system whose salient features made local governments (parishes) responsible for the sick, poor, aged, and afflicted; placed the justices of the peace and overseers of the poor in charge; and endowed the overseer with specific powers and duties, including the duty to make the ablebodied work, the duty to provide relief to those who could not work, and the power to levy and collect taxes (McClure 1968:2). This system, together with the 1662 Act of Settlement, which permitted authorities to move nonresident paupers to the parishes of their last legal settlement, "embodied the principles of local responsibility, family responsibility, and legal settlement which were the basis for the poor relief systems of [North America]" (McClure 1968:2). ${ }^{4}$

Poor laws were passed in American colonies such as Virginia and South Carolina by 1642 , and the role of the church remained relatively strong until the American Revolution. According to Green (1999:vii-xviii), some communities on the Atlantic seaboard began to build workhouses or almshouses by the eighteenth century, but southern and northern colonies differed in their residency requirements: New England required a more lengthy residency by individuals before they were eligible to receive public support, while the southern colonies were more lenient. In general, there were few almshouses or other institutions to house the poor, the elderly, or dependent children. Rather, outdoor relief in their own homes, or those of others, was the prevalent form of support for

4 McClure's actual wording stated that the English system was the basis for the poor relief systems of the "New World." In fact, the Spanish system found in Latin America, Mexico, and, eventually, the American Southwest, differed from the English system. paupers. It was supplemented, in limited form, by state support in public institutions for some special classes of dependents, such as orphans.

State laws regarding the treatment and regulation of paupers were not always readily passed: in North Carolina in 1749, the first bill introduced in the legislature that was designed to provide relief to the poor and prevent idleness failed. Subsequent bills passed in 1755 and 1759 , on the other hand, outlined treatment of poor people and vagabonds, addressed issues concerning work, and discussed permanent settlement (Brown 1928:18-19). These, with laws passed in the colonies and using English poor law as a model, became the legal structure that was incorporated in the laws of the Northwest Territory in 1787, an area that embraced the Midwestern portion of the country (McClure 1968:ix). There, as elsewhere in the eastern half of the continental United States, most care was provided in one or more of four ways on a local level: 1) outdoor relief (giving assistance to the poor in their own homes), 2) farming paupers out to families, sometimes by auction, 3) contracting with one resident to care for all the town's paupers, or 4) providing a town almshouse (McClure 1968:6-7).

After the American Revolution, the administration of relief remained local but appears to have become more structured or bureaucratic. In North Carolina, for example the freemen in a county elected seven other freeholders to serve as overseers of the poor for three-year terms. The seven freeholders elected three of their members to serve as wardens. The seven freeholders, or overseers, could levy taxes for the care of the poor, who could be removed to the place of their legal settlement. However, the system was less than successful because few citizens could be persuaded to serve (Brown 1928:26-27). Subsequently, in the 1780s, the legislature empowered wardens in seven North Carolina counties to buy land and build almshouses where the poor and insane were housed. An increasing number of counties established such institutions between 1793 and 1830, and they served both a poorhouse and a workhouse function (Brown 1928:28-29, 32). At the same time, a concept developed that farming operations in connection with almshouses would create a system where the poor might be able to support themselves by their own labor or with the help of labor provided by "certain classes of 
misdemeanants" (Brown 1928:33).

Such a system-one in which paupers of various classes were housed in almshouses that had agricultural land attached where the able-bodied labored, sometimes with the assistance of petty criminals-was common throughout the eastern United States by the 1820 s. Outdoor relief was discouraged, but its persistence and the varieties of local mores meant that almshouses varied considerably from one another. Typical institutions included one in Baltimore where the almshouse was located on a 300 -acre farm within 2.5 miles of the city. Inmates were classified and included the aged and infirm, lame, maimed, and those otherwise incapable of labor; children; the sick; and vagrants and others capable of contributing to their own support. Within the institution there was an infirmary, a lying-in hospital, a workhouse, an asylum, a school, a lunatic hospital, and a medical and surgical school so that doctors could study the inmates. Employees included a master or steward, a matron, a physician and residents, and a farm superintendent. Other duties were carried out by paupers. Insane persons could be separated from the general population and sent to another hospital. The almshouse was capable of accommodating 800-900 paupers, but the average number was about 400 (Philadelphia Board of Guardians 1827:4-5). This phenomenon of large capacity and relatively small resident population was a pattern that the federal government identified in the first decade of the twentieth century, when Harris (1915:9) noted that almshouse paupers tended to move in and out of almshouses rapidly.

The New York City almshouse was on 26 acres, also about 2.5 miles from the city, and had an associated 100-acre farm. As in Baltimore, there was an attempt to classify and separate the inmates-men from women and then by nationality and race. The sick and insane were housed in a separate building, and the insane were further separated from one another based on their conditions. Children were housed in detached buildings and bound out for work when it was appropriate. Strangers without settlement were sent away, and husbands who deserted their families were expected to support them. Those paupers who were able worked at various tasks, including spinning, weaving, carding, wool-picking, car- pentry, shoemaking, smithing, tailoring, and gardening (Philadelphia Board of Guardians 1827:8-10, 12).

In Providence, Rhode Island, the almshouse was not associated with a farm. Rather, paupers worked at picking oakum (a fibrous material used for caulking ships). Children were bound out at the age of seven, and paupers were sent home according to the law of settlement. As a smaller facility, the Providence almshouse was overseen by one appointed person; a paid keeper boarded the inmates and received an allowance for them. Outdoor relief in the forms of wood for household use and money also were provided. Merchants who introduced foreigners had to pay a bond so that the state did not become liable if the immigrant became a pauper (Philadelphia Board of Guardians 1827:13). In Newport, the almshouse was located on an island where there was no outdoor relief, and the paupers worked (Philadelphia Board of Guardians 1827:13).

The Boston, Massachusetts, almshouse was located on a ca. 60 -acre farm about 2 miles from town. Resistance to replacing outdoor relief meant that there were two parallel systems and two boards of oversight. Paupers at the almshouse/farm were grossly separated, with blacks and those with the worst cases of insanity being housed in separate buildings. Children were housed with adults, a practice not widely encouraged. The paupers worked at manual jobs, including farming, and employees included a superintendent, assistant superintendent, physician, chaplain/teacher, a clerk, and others. As in Providence, merchants had to give bonds when introducing foreigners; and as in New York, pregnant women were discharged with their children after confinement, when they were expected to seek support from the fathers (Philadelphia Board of Guardians 1827:14-16).

The Salem, Massachusetts, almshouse was on a farm about 1 mile from town. As in Boston, outdoor relief was available, although only to families or aged and respectable individuals. Paupers worked at light industrial and some agricultural tasks. Employees included the superintendent and his wife, and a clerk, physician, chaplain, and druggist. About 25 percent of the inmates were foreign. Regulations about bastardy were similar to those in the Boston and New York institutions. As a result, there 
were only two to three paupers in the category of pregnant women without support at the Salem almshouse (Philadelphia Board of Guardians 1827:17-18).

The Hartford, Connecticut, almshouse and associated farm were located 1 mile out of the city and were combined with a house of correction. As in the other states and cities, costs associated with pauper care had lessened since the opening of the almshouse, and in Hartford outdoor relief had been reduced to wood and some medicine. The inmates worked at farming and light industrial tasks, and only those paupers having legal settlement received aid. Employees consisted of a steward and his wife and a physician, who also was available to assist outdoor paupers (Philadelphia Board of Guardians 1827:19-20).

Early studies in the United States-which included an 1834 report on poorhouses, jails, and other institutions in New York, Massachusetts, Connecticut, and Vermont-not only inventoried physical facilities and public policies, they also attempted to classify paupers and criminals and to analyze possible links among intemperance, poverty, and criminality (Chipman 1834). Similar studies were undertaken in England, where extensive literature was published about poverty, pauperism, and relief between the 1790 s and the $1830 \mathrm{~s}$. The same period saw a revolution and counterrevolution in attitudes towards poor relief. Nearly 250 years after its passage, the 1601 Act for the Relief of the Poor had resulted in a "system" that was intensely local and thus heterogeneous. As Poynter described it, poor relief consisted of "a multitude of practices within (and sometimes without) the framework of a complicated aggregation of law." This aggregation tended over time to become increasingly permissive, "increasing the range of action which local officials might take within the law" because there were no national policies. The resulting flexibility was efficient in serving local needs, but the growing numbers of paupers alarmed many critics, who believed the Poor Law to be "an important element in that economic and social system in which distress so obviously occurred" (Poynter 1969:ix, $\mathrm{xx}, \mathrm{xxiii}, \mathrm{xxv}, 1$ ).

According to some critics, the English Poor Law was responsible for the development of "a legal establishment for the relief of poverty [that] created the paupers it set out to relieve"
(Poynter 1969:xxiii, xxiv). Others believed that it was at the root of undesirable practices such as improvident marriage, excessive breeding, and unfettered growth of population. Perhaps because of the increasing number of paupers, or at least the perception that their numbers were growing at a more rapid rate than that of the non-indigent population, there was a "genuine revulsion against pauperism as a way of life... especially after 1815" (Poynter 1969:xvii-xviii). This revulsion combined with an assumption that self-help could improve the lives of laborers, and Parliament created the Poor Law Amendment Act of 1834, which expressed specific dogmas about relief and challenged the old order as too permissive. Ultimately, the new law created a centralized professional administrative structure and a theoretical basis, the goal of which was to make pauperism less desirable than independent labor as a way of life. The instrument of enforcement in England was the Union Workhouse (Poynter 1969:xviixviii, xxii-xxv). According to Poynter (1969: $\mathrm{xxv}$ ), the same institution that seemed harsh and oppressive to the lower classes appeared in a different light to the upper classes and philanthropic individuals, who saw the workhouse as a bulwark to protect society from the starvation and insurrection of the poor on the one hand, and the "moral depravity and economic ruin of progressively increasing pauperism on the other."

The alarm about an increasing pauper population in Europe, which New York Secretary of State John Yates had estimated in the mid1820 s as representing 10 percent of the total population, was cause for concern in the United States as well. The permanent pauper population on the East Coast of the United States was but a fraction of Europe's (.5 percent in New York, 1.5 percent in Massachusetts, .6 percent in Connecticut, 1 percent in New Hampshire, .4 percent in Delaware and Pennsylvania, and none reported in Illinois) (Yates 1971:939-943), but reformers such as Yates believed that outdoor relief encouraged "the sturdy beggar and profligate vagrant to become pensioners upon the public funds" (Wagner 2005:9). In addition, immigrants, many of them from Europe, made up a disproportionate percentage of the New York state pauper population (27 percent in about 1824) (Yates 1971:942). After a study of the poor in New York and other 
states and of poor laws in most of the states of the union, Yates concluded that the poor consisted of two classes-the permanent poor, who typically included idiots, lunatics, the blind, extremely aged and infirm individuals, the lame, and children; and the occasional or temporary poor. There were slightly more females than males. Most paupers were found in large cities and towns (Yates 1971:939-943). Yates remarked on the varieties of laws concerning settlement, and he urged the establishment of poorhouses, remarking that in every state where that system prevailed, the evils of and expenses associated with pauperism had lessened (Yates 1971:1111).

Yates's study resulted in the establishment in New York of county "houses of employment" that became the county almshouse system common in the Midwest and elsewhere (McClure 1968:4). In addition, Dorothea Dix's ${ }^{5}$ campaign in the 1830 s to remove the mentally ill from almshouses began to bear fruit by the $1850 \mathrm{~s}$, when a number of states funded and constructed asylums (Wagner 2005:10), thereby assisting in the segregation of one type of dependent class that everyone seemed to agree would benefit from professional treatment in a specialized public institution. Nonetheless, the pauper population and its care remained a complex problem. Thomas Hazard's 1851 report on care of the poor and insane in Rhode Island revealed a layered and even chaotic system that probably was more or less typical of that in many other states. The population itself was heterogeneous, being comprised of the infirm, blind, intemperate, imbecilic, insane, aged, and ill, and of individuals abandoned by potential caregivers, such as family members. Programs in towns attempting to bring order to the situation typically placed paupers and the insane who had no home in a town asylum, administering outdoor relief to those who had a home or friends who would take them in, parceling paupers out to the lowest bidder for whom they would work, and contracting for their maintenance through the agency of a committee (Hazard 1851:10-11, 15, 32, 85).

A similar study by Dr. Charles S. Hoyt in New York in 1874-1875 found that many of the characteristics described in Hazard persisted 25 years later. Hoyt found that, while most

5 Dix was an American social reformer who worked on behalf of the mentally ill. occupants had received little public assistance before entering the poorhouse, the fact that the men tended to be unskilled laborers and women either had no occupation or had been domestic servants meant that they occupied "the most vulnerable sectors of the working class." More women than men were dependent, and they tended to stay dependent longer. On the other hand, more elderly men than women were inmates because children were more likely to be willing to care for their mothers than for their fathers (Katz 1986:90-91).

Typically, poorhouse inmates had no children, a characteristic that set them apart from most nineteenth- to early twentieth-century families. Many had never married, and about 75 percent of the widows had no living children or only one. Thus, paupers tended to enter poor homes and poor farms not because they were "particularly debauched, idle, or thriftless. Rather, they were so poor that when the death of a spouse or sickness pushed them over the 'verge of pauperism,' they were unlucky enough to lack grown children to whom they could turn for help." In sum, Hoyt found nineteenth-century poorhouse inmates to be literate, having attended school; from working-class families, many of whom had engaged in agriculture; not so likely to earn livings through agricultural pursuits and thus possibly "caught in transition from agriculture to industry"; not from pauper backgrounds; and generally temperate, from families that were temperate as well. As Katz summarized the pattern, many dependent individuals suffered from conditions that accompanied working-class life, including "[s]easonal work, fluctuating demands for labor, and periodic [economic] depressions..." (Katz 1986:91-92).

The numbers of individuals seeking aid in almshouses and benevolent institutions, who received outdoor aid, or who were housed in hospitals and asylums declined by about half between 1850 and 1890. Furthermore, the population never amounted to more than an extremely small fraction of the general population even at its apex in 1850, when it comprised 2,171 individuals out of a million, or ca. two-tenths of one percent (U.S. Department of the Interior, Census Office 1896:1,267). Nonetheless, as a class, paupers maintained a high profile and remained at the center of competing ideas about indigent care as well 
as of concern from the public, local and state governments, and reformers. In states such as Minnesota and Kansas, for example, the county-run poorhouses and poor farms were thoroughly entrenched, and they remained so even in states that supported state-run institutions for the care of special classes such as the insane, blind, and deaf, and children (McClure 1968:20, 36-38; Kansas Emergency Relief Committee 1935:1). In many regions of the country, states created state-level boards that assumed expanded roles in overseeing the care of paupers and other needy classes, even in institutions having no state-level affiliations. Eventually, the American Social Science Association founded a Conference of Boards of Public Charities that promoted collection of uniform statistics by state boards (McClure 1968:73-75).

According to Wagner (2005:154), the appearance of social welfare specialists in the late nineteenth century and their work to collect data about paupers resulted in renewed attacks on the poorhouse system. Probably bolstered by work of the English Poor Law Commission of 1905-1909, which recommended a "clean sweep" of English Poor Law and criticized the existing structure for the care of paupers, American social workers became increasingly critical of poorhouses, insisting that dependent care could be better offered in "specialized institutions and by social work professionals" (Wagner 2005:154; Webb and Webb 1909:ix, xiv).

The tenor of the debate over and criticism of pauper care in both Europe and the United States during the first third of the twentieth century was heavily colored by the new science of eugenics, which asserted that certain classes of individuals should not be allowed to reproduce. In England in 1908, the English Royal Commission on the Care and Control of the Feebleminded concluded that reproduction of that class should be controlled, while Dr. Martin W. Barr of Pennsylvania wrote in 1912 that "the modern institutional care of the feeble-minded [was] the utilization of a waste product..." (Devine 1916:10). Edward Devine, with Margaret Sanger and many other social reformers, believed that the mentally defective were unfit for parenthood because of their biologic character and their inability to give children moral or economic training. Devine believed that defectives of various classes "clog[ged] the wheels" of industry, and that mental defectives, like the insane, should be segregated in institutions where their reproduction could be controlled. They were, after all, people "whose minds cannot be cured but who can transmit their defect, with its train of pauperism, prostitution, criminality, and other grievous consequences" (Devine 1916:10-12).

Devine linked the condition of being mentally defective to the condition of poverty and pauperism (Devine 1916:9), despite earlier studies to the contrary (Hoyt summarized in Katz 1986:91-92). It was predictable, then, that the poorhouse and poor farm, as two of the institutions having concentrations of both paupers and those suffering from a variety of mental and physical conditions, should be targeted by reformers of the early twentieth century. Alexander Johnson, for example, who was General Secretary of the National Conference of Charities and Correction, thought that poorhouses, if not redesigned, had the potential to "encourage and foster degeneracy" in cases where it did nothing more for "degenerate human beings but to keep them alive and allow them to increase and multiply..." (Johnson 1911:5-6).

A favorite secondary theme of the reformers was that a significant proportion, perhaps even a majority, of those receiving care in poorhouses were related to one another. The statistical study by the U.S. Department of the Interior, Census Office (1896:361) and the late nineteenth-century work by Hoyt had found that there were insufficient data to draw firm conclusions about the occurrence of pauperism within families and over multiple generations. Yet reformers such as George Warfield wrote in 1915 that a large number of those receiving relief were related by blood or marriage. "So striking was this fact that it raises a question whether the dependent element of the population, and, from many indications, the defective and criminal elements also, do not belong to a comparatively small number of families in which degeneracy is marked" (Warfield 1915: v).

The criticism of poor farms and poorhouses persisted and grew among many reformers after World War I, one of the most outspoken critics being Harry C. Evans. Inspired by critical remarks by the Secretary of Labor in 1924 
and using data collected by the Department of Labor, Bureau of Labor Statistics and several fraternal organizations, Evans published a study that purported to be an accurate representation of conditions on American poor farms. As a number of subsequent studies pointed out, Evans's work was flawed because his approach to the data was clearly driven by certain foregone conclusions: the poor farm system degraded the human condition, poor farms were a waste of taxpayers' money, and their inhabitants lived in wretched conditions. Above all, Evans asserted, the poor farm was a breeding ground for generations of mental defectives and feebleminded individuals, many of whom were foreign-born. He believed that actions should be taken, among them sterilization, to refine and maintain the purity of the "superior human stock" that had been polluted by foreign-born and their feeble-minded children (Evans 1926:1, 3, 6-20, 93-99).

The reform agenda that was driven, in part, by the eugenics and nativistic movements of the late nineteenth and early twentieth centuries, was balanced by government studies, two of which were published in 1925. The first, which examined pauper censuses taken in $1850,1860,1870,1880,1890,1904,1910$, and 1923 , started with a definition of an almshouse as "an institution supported or controlled by town, municipal, county, or State authorities and used for the shelter of persons who are without means of self-support and who have no relatives able and willing or legally bound to aid them." The study also noted that almshouse pauperism was not a complete measure of poverty, because recipients of outdoor relief and pauper inmates of other institutions were not always included in enumerations. The author, W. M. Stewart, was able to make certain conclusions based on statistics collected in 1922-1923: paupers in almshouses were a "rapidly shifting group," many members of which were not paupers at all because they were not permanently indigent; and there were marked differences in the degree of permanency of poorhouse populations within different parts of the country. Stewart's study revealed that the West-South Central region (Arkansas, Louisiana, Oklahoma, and Texas) had, by far, the least number of paupers in almshouses per 100,000 population (U.S. Department of Commerce, Bureau of the Census 1925:2). He noted that in the United States at large there had been a "marked decline" in the number of almshouse paupers between 1880 and $1925,{ }^{6}$ although some selected regions had experienced an increase. Finally, Stewart's statistics, like those published in the U.S. Department of the Interior study of 1896 that enumerated a broader population of needy individuals, revealed that the percentages of almshouse paupers per 100,000 United States population were always minuscule, being .0013 in 1880, .0012 in 1890, .001 in 1904, .0009 in 1910, and .0007 in 1923 (U.S. Department of Commerce, Bureau of the Census 1925:6-7, 9).

ThesameyeartheDepartmentofCommerce study was published, Estelle Stewart's study of the American almshouse ${ }^{7}$ was published as a bulletin of the U.S. Bureau of Labor Statistics. Like Evans, Stewart referenced statistics gathered by the Bureau of Labor Statistics and fraternal organizations. Unlike Evans, whose findings appear to have been driven by a particular point of view then prevalent among the more extreme social reformers, Stewart used the data to discuss topics such as administrative control, the character of inmates, and the practical operation of facilities. She opened her study with a number of observations concerning the roots of the American almshouse in English poor law. She noted that England had passed from an era characterized by "promiscuous, unsupervised" indigent support, when paupers were maintained by private and public charity and lived as they pleased, to a new era of maintaining paupers in public institutions. Americans noted the changes in England and adopted the institutional format "in their own experiment in nation building." By the 1920s, pauper institutions were being supplanted by the older system of outdoor relief, in which indigents were granted enough aid in the forms of money, food, and fuel to enable them to live at home (Stewart 1925:iii).

According to Stewart, there were almshouses in every state in the early to mid-1920s, and in 40 of 47 states they were run by coun-

$6 \quad$ McClure's study of Minnesota poor farms and homes for the aged (1968:90-91) suggested that some of the decrease in the almshouse population may have occurred because, as states built institutions for certain special classes of needy citizens, some almshouse residents were "siphoned off to the new facilities."

7 Stewart's term "almshouse" was meant to include the poor farm model (Stewart 1925:1). 
ties. Indiana had a state law that mandated an almshouse in every county, and only New Mexico had no almshouses. In a few states, there were both county and city almshouses. In counties where there were no almshouses, paupers were provided outdoor relief, were placed with private individuals under contract, furnished clothing and medical care, or placed in an almshouse in a neighboring county, which then was reimbursed for associated expenses (Stewart 1925:1, 3).

In 40 of 47 states, administrative control was on a county level, with commissioners, trustees, or supervisors being responsible for related activities. Only Michigan had a statelevel department with the power to administer state laws and enforce recommendations. In 13 states, agents of state boards made yearly inspections. The general pattern, however, meant that state authorities and the general public knew little, if anything, about almshouses or poor farms (Stewart 1925:1, 3).

In 1922, there were 78,090 almshouse residents in the entire country. Of those, Stewart classified 20 percent as crippled, 16 percent as feebleminded, 4 percent as blind, 3 percent as insane, .1 percent as epileptic, and .07 percent as deaf-mute. Presumably, the balance of 43,805 , or 56 percent, were indigent aged, children, or some other category of dependent, but Stewart did not enumerate their condition(s). Almost all states had laws that allowed them to remove the mentally ill from almshouses, but only New York and states in New England made an effort to segregate this class. Stewart believed that New England almshouses, which mostly provided refuge, care, and some comfort to the old and infirm, most nearly fulfilled the institution's "real purpose" (Stewart 1925:4-5).

According to Stewart, 88 percent of the institutions were directly managed by a county official or by a hired superintendent or keeper who answered to poor officials. The remaining 12 percent were run through a contract system in which the farm and almshouse were leased to an operator, who cared for the poor. Any produce raised on the farm belonged to the institution, and what was not consumed was sold and the proceeds deposited in the local treasury or made available to the almshouse superintendent. The contract system that was typical of the remaining 12 percent of institutions consisted of the lessee being paid a rela- tively small amount of money per inmate for board. The county or town provided clothing, bedding, fuel, medical necessities, and tobacco. The lessee paid a minimal rent for the farm, furnished his own implements, and was entitled to all produce. The contract model was common to counties in Alabama, Arkansas, Kansas, Kentucky, Mississippi, Missouri, Nebraska, South Dakota, Tennessee, and Texas (Stewart 1925:5-7).

Stewart was particularly critical of small almshouses, which she characterized as often being dilapidated, inadequate, and even indecent. With the North Carolina Board of Charities, she concluded that the county home was a failure and possessed certain drawbacks: such homes provided care for paupers "against tremendous odds," an inordinate amount of money was required annually to maintain them, thousands of acres of land on associated farms were idle, efforts put into care were duplicated, and much employment was unproductive. She agreed with a number of state boards that consolidation of local almshouses and poor farms and the establishment of district facilities would be the most efficient and economical approach. Certain states were working towards such a model, but other states faced fierce opposition from local superintendents and county officials, for whom the local institutions had become integral elements in the counties' economic and political systems, even when the number of inmates had dwindled to almost nothing. Stewart concluded by urging that the care of the "indigent old," who comprised the greatest part of the county home and poor farm population by the 1920 s, be given the same "thought and consideration" that the care of other specific classes (blind, feebleminded, epileptic, and children) had received (Stewart 1925:41, 47, 50, 52).

The three comprehensive national studies conducted in the early to mid-1920s concluded that: 1) the poorhouse population appeared to have peaked in numbers; 2) some poorhouses were becoming primarily homes for the aged, but the populations still were heterogeneous and included the ill, feebleminded, insane, deaf, blind, able-bodied and mentally capable, and children; 3) there had been little change in methods of institutional management, 88 percent of the institutions being managed by a salaried superintendent who reported to 
county officials; 4) poorhouse care was very expensive, and the operating cost per inmate was directly inverse to the size of the poorhouse; $5)$ poorhouse facilities varied greatly in size, construction, and state of repair; and 6) there were many cases of neglect and mistreatment. Recommendations stemming from the studies included closing local poorhouses, creating larger, nonlocal institutions, and urging states to take over direct care of the aged just as they had done with other categories of indigents (McClure 1968:129-134).

The government-sponsored studies and Evans's widely read, if not always accurate, study, proved to be influential ones that spurred states to perform their own investigations after 1925. Arthur James, for example, studied the Virginia system and concurred with Evans that many county poorhouses were institutions "symbolic of the uttermost despair of mankind, a word to connote poverty, neglect, disease, filth, loneliness and death itself. It has continued as a perfect testimonial of man's inhumanity to man, as well as a conspicuous example of inefficient and reactionary government." Countering Evans's findings, however, James criticized the earlier work for only "pointing out a few of the worst institutions" and not recognizing Virginia's successes as it gradually changed its system (James 1926:5). The state legislature in 1918, for example, had taken steps to consolidate county and city almshouses into district homes, an approach that James applauded for its economic benefits and appropriate response to a dwindling aged population who might then receive outdoor relief or be boarded privately (James 1926:21). He concluded that the issue of care in almshouses was a complicated one because the institution was "part of the whole problem of poverty and poor relief in the localities, which involves the entire social life of the people, and cannot be separated from the localities as a case of smallpox or insanity. Family life, employment, community organization, community institutions, local government, and many other things, play a part in almshouse affairs, and the community that is not working on all these is not really making any headway on the almshouse problem" (James 1926:22).

The institution that was widely held by reformers and social scientists to be a persistent and problematic element in the landscape of indigent care received something of a rejuvena- tion during the 1930s, when a national depression increased the number of poor. As a result of the economic crisis, poorhouses continued to have an important place in the welfare system during the 1930s (Kansas Emergency Relief Committee 1935:v), and a proportional increase in the number of those who were both poor and aged assured the persistent use of county homes as facilities for the aged. The county home and farm retained that function, even after passage of the Social Security Act, which disallowed payment of old age benefits to inmates of public institutions (McClure 1968:162-165), primarily because a relatively large segment of the population was not covered by the Act. Indeed, entire occupations such as public employees, and agricultural and domestic workers (those most likely to be paupers in the nineteenth century) were excluded, as well as anyone who had not made at least 10 years of contributory payments (Wagner 2005:132-133).

According to McClure, the poorhouse continued to serve the needs, albeit on a lesser scale, of the homeless whose population tended to grow during the twentieth century because of a lengthening life span, a shift from rural to urban living that occurred after World War II, the emergence of a youth-centered society with little disposition to take on care of elderly parents, and the development of a new philosophy in the mid-twentieth century that demanded a secure old age (McClure 1968:231). Additionally, Social Security coverage of the disabled, who had always comprised one of the largest components of the poorhouse/poor farm population, was not allowed until 1956, and then only with certain requirements. In fact, a great number of the typical pauper class were not eligible for many federal government relief programs (Wagner 2005:133), and so the poorhouse and farm remained a much-needed safety net in many parts of the country until the 1970 s.

While some scholars focused on the narrow and broad patterns of pauper care during its centuries of history in the Americas, Michael Katz provided a summary of trends in the heyday of pauper homes and poor farms (ca. 1870s-1940s) and characterized the institutions' inhabitants. In general, Katz concluded that during the nineteenth and early twentieth centuries, the poorhouse was not a monolithic institution because it sheltered so many differ- 
ent kinds of people who sought both short-term and long-term relief. Inmates were a heterogeneous group, their heterogeneity "mirror[ing] the complex causes of destitution...." As such, the poorhouse was a "structural artifact of working-class life." Evans's conclusions aside, most inmates did not come from "a degraded culture of poverty marked by illiteracy and intemperance." Nor were they "apathetic, unwilling to work, and permanently pauperized." Rather, they were more often families in crises created by temporary unemployment, harsh weather, illness, or old age (Katz 1986:9294). The poorhouse and poor farm provided a structure of relief that, if not ideal, persisted well into the mid-twentieth century because it met specific social needs.

A review of the history of indigent care in Europe and the Americas suggests the following:

- Europe had two different traditions of care after the Reformation:

- The first, whose nucleus was in Spain, spread to Latin America, Mexico, and Texas. Because the Catholic Church retained its properties, the church continued to play a leading role in indigent care and worked in association with the royalty, influential individuals, guilds, cofradias, and local political structures. The system was relatively well-organized and depended heavily on hospitals, or hospices, that cared for the sick, infirm, and aged; orphans; and other needy classes.

- The second, whose nucleus was in England and western Europe, spread to the non-Spanish North American colonies. Of necessity, after churches were largely stripped of their properties in the Reformation, care was provided within a secular system that assumed that the community was obligated to relieve the suffering of the poor, relied on the law of legal settlement to restrict the movement of beggars and laborers, asserted that those needy who were able to work were obligated to do so, and believed that the role of the church was to collect voluntary alms.

- In England, the system increasingly became focused on local political structures to raise taxes and provide oversight of tax collection, distribution, use, and record keeping.

- By the seventeenth century, there were attempts to classify the poor, the broadest categories being dependent children, the impotent poor (the lame, blind, and those unable to work), and the able-bodied poor who either worked or were committed to houses of correction or jails.

- Increasingly, English laws concerning the poor became entwined in the country's economic and social systems. With a lack of standardized national structure provided by Parliament, the laws tended to be varied and permissive, reflecting local conditions and values. Certain benefits accrued to local structures, businesses, and politicians, who provided services to and oversight of the poor.

- The English principles of local responsibility, family responsibility, and legal settlement became the basis for North American poor relief systems.

- As in England, American colonial poor relief policy was local, and there were differences between southern and northern colonies in its administration.

- Through the eighteenth century, outdoor relief was the prevalent form of support.

- A few public institutions existed for specific classes of dependents, such as orphans.

- By the 1820 s, a common pattern in the United States was to house different classes of paupers in single almshouses that had agricultural land attached. The able-bodied worked, sometimes with the help of petty criminals. Typically, almshouses and poor farms were located in proximity to urban centers, often 1-3 miles distant.

- A revulsion in England against pauperism resulted in a major overhaul of the relief system and creation of a 
centralized professional administration whose purpose was to make relief less desirable than labor. This revulsion was mirrored in the United States, where public officials undertook studies of poorhouse populations. A contemporaneous reform movement in the United States identified outdoor relief as the culprit in the system and encouraged the establishment of poorhouses because they were believed to be more economical to operate.

- During the first half of the nineteenth century in the United States, there was a perception among reformers that the pauper class was increasing at a rate disproportionate to the general population. Laws pertaining to relief were criticized for contributing to the perpetuation and growth of the pauper population.

- By the mid-nineteenth century, reformers increasingly worked to identify different classes of dependents, encourage their segregation from one another, and provide for the care of specific classes in state-run institutions.

- Increasingly in the second third of the nineteenth century, reformers attempted to classify poorhouse occupants and analyze the root causes of pauperism.

- Paupers enumerated in federal censuses beginning in 1850 represented a minute percentage of the total United States population (two-tenths of one percent in 1850), and their numbers steadily declined to 1890 . Typically, the men were unskilled laborers and the women were domestic servants. Agricultural workers were heavily represented. Most institutionalized paupers did not have families (children or spouses) to provide for their care.

- During the second half of the nineteenth century, the number of state-level oversight boards steadily increased, and by the end of the century there was a national Conference of Boards of Public Charities that promoted collection of uniform statistics.

- Social welfare specialists appeared in the late nineteenth century and mounted a full-scale attack on the poorhouse and poor farm system.

- The social philosophy of eugenics heavily colored debate about indigent care in the United States and Europe. Social scientists promoted the separation of sexes as well as other categories of indigents, and they advocated the sterilization of those believed to be unfit to reproduce, citing the social and economic costs to the public of unregulated intercourse. They linked poverty and pauperism, and by extension the poorhouse and poor farm system, with the condition of being mentally defective. Criticism reached an apex in the mid-1920s, when social scientists asserted that the poorhouse population was comprised largely of individuals related by blood.

- Studies by government agencies that were based on census records, on the other hand, asserted that almshouse paupers represented a rapidly shifting group, that not all were permanently indigent, and that the decrease in numbers from 1850 to 1890 had continued to the mid-1920s.

- The depression of the 1930 s rejuvenated the poorhouse and poor farm systems because of an increase in the numbers of indigents.

- The Social Security Act of 1935 and subsequent legislation provided some relief but did not cover the majority of the residents of poor farms and poorhouses until the 1960 s.

\section{PAUPER CARE IN TEXAS}

Pauper care in Texas has a history that spanned almost 150 years. Rooted in Spanish traditions that expected the church, civil authorities, and families to care for the needy, pauper care rapidly became embraced within the laws of the Republic of Texas. By the Civil War, practices of care in Texas closely paralleled those of other states: the greatest number of indigents, who were a heterogeneous population, received care locally within a system that was overseen by county officials; the remainder-those whose condition had been 
attributed to insanity, or were deaf, dumb, or blind-were segregated and accommodated to the extent possible in state institutions.

As in other states, the pauper population in Texas was heterogeneous and their care lacked a systematic approach. Rather, laws governing care were permissive: few state laws were passed, and so local mores prevailed concerning the amount of support offered, segregation of classes of indigents, requirements for settlement, responsibilities of family members, and other pertinent issues. Texas also was one of numerous states in which state-level oversight by a professional board was delayed until the 1920 s, and then occurred only incompletely. As a result, while there were some reformers and health care specialists who published studies that pointed out the shortcomings of the state's approach to indigent care, focusing particularly on the insane, there was little legislation passed that was based on those studies.

To a great extent, the history of pauper care in Texas paralleled that of other states: social scientists of the early twentieth century decried the poor farm because they believed it was destructive to the very populations it sought to serve and contributory to the persistence of pauperism. Renewed concern for indigent populations prior to the $1930 \mathrm{~s}$ and increases in their numbers during the Great Depression resulted in the creation of state programs and bureaucracies designed to provide relief to needy citizens, including those traditionally served by poor farms and homes. However, the employment and other qualifications embedded within programs such as Social Security left traditional residents of poor farms unable to qualify for assistance and assured the survival of county-based programs for another 30 years.

The earliest records concerning care of indigents and other needy individuals in Texas provide only scant information about the size of the population prior to 1850 s and the system used to deliver care. De la Teja and Wheat (1985) recorded needs for charity in the urban center of Bexar in the 1810s through the 1830s that resulted from poverty rooted in political struggles, economic disarray, natural disasters, and disease. The three vehicles available for the delivery of care, specifically in the forms of food and shelter, were a citizens' board that collected and distributed supplies, private charity, and the church. Municipal ordinances stated that the city had a responsibility to assist orphans, widows, the aged and infirm, and the poor, a reiteration of Spain's pre-Reformation belief system concerning the obligation of the community to provide relief to those less fortunate (Borah 1966). But unlike Spain, Latin America, and Mexico in the early nineteenth century, no formal apparatus existed to deliver relief in Bexar.

With revolution and formation of a Republic in 1835-1836, care for those in need changed to a system rooted in English poor law. An act approved on December 20,1836, organized justices' courts and defined their powers and jurisdiction, and it created and defined the office and powers of commissioners of roads and revenue. Section 29 specified that it was the "duty of said board of commissioners to provide at the expense of the county, for the support of indigent, lame, and blind persons, who are unable to support themselves" (Gammel 1898a:12011206). This act was modified in 1846 by a law passed by the First Legislature of the State of Texas that organized county courts and gave them not only the previously vested powers "to provide for the support of indigent persons resident in their county, who cannot support themselves," but also to provide for "the burial of paupers" (Gammel 1898b:1639-1642).

References in state law suggest that a pauper population existed in the Republic and young state, and reports from Houston describing local conditions reveal that the numbers were sufficiently large in that urban area to require the creation of a charity hospital shortly after Houston was incorporated. Those numbers apparently increased after the capital was moved from Houston to Austin and local municipal revenue fell. The capacity of the city hospital became overwhelmed by the numbers of sick poor, and the city council was forced to sign a resolution in 1839 limiting patients to those who were applying to be resident citizens ${ }^{8}$

\footnotetext{
8 The resolution probably was a reflection both of the numbers of European immigrants entering the Republic through its ports and the numbers of individuals and families immigrating from the United States. Houston in the 1830 s and 1840 s was a hotbed of speculation in land certificates and attracted numerous buyers and sellers of land scrip. Once they had sold their scrip, veterans and those who had received certificates by virtue of their immigration status often had little in the way of money or other items of value with which to support themselves.
} 
and who lived within the corporate limits of Harris County. The local newspaper urged citizens to aid the poor, and the council increased the residency requirement to six months. But the numbers of indigents apparently increased, together with the cost of their care (Writers' Program 1942:325).

The presence of foreign immigrants among the pauper population in the 1840 s raised concerns among nativists who also expressed prejudice against Hispanic people. William Kennedy, for example, compared the slave labor that made it possible to create wealth in Texas with what he called the "motley pauper population" that fulfilled the same role to the "great landed proprietors of Central Mexico, the monopolists of the soil" (Kennedy 1841:369). There was suspicion of European immigrants, as well, who resident Texans assumed comprised the majority of paupers and might league themselves against "true Americans." Frederick Law Olmsted characterized the efforts of the German royalty that culminated in the formation of the Adelsverein as being directed at "the diminution of pauperism [in Germany] by the organized assistance and protection of emigrants" (Olmsted 1857:173). Little wonder, then, that "American" citizens of San Antonio, which had a large population of both Hispanics and Germans, were alarmed by the results of an election in the 1850s in which those two groups voted against the "American candidates." The Germans were classified as "European paupers," while the Mexicans were characterized as "ignorant, vicious, besotted greasers" and "peons" who took their direction from priests (Olmsted 1857:499).

The federal census of 1850 enumerated only 9 native and 1 foreign pauper in Texas out of a total population of 212,592 . These 10 individuals were located in Anderson, Cherokee, Cass, DeWitt, Fayette, Liberty, Matagorda, and Tyler Counties (Figure 1). Of the eight counties represented, only five offered monetary support to paupers (Figure 2) despite laws passed by the legislature. Of these, Anderson had spent \$14 per month, Cherokee had spent $\$ 120$, Fayette had spent $\$ 40$, and Cass and Liberty had spent $\$ 75$, all for unspecified amounts of time.

It can be safely assumed that the numbers of indigents were underreported in the federal census, given the amount of public concern about their numbers during the 1850 s and the steps the state took to provide for the care of certain classes of paupers. In 1855, Sam Houston was moved to address the issue of the impact of paupers on Texas twice: a letter from Independence on July 24 expressed his opposition to "the policy of European potentates and statesmen, to throw upon our shores their refuse population of convicts and paupers, to pervert our ballot boxes, and populate our poor houses..."(Jones 1859:607), while his December speech in Nacogdoches stated his opposition to a bill before Congress that would allow foreigners to vote after a six-months' residence in the United States. He noted that even felons and former residents of European poorhouses "with the mark of the fetters or the parish garb upon their limbs" would be able to vote (Thrall 1879:561).

Concern with the foreign indigent appears to have been segregated during the 1850s from a genuine desire to aid resident citizens who were in need due to conditions beyond their control. In 1853, for example, Guy Morrison Bryan, nephew of Stephen F. Austin, introduced a bill to the state legislature for the erection of a lunatic hospital; and two years later, Governor E. M. Pease drew the attention of the legislature to the need for state institutions that would care for the insane, deaf, dumb, and blind. The efforts of Bryan and Pease came to fruition in 1856, when a bill to fund a state asylum was passed. Speaking in support of the bill, Guy Bryan described the current state of care for the insane and reiterated the responsibility of the government. He remarked that every citizen should be interested in the erection of an asylum that would be staffed, as the governor had imagined, with professionals who were skilled in the causes and treatment of insanity because insanity was "the heritage of all classes." At any time, any Texan might become a "raving maniac." The lot of such a person would be the same as that of felons: "chains and a cell in the county jail." Bryan then described the system as it existed in the mid-nineteenth century: "Jails are often made asylums for the poor, and the raving maniac." He reminded his fellow legislators that "[t]he government is responsible to the people for its omissions, as well as for its commissions, and must take care of its citizens" (Nelson 1926:1-3).

Passage of a bill to construct state insti- 


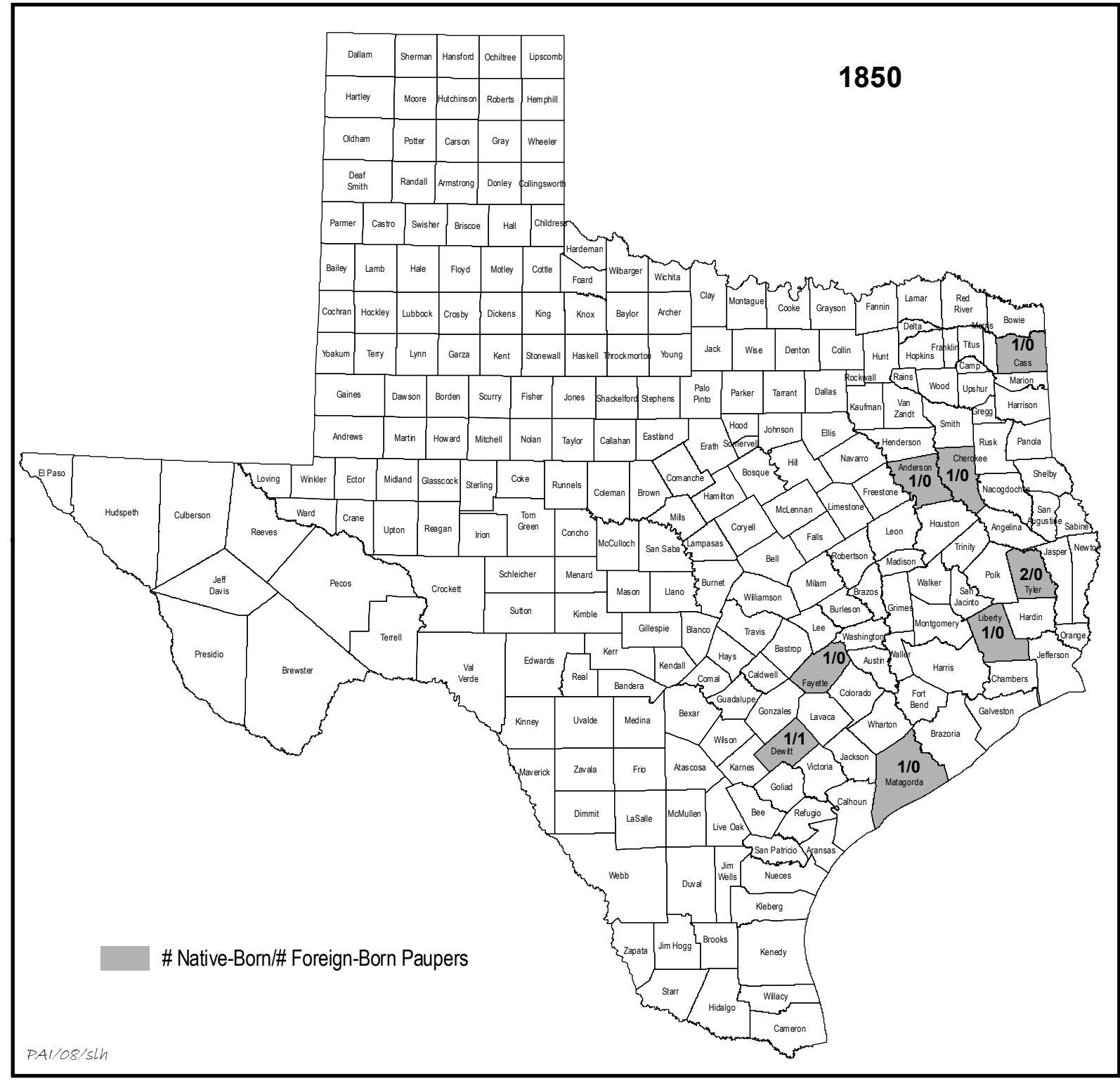

Figure 1. Numbers of native- and foreign-born paupers supported by counties, 1850. Data source is U.S. Total Texas population 212,592. Federal Census, 1850.

tutions for the care of certain classes of needy, many of whom were the responsibility of county government, resulted in the erection and opening of the Texas Institute for the Deaf and Dumb and Institution for the Education of the Blind in 1857, and the State Lunatic Asylum in 1860-1861 (Nelson 1926:7-8, 21, 33-36). Nonetheless, the majority of individuals classified as defectives remained the responsibility of county-level government. In part, this was due to the limited space available in the state institutions.

The legal method of commitment required that the county judge be notified of the presence of a person identified as being an idiot or insane. The judge ordered the person brought and tried before a jury of 12 men. If the jury found the individual to be insane, he was either sent to the asylum or handed over to a friend who had to post bond assuring his safekeeping. Idiots who could be kept safely in the county and persons who were infected with contagious diseases had to be kept in the county. Preference for admission to the asylum was given to indigents and patients who had been ill less than one year. Where indigents were concerned, the 


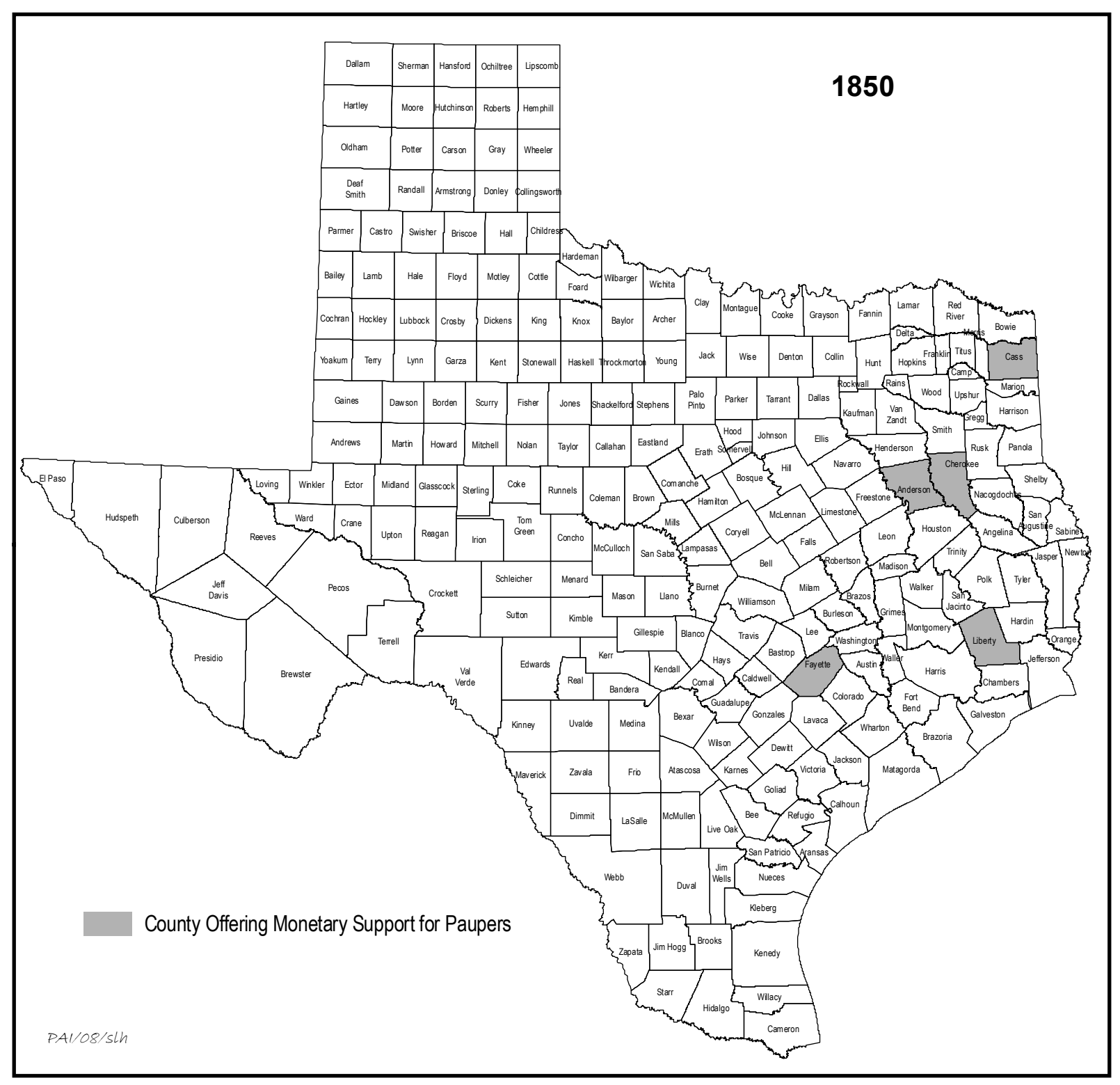

Figure 2. Counties offering monetary support for paupers, 1850. Total Texas population 212,592. Data source is U.S. Federal Census, 1850.

county of origin was required to pay $\$ 2.00$ per week per indigent patient to the state (Nelson 1926:36-37).

The county-level character of indigent care was reiterated in state legislation that incorporated cities and spelled out their responsibilities to paupers. The 1858 Act to incorporate Indianola, for example, allowed the city board to provide "for the support of paupers and others while in the hospital, and for their burial in death...," and it specified that the hospital fund was "declared sacred for.
. the support of paupers and sick persons..." (Gammel 1898c:1212,1215). Indigent care also was described as a local concern in cities such as Houston, where the cost of care had increased to such an extent by 1858 that the local newspaper suggested establishing an almshouse in connection with the city hospital. Such action would reduce the pauper accounts by $\$ 1,500$ per year (Writers' Program 1942:325), a sum that suggested a considerable number of paupers under the care of the city. A typical county might have been Collin, where records 


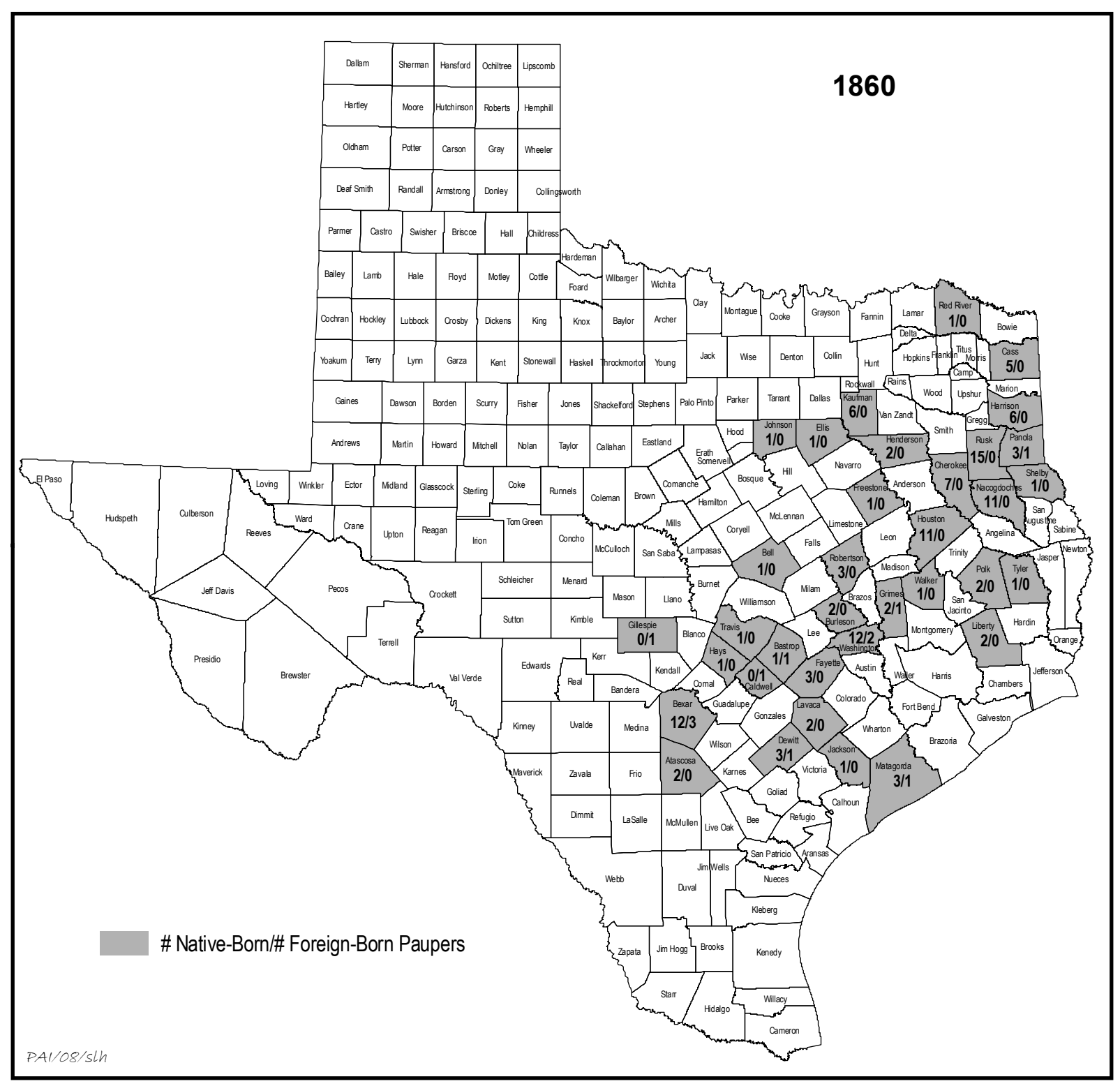

Figure 3. Numbers of native- and foreign-born paupers supported by counties, 1860. Total Texas population 604,215. Data source is U.S. Federal Census, 1860.

in 1858-1859 listed four cases of support: in two cases, county residents were given $\$ 10$ and $\$ 45$ for the support of a pauper; in the other two cases, the county paid two individuals $\$ 12$ and $\$ 12.50$ to make coffins for indigents. That pattern repeated in 1860 , when the commissioners' court provided funds for three additional coffins, and money was provided for the care of an indigent child and one adult, both in private homes (Bland 1994:78).

By 1860, the number of Texas paupers enumerated in the federal census had increased to 138 (126 natives and 12 foreigners) out of a total population of 604,215 . These individuals were located in 35 counties, with the greatest number being located in Rusk (15), Bexar (15), Washington (14), Houston (11), and Nacogdoches Counties (11) (Figure 3). In 10 years, the number of counties offering monetary support to paupers had increased as well from those listed in 1850, and included a total of 30 (Figure 4). In counties that made provisions for paupers, the amounts of money provided for support varied widely from a low of $\$ 72$ in Tyler County to a high of $\$ 2,000$ in Bexar County. But because the census was not specific 


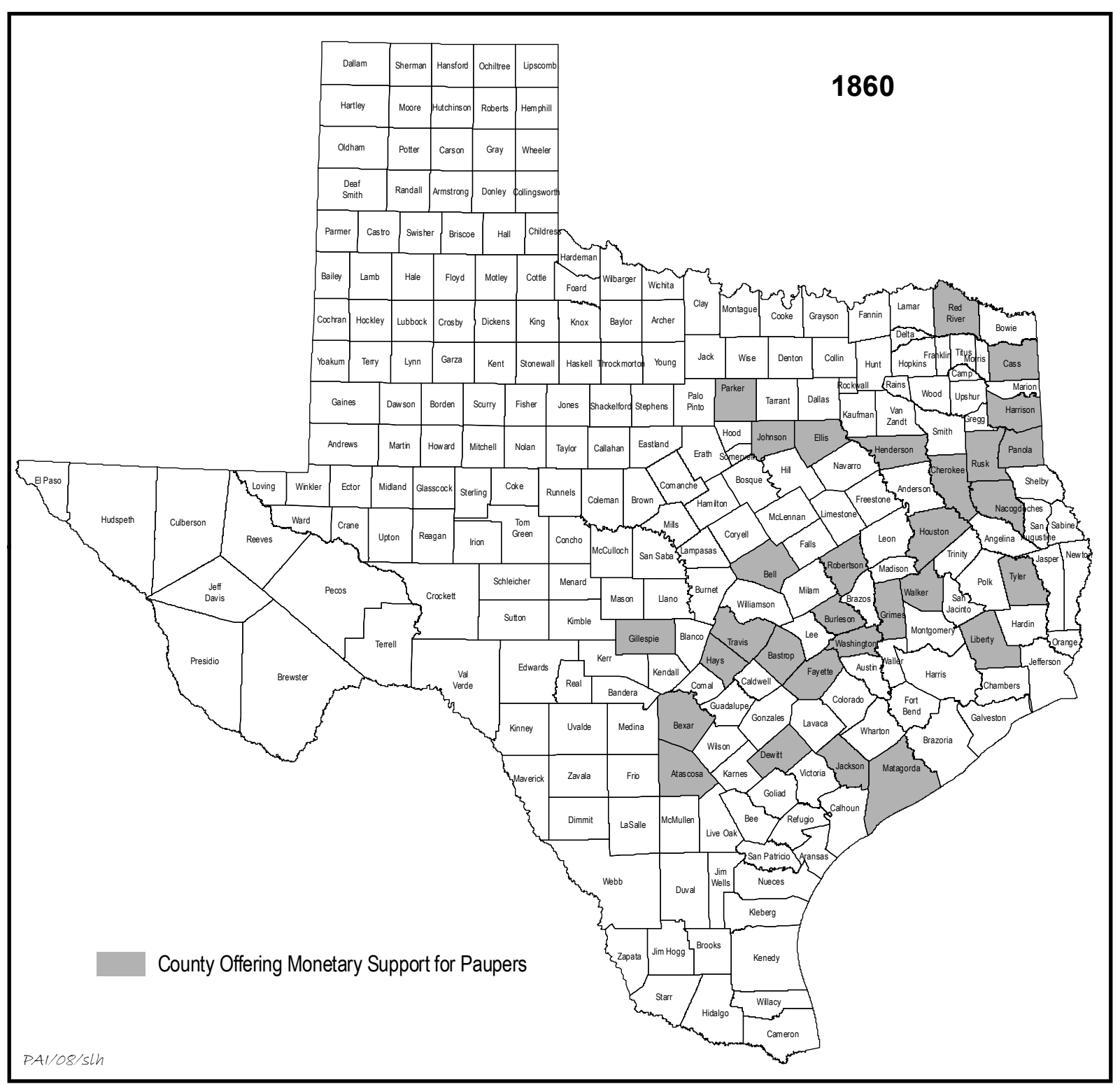

Figure 4. Counties offering monetary support for paupers, 1860. Texas population 604,215. Data source is U.S. Federal Census, 1860.

about the meaning of the dollar amounts, it is not possible to compare costs from county to county. Only Houston County offered any specificity, listing the numbers of paupers supported in each beat and the corresponding amount of money spent per beat.

The Civil War brought with it dislocation and, presumably, a burden on counties that were expected to support widows, orphans, and families whose husbands and fathers were absent. Records from Collin County are particularly informative about relief efforts that offi- cials undertook: according to Hunt (2008), the commissioners' court allocated money, staples, and cotton cards to needy families. Records between 1862 and 1865 included two references about aid to groups of citizens as opposed to specific individuals. In 1862 and 1863 there were two references to money distributed to destitute wives of war veterans and raw cotton distributed to soldiers' wives. Between 1862 and 1864, the commissioners made repeated efforts to identify families in need of support, to distribute money for the support of soldiers, 
and to purchase and distribute cotton cards. By 1864 , the county availed itself of funds made available in Austin for the establishment of an indigent fund, and it appropriated $\$ 5,000$ in county funds to be used for indigent families (Bland 1994:78-80).

On the other hand, paupers supported individually did not increase disproportionately in Collin County during the Civil War, and a comparison of statistics for the period before with the years during the war suggests little change in the actual number of charges on the court. Commissioners' court minutes record that between 1858 and 1860, 6 individuals received support, a number that increased to 7 individuals between 1861 and 1865. In most cases, the money was distributed by the court to citizens who became responsible for the care of a pauper. Between 1858 and 1865, the indigent included 6 males and 5 females; 1 of the females was a child. During the same period, the commissioners provided funding for the burials of approximately 11 paupers. Interestingly, only 1 of the 11 received funds from the county before her death; the remaining 10 were classified as paupers at the time of their deaths but received no public funds prior to that time (Bland 1994:78-80), suggesting that relatives or friends may have provided unreimbursed support until the time of death.

The need for care evident during the Civil War continued unabated during the late 1860s: Collin County Commissioners' Court minutes recorded 29 entries between 1866 and 1869 for a variety of types of care. For the first time, county support was sought for a Negro, presumably a freedwoman. Caretakers sought money from the commissioners, and county funds were spent for food, beef, and medical treatment (Bland 1994:80-81).

On a state level, conflicting needs resulted in the implementation of conflicting policies, particularly as they pertained to immigrant labor. Loss of slave labor after the Civil War left many agriculturists without a source of workers, and the Texas Bureau of Immigration began to promote Texas to prospective settlers, many of them from Europe. A number of large-scale landowners participated in the programs, hoping that immigrants from France, Ireland, Sweden, and other countries would replace the freed slave community, who could no longer be counted on as a source of labor.
Three laws passed by the legislature between 1866 and 1869, however, suggested that lawmakers feared that the new immigrants, rather than being a blessing, would become a burden to towns, cities, and counties. An act concerning alien passengers approved in October 1866 allowed the Commissioner of Immigration or any mayor to examine ships' passengers and to deny any of them to land who were found to be a "lunatic, idiot, maimed, aged or infirm...[or] incompetent...." Other classes who could be turned away included individuals who had been paupers or criminals in any other state or country (Gammel 1898d:948).

The next month, the legislature passed an act to incorporate the Western Texas Colonial Land Immigration Company. In the act, the legislature specified that the company would forfeit all "franchises, privileges and benefits" conferred by the act if it introduced to Texas "any pauper, convict or criminal..." (Gammel 1898d:1459-1463). In 1869, the Liverpool and Texas Steamship Company, Limited, one of whose purposes was to introduce immigrants to Texas, was warned that it would be fined between $\$ 1,000$ and $\$ 5,000$ for each individual pauper or convict it introduced to the state (Gammel 1898e:126-129).

Belief that the pauper population might increase significantly as a result of unregulated immigration was accompanied by measures to deal with the resident indigent population as well as with petty criminals. In 1868-1869, the Constitutional Convention gathered but disbanded without completing a constitutional document. The work was then collected, published as a constitution, and approved by the electorate (McKay 1996:2:289). Among its provisions was the first reference to county poorhouses:

Each county in the State shall provide, in such manner as may be prescribed by law, a Manual Labor Poor House, for taking care of, managing, employing and supplying the wants of its indigent and poor inhabitants; and under such regulations as the legislature may direct, all persons committing petty offences in the county may be committed to such Manual Poor House, for correction and employment (Cottrell 1989:70). 
While the 1869 constitution provided for the establishment of county manual labor poorhouses, no evidence was found that any county actually established such an institution. Rather, the pattern of providing outdoor relief appears to have persisted as the primary, if not sole, method of indigent support for almost a decade. A compelling reason for the absence of county poorhouses and farms in Texas may have been the small number of paupers who received county support relative to the total population: while census statistics for 1870 are anything but complete, given that many paupers were cared for by family members who did not seek reimbursement from the county, only 219 out of a total population of 818,579 were listed as receiving support during $1870 .{ }^{9}$ Of those, the majority of native-born paupers were black (107) and the minority were white (74). Also enumerated were at least 25 foreign-born ${ }^{10}$ (Figure 5), a number that suggests either that fears about the threat of foreign-born beggars was exaggerated, or that the laws passed between 1866 and 1869 had been effective. Forty-four counties were listed in the pauper count, while 45 counties provided support to and/or levied a special tax for the support of lunatics and paupers (Figure 6). As in 1850 and 1860, the amount of money expended for support varied widely, pointing to the intensely local character of indigent care. A total of 9 counties recorded that they had levied a special tax for the support or maintenance of lunatics (otherwise known as a "lunatic tax") and paupers and indigents. ${ }^{11}$

There appears to have been little legislation concerning indigent care in Texas during the early 1870 s, with the exception of a reiteration of the county courts' duty to provide for the care of indigents and burial of paupers (Gammel 1898e:108), and a provision in the

9 The incomplete character of the statistics provided in census returns prior to 1880 is reflected in a comparison of the 1870 return for Collin County, which listed no paupers supported within the year and no money expended for their care, with records of the Collin County Commissioners' Court, which enumerated payments in 1870 of $\$ 169.57$ to paupers, indigent families, or those responsible for their care (Bland 1994:81).

10 The number of foreign-born paupers may actually have been 34 . The 1870 Walker County census listed 9 foreign-born but failed to list any paupers in that category present on June 1. Rather, 9 blacks were listed on that date.

11 Interestingly, in four of the nine cases, the special tax levied for the support of lunatics and/or paupers was paired with a tax to be used for the construction of public buildings. power of city councils to levy poll taxes that excluded "paupers and persons of unsound mind" from the tax (Gammel 1898f:832). The Constitutional Convention of 1875, however, adopted a document that included a number of provisions that affected special classes of citizens. Article VI, for example, stated that idiots, lunatics, "[a]ll paupers supported by any county," felons, and servicemen were not allowed to vote (Gammel 1898g:808). Article XI of the adopted Constitution of 1876 mandated that "construction of county poorhouses and farms, along with jails, courthouses and bridges, should be provided for in the general law." Article XVI mandated that "[e]ach county must provide in such manner as may be prescribed by law, a manual labor poorhouse and farm, for taking care of, managing, employing and supplying the wants of its indigent and poor inhabitants" (Whiteside 1973:9).

The constitutional requirements enumerated in 1876, and the mandate that poorhouses, poor farms, and other public institutions "should be provided for in the general law" resulted almost immediately in the passage of an act to organize commissioners' courts and define their jurisdiction and duties. Specifically, the legislature empowered the courts to "provide for the support of paupers, and such idiots and lunatics as cannot be admitted into the Lunatic Asylum, [and] residents of their county, who are unable to support themselves[;] [and to] provide for the burial of paupers." Another act pertained to convicted persons and specified that convicts committed to jail, who were unable to discharge their fines, could do so by working manually in any workhouse or associated farm, or on any bridge or public road. The county commissioners were directed to build work houses and acquire work farms necessary to use the labor of county convicts and to manage and control those institutions (Gammel 1898g:887-890, 1064-1066).

While the general laws passed in 1876 were not specific about a requirement for a county to erect a manual labor poorhouse and farm for its indigent and poor inhabitants but rather specified erection of a workhouse and farm for county convicts, the mandate of the 1876 Constitution soon resulted in the acquisition of poor farms that may or may not have been occupied and used by convicts but most certainly were primarily for the benefit of paupers. According 


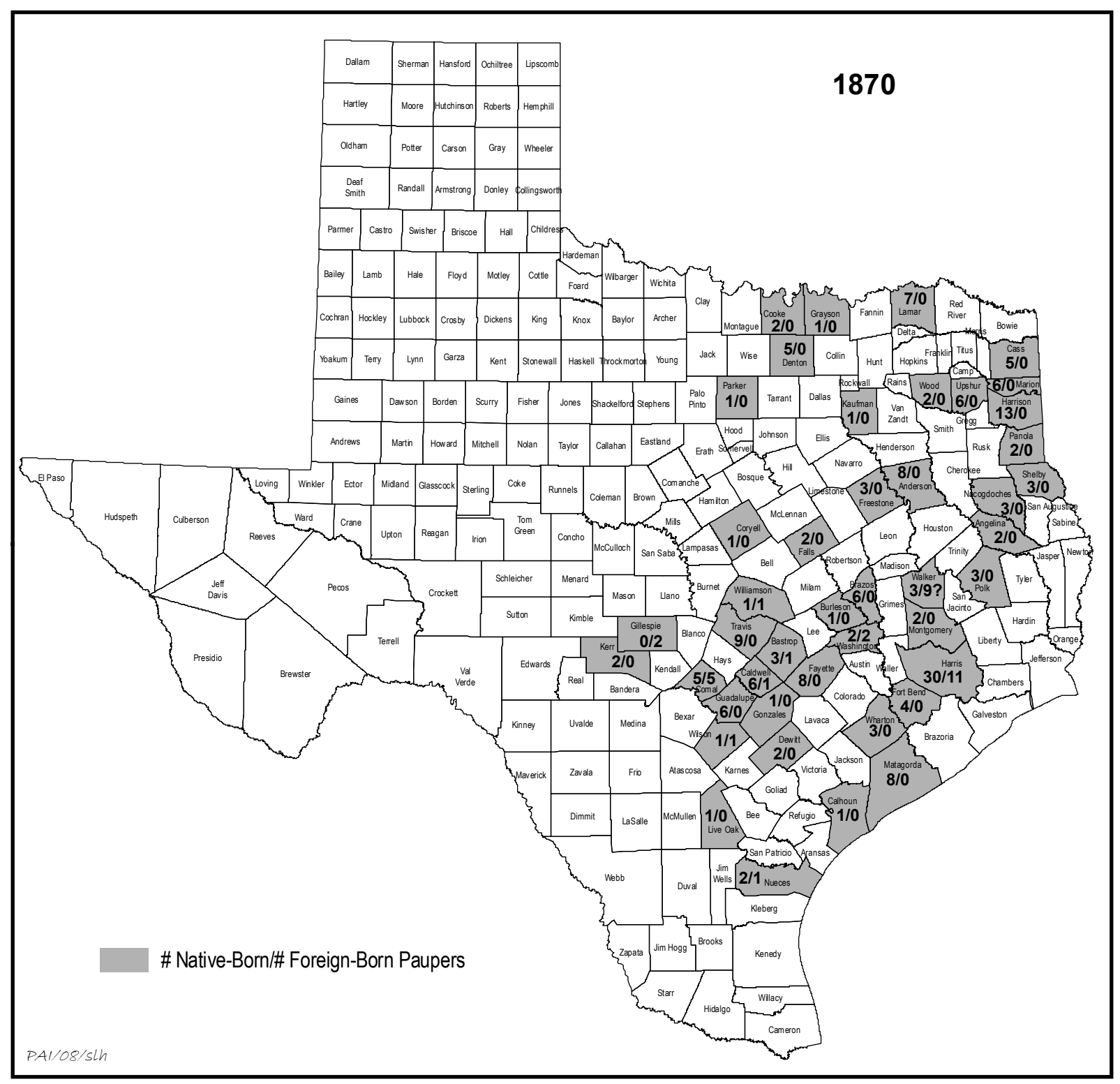

Figure 5. Numbers of native- and foreign-born paupers supported by counties, 1870. Total Texas population 818,579. Data source is U.S. Federal Census, 1870.

to Cottrell (1989:174-175), the first poor farm was acquired by a county in 1876 . Three years later, Kaufman County commissioners began to scout for land that the county could use as a poor farm (Hunt 2008). By 1880, approximately 24 counties had poorhouses or poor farms (U.S. Bureau of the Census 1880).

The federal census of 1880 was important to a history of pauper care in Texas not only because it identified the counties that were the locations of physical institutions, but also because it included a special census that enumerated and described, for the first time, the character of the poorhouse inmates who lived in institutions as well as those who received outdoor relief. Finally, it provided information about the individuals and families who were the keepers of the poorhouses and poor farms.

According to the special census schedule of 1880 entitled "Paupers and Indigents in Institutions, Poor Houses, Asylums; or in Private Homes," 85 counties delivered support to 558 individuals within a total population of 1,591,749. Of those 85 counties, 25 had poorhouses or poor farms (Figure 7) whose residents numbered from a low of 1 in Upshur 


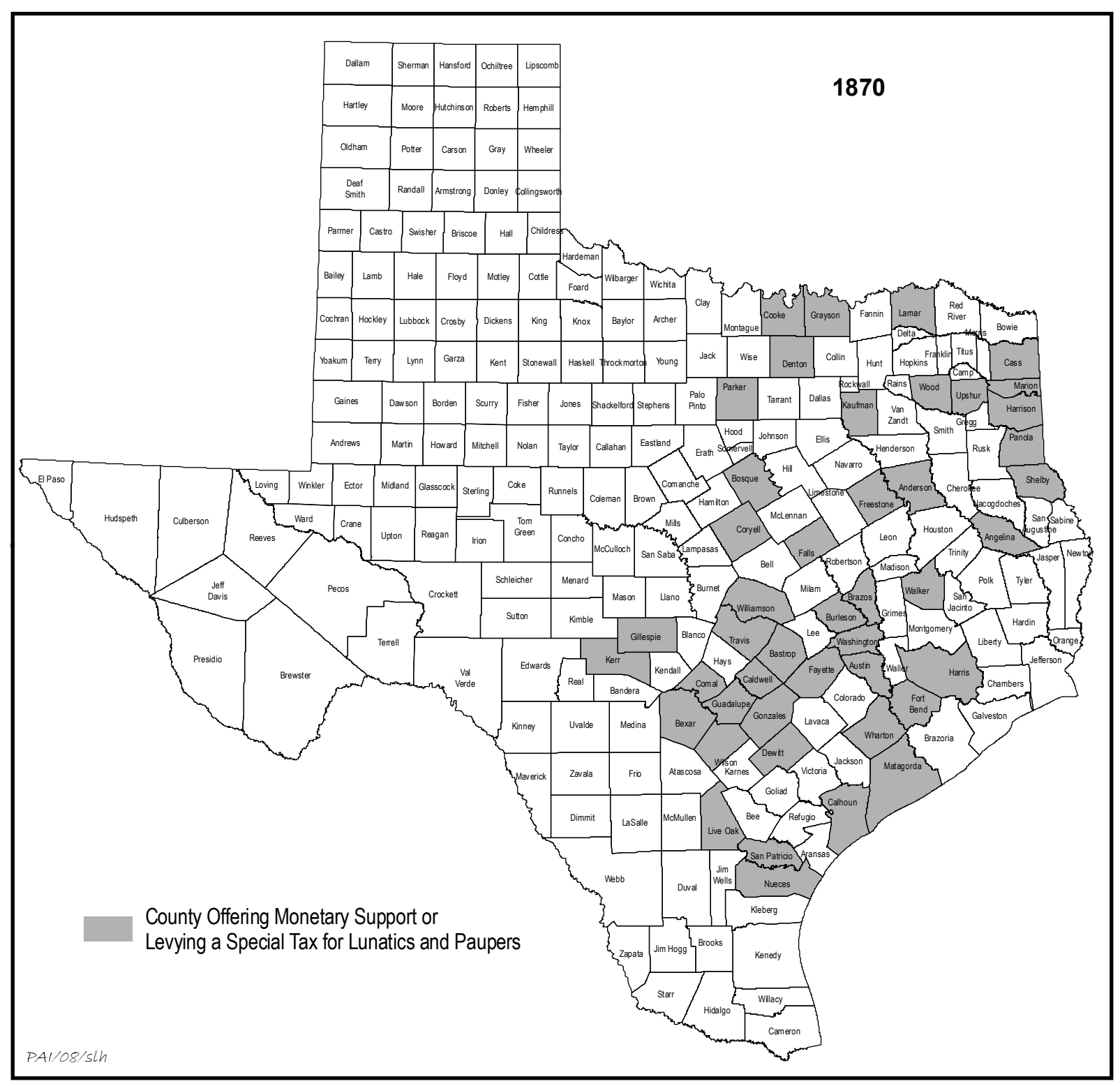

Figure 6. Counties offering monetary support for paupers or levying a special tax for lunatics and paupers, 1870. Total Texas population 818,579. Data source is U.S. Federal Census, 1870.

and Hays Counties to a high of 52 in Bexar County, and whose total was 223 or 39 percent of the total enumerated pauper population. Noninstitutional care included care provided by parents, relatives, friends with homes, or the charity of individuals, and that provided by some combination of county, city, town, or citizens.

The statistics that described individual paupers were incomplete. That is, when providers were given the opportunity to describe whether or not a pauper was able-bodied, temperate, criminal, aged, or mentally or physically disabled, they did not always supply complete information. What is apparent from the information that appeared in the special census, however, is that more than twice as many paupers were not able-bodied (267) as were (123), most were temperate (295) and very few intemperate (22), most were not criminal (272) versus those who were (3), and parents (10) with children (29) represented a relatively small number of the total. The greatest number of paupers suffered physical disabilities or diseases such as paralysis, blindness, rheumatism, dropsy, palsy, scrofula, or pregnancy; a number 


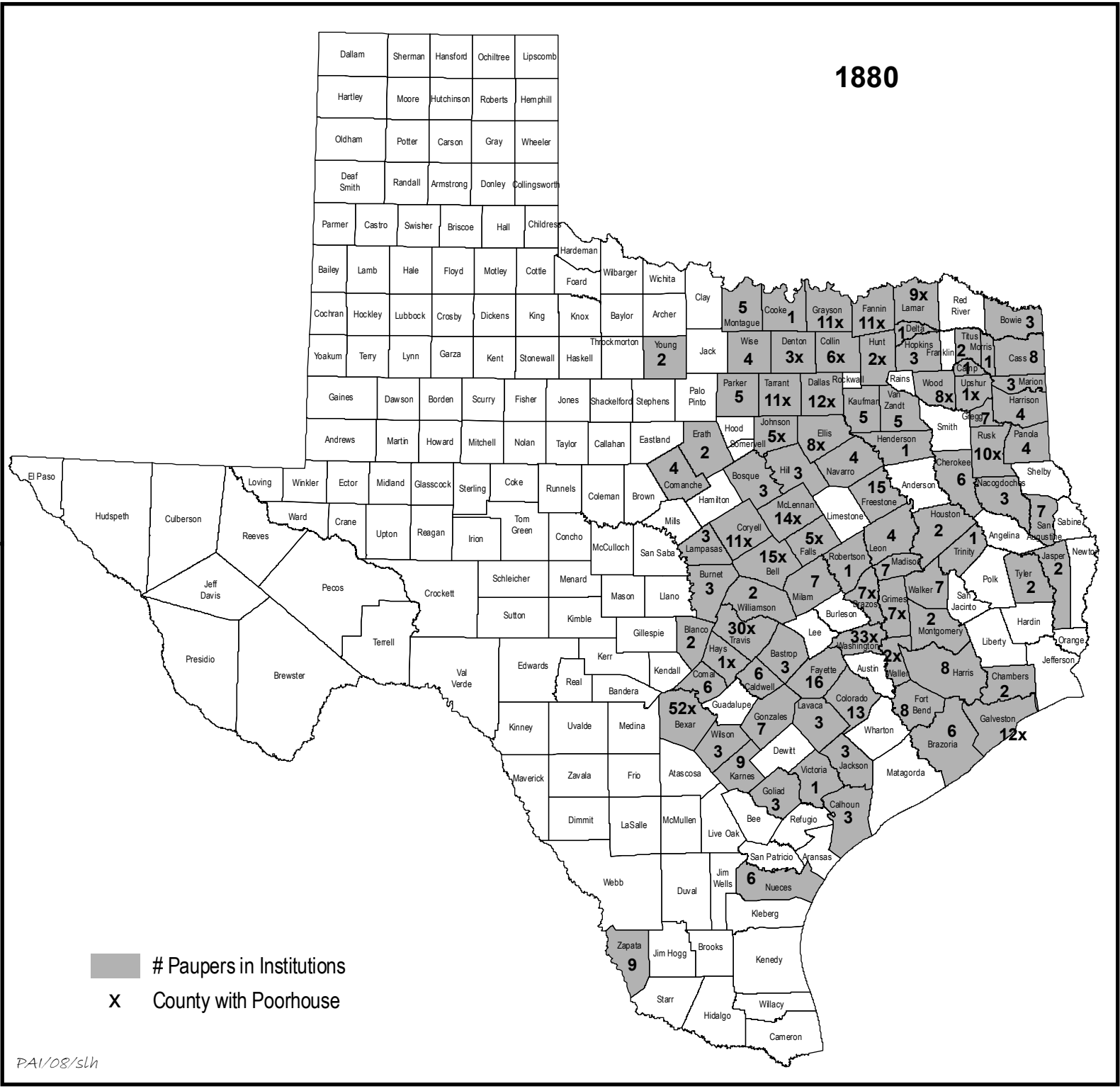

Figure 7. Counties with poorhouses and numbers of paupers and indigents in institutions, poorhouses, and asylums or in private homes, 1880. Total Texas population 1,591,749. Data source is U.S. Federal Census, 1880.

were crippled. Almost an equal number were paupers because they were elderly (118), and of those, many had physical and mental disabilities that contributed to their condition of impoverishment. Many (110) were mentally disabled from conditions such as epilepsy, idiocy, insanity, and dementia. ${ }^{12}$

12 Contrary to the growing perception that many, or even most, institutionalized paupers were related and suffered from mental disabilities, the 1880 census identified 63 individuals who said they had other family present who were being cared for. Of those, 7 suffered from insanity and idiocy. Still, the suspicion existed that heredity played a large role. The Caldwell County
A review of the statistics for those counties that had institutional care revealed that there were five for which additional information about the pauper population was provided-Dallas, Denton, Fannin, Grimes, and Hays. In all five counties, the superintendent listed the total number of paupers who had received care during the year 1879-1880, as well as the number

enumerator said of one pauper that his epilepsy and insanity appeared to have been precipitated by a fall, but he had learned from a neighbor that the pauper's mother had two idiotic daughters whom she would not report. He concluded that the condition of all three children was due to heredity. 
under his care at the time of the 1880 census enumeration. In four of the five cases, the total number cared for during the entire 12 months compared to the resident population at the time the census was taken was larger by a significant factor (Dallas, 52 versus 10; Fannin, 19 versus 9; Grimes, 12 versus 7; and Hays, 2 versus 1), suggesting a nineteenth-century corollary to the pattern noted in the early 1920s that paupers in almshouses were a "rapidly shifting group" that included many individuals who were not permanently indigent (U.S. Department of Commerce, Bureau of the Census 1925:2).

The facilities where paupers were housed included 15 that were designated as poor farms or that were called poorhouses but were run by superintendents who farmed. Another 5 were designated poorhouses or city poorhouses. Coryell, Dallas, and Grayson Counties included jail or prison functions. The Coryell County facility was called the Coryell County Poorhouse and Convict Farm, although there was nothing elsewhere in the schedules to indicate that prisoners or criminals were part of the population. In Dallas County, the keeper of the poor farm was the jailer as well, and a guard was part of the poor farm population. None of the inhabitants of the poor farm was a criminal, but the enumeration for the Dallas County prison schedule listed 14 individuals whose location was the Poor House Prison. In Grayson County, the poor farm population included 1 white and 3 black convicts, and a white guard.

The 1880 census provided statistics for 19 poorhouse/poor farm keepers, one of whom was African-American (Waller County). They ranged in age from 33 to 60 years old, and the average age was 44 years old. All the keepers were married, and 14 of the households included children. One household had no children but did have grandchildren; another had no children but had 5 servants. Presumably, a keeper would have been assisted with the household duties by his wife and with farm chores by his children if they were old enough. They were responsible for a population that was disproportionately African-American: out of 16 poorhouses or poor farms where the races of the paupers were provided, 57 percent were white and 43 percent were black.

By 1880, county commissioners in Texas appear to have taken the charge to establish poor farms seriously. Facilities about which there is information during the 1880s included the Kaufman County Poor Farm, which was located ca. 1.25 miles from the courthouse square on 408 1/3 acres and replaced care that had housed paupers in local hotels and boardinghouses. Buildings to house residents, guards, and farm animals had been erected by November 1883 (Hunt 2008). According to the Kaufman County Historical Commission (2007), the improvements eventually included a superintendent's residence, dining hall, dormitory, silo, water well and well house, blacksmith shop, barns, chapel, jailhouse (for inhabitants who had been incarcerated for minor offences), and other outbuildings. The site also included a paupers' cemetery. According to the Texas Historical Commission (Historical Markers: Kaufman County Poor Farm), the program at the Kaufman County Poor Farm required all able-bodied persons to work, and the resident pauper population was supplemented by county inmates brought daily from the county jail to the farm, where they were housed beginning in 1893. Presumably, they replaced the outside vendors who had been paid by the county to aid the poor farm residents (Hunt 2008), who were not always strong or healthy enough to provide for themselves.

In 1883, Parker County established a poor farm on 320 acres as a replacement for outdoor relief in the belief that the county expenses associated with pauper care would decrease if the paupers worked for their keep on the farm (Bruce 2007). Buildings included a superintendent's house, paupers' barracks, and outbuildings, as well as a cemetery. The farm was located about 3 miles south of Weatherford. As in Kaufman County, convict labor supplemented the labor of paupers, but there was no jail on-site (Cottrell 1989:185-186; Texas Historical Commission Historical Markers: Parker County Poor Farm).

Sometime between 1883 and 1885, Navarro County established a poor farm about a mile from Corsicana (Texas Historical Commission Historical Markers: Smith-McCrery Home), and Anderson County commissioners purchased poor farm property in 1884 (Texas Historical Commission Historical Markers: Anderson County Poor Farm). Eventually, the Anderson County property included housing for the residents and superintendent, barns, wells, 
a cotton gin, and a cannery. A jail building was used for the convict laborers who assisted the paupers with labor and worked on county roads. A cemetery was located on the edge of the property (Texas Historical Commission Historical Markers: Anderson County Poor Farm). In Wise County, a poor farm began operation in 1885 on 320 acres, which encompassed a cemetery (Texas Historical Commission Historical Markers: Wise County Poor Farm). The following year, the Collin County poor farm began operation on 336 acres southwest of McKinney, and Galveston County Commissioners began planning for a poor farm. In 1887, Galveston County purchased 213 acres on Clear Creek. Remarkably, the first building at the farm, which contained a dining hall, was designed by Galveston architect Nicholas J. Clayton. The facility housed indigents who were poor, mentally ill, and elderly. Those who were able assisted with farming chores, probably assisted by residents who had been convicted of crimes $^{13}$ (Texas Historical Commission Historical Markers: Galveston County Poor Farm; The Dallas Morning News, April 14, 1998).

The number of counties in Texas providing poor farms or other institutional assistance had increased in numbers from 25 in 1880 to 36 in 1887-1888, with the greatest increase occurring in the west-central part of the state. The population of paupers in institutions or private homes had increased at a much higher rate: 223 in 1880 versus 857 in 1887-1888. According to statistics provided by Foster (2001), the total population of paupers had increased dramatically as well, from 578 in 1880 to 1,822 in 18871888 (Figure 8). Of the total, both inside and outside institutions, 51 percent of the pauper population was noncolored native, 32 percent was colored, and 16 percent was foreign-born. Approximately 47 percent of paupers lived on poor farms, a statistic that shows that outdoor relief still was widely practiced, despite the perception that poor farms were a more economical way to supply relief.

13 The close relationship between convicts and poor farms, whose primary purpose was the care of paupers, was expressed in various state laws, including an act approved in March 1889. The intent of the law was to credit county convicts at the rate of 50 cents per day if they performed manual labor "on public streets or roads, or on county poor farms" (Gammel 1898h:1042). Sometimes these county poor farms were for the care of paupers; in other cases, they were county-level prison farms.
The more than threefold increase in numbers of paupers in seven years is noteworthy, particularly given that the entire population of the state grew 40 percent between 1880 and 1890. Reasons for the apparent increase probably are attributable to one or more variables: the data collected in 1880 and 1887-1888 were obtained by two different agencies that may have employed more or less thorough procedures, or, the growth in numbers of paupers was real but probably not representative of a sustained trend. Texas in 1887-1888 was in the throes of a dramatic economic downturn whose roots were embedded in a series of catastrophic weather events. The resulting decline and, in West Texas, collapse of certain agricultural markets would have had its largest impacts on marginal communities. ${ }^{14}$

Whether because of economic stresses or from other factors, the number of poorhouses and poor farms continued to grow, and by 1890 , the U.S. census enumerated 56 Texas counties with almshouses serving 464 paupers (Figure 9). Information from commissioners' court minutes in Bowie and Cass Counties in northeast Texas documents what probably were typical operations at a poor farm in the 1890s. The Bowie County facility was located 1.5 miles from the county seat of Boston on 70 acres purchased by the county in 1891 . Buildings were erected immediately, and two men and two women were admitted. A superintendent was paid $\$ 25$ a month, and a county commissioner bought necessities for the paupers. County paupers who requested outdoor support were told that assistance by the county was contingent on their moving to the county farm. Typical residents included a family that "had been living near [a] water tank, in destitute circumstances and being cared for by their neighbors." Others were blind, old and feeble, and widowed (Brett n.d.).

Merchandise necessary for the poor farm occupants was purchased at local New Boston

14 Local concerns about the social displacement that accompanied the agricultural crisis of the late 1880s may have contributed to laws passed about the same time. The so-called paupers oaths were addressed by the state legislature in 1887, and in 1889 an act to incorporate the City of Dallas suggested that paupers had become troublesome in that community. The act empowered the city to "license, tax, regulate, or prevent or suppress paupers, peddlers, pawnbrokers, and keepers of theatrical or other exhibitions, shows, and amusements" (Gammel 1898h:15, 900). 


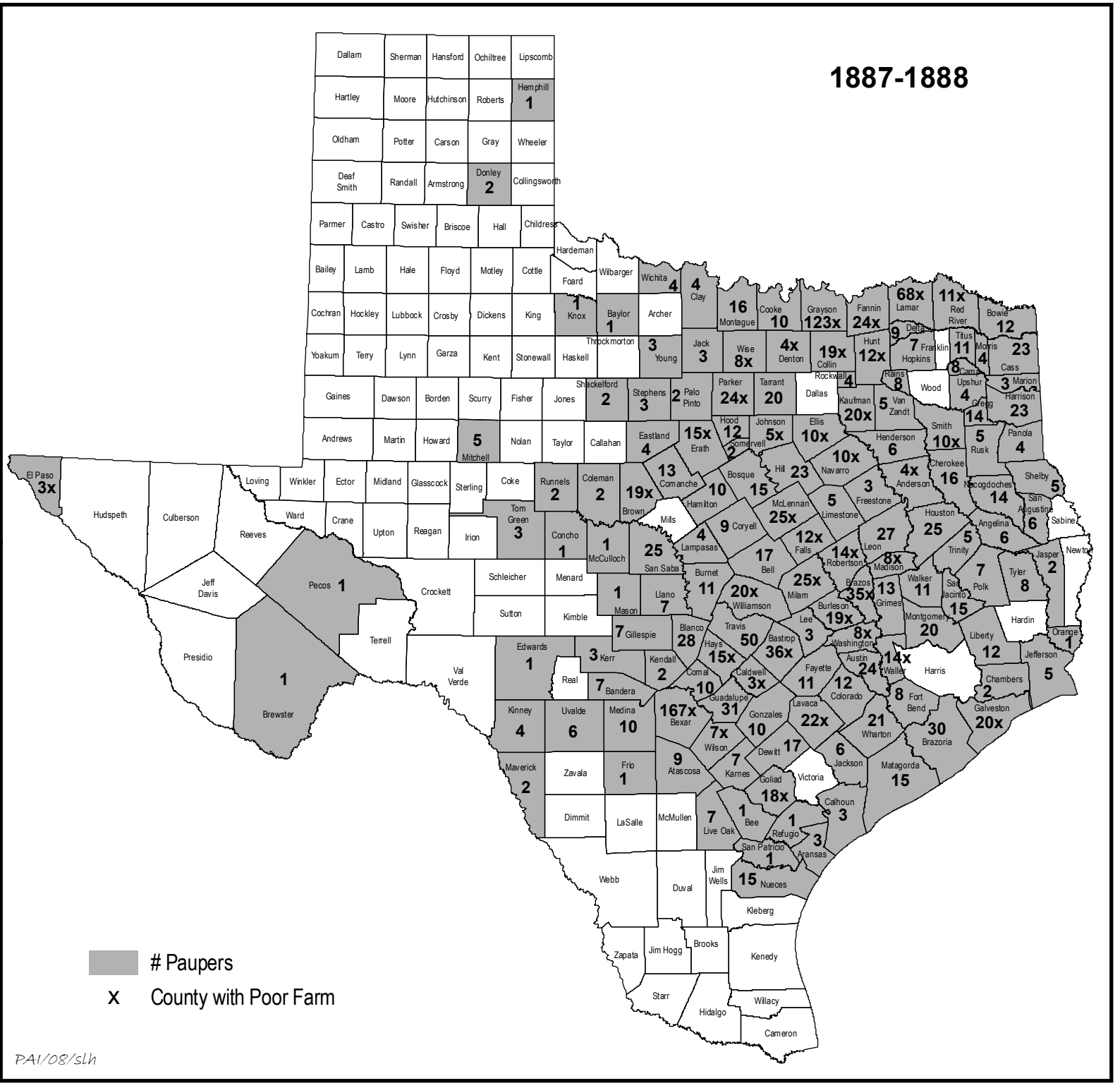

Figure 8. Counties with poor farms and numbers of paupers, 1887-1888. Data source is Foster (2001).

stores, and extraneous services such as sewing, washing, and other work were hired out to local residents. The superintendent hired in 1892 was paid $\$ 20$ per month, and his responsibilities included planting and cultivating 5 acres at the farm in profitable crops. He also was responsible for furnishing milch cows and a workhorse. Subsequent contracts with superintendents required them to perform repairs, care for the inmates, haul supplies, cultivate and raise garden truck, and have cooking done for the paupers. The county was responsible for furnishing provisions to the superintendent and his family and the inmates; seed, feed, and labor associated with washing; and sewing for inmates unable to perform those tasks for themselves (Brett n.d.).

The Cass County Poor Farm was located about 2.5 miles from the county seat, Linden, and was authorized in 1895 when county commissioners decided that it would be less expensive to operate a poor farm than to provide outdoor relief of $\$ 3$ to $\$ 8$ per month per pauper. Anyone who owned a maximum of $\$ 10$ in worldly goods was eligible for residence, and the commissioners set a specific date after which outdoor relief 


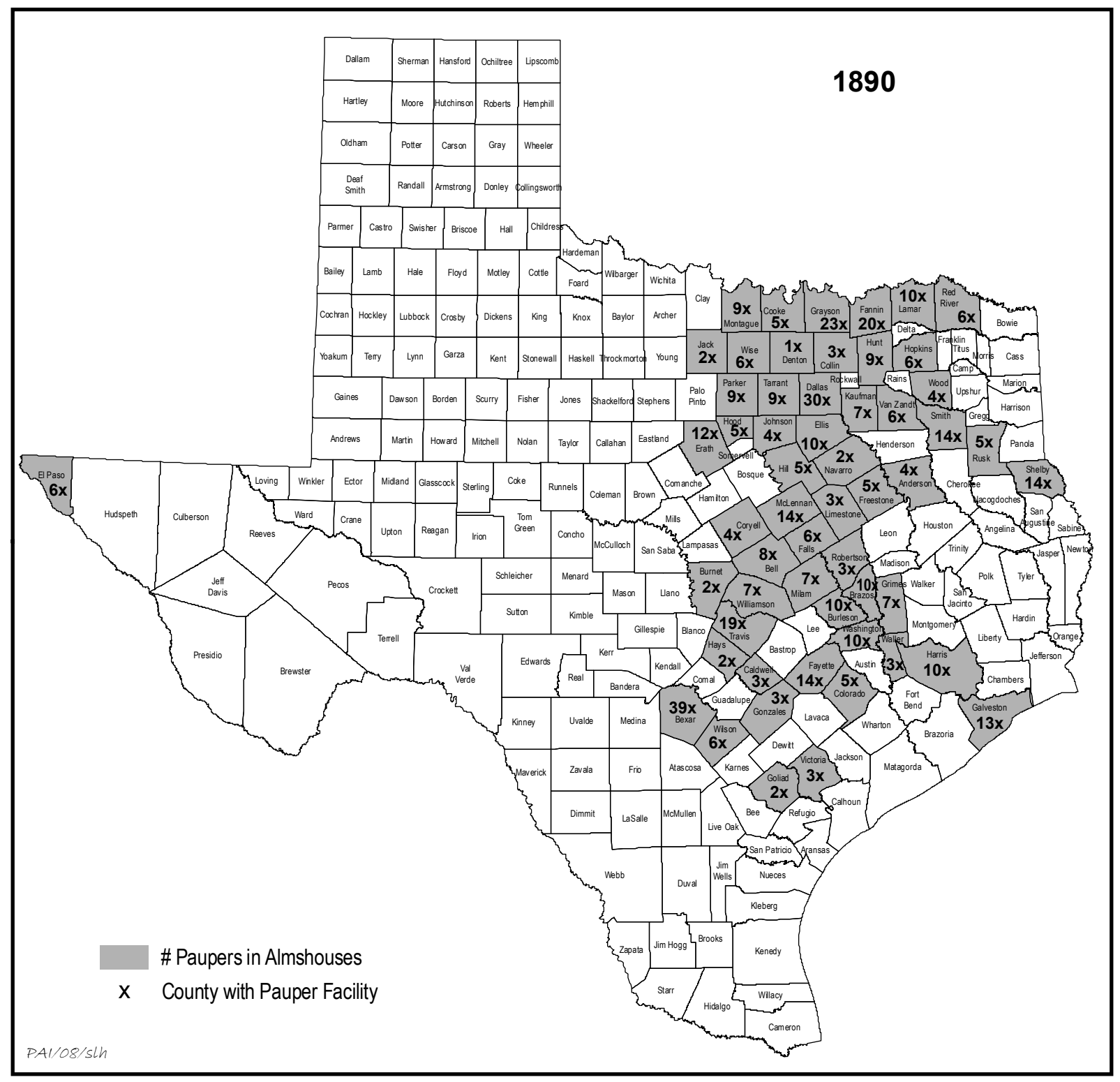

Figure 9. Counties having a county poorhouse, city poorhouse, almshouse, or poor farm, and numbers of paupers in almshouses, 1890. Total Texas population 2,235,527. Data source is United States Department of the Interior, Census Office (1895).

ended. Residents at the farm included paupers and short-term prisoners, most of whom had committed minor offenses. The prisoners typically worked out their fines through labor on the farm or on public roads, and paupers who were able were required to work as well (Stow 1974:22-23).

Rules applied to the superintendents at the Cass County Poor Farm as well as to the paupers and prisoners. The first superintendent hired, who also acted as foreman of the county farm, was paid $\$ 25$ a month and given the livestock, tools, and other necessities his family required. In turn, he had to live on and improve the farm, give his whole time to its operation, and care for the livestock and crops. He also had to take charge of the convicts and paupers and make sure that they worked as the law required and, if they were paupers, as they were able to. The superintendent was expected to treat the paupers and convicts in a humane fashion, and they, in turn, could not swear or use vulgar or obscene language. They could not leave the farm without the superintendent's 
permission, a rule that reflected the commissioners' concern with paupers who might come and go as they pleased. According to Stow, most of the poor farm paupers were elderly people who had no income and no family who would or could care for them. During the 1890s, there were some mothers and dependent children, but by 1900 , state laws were more restrictive, and few children were kept at the Cass County facility after the turn of the last century (Stow 1974:22-23).

No source exists for the 1900 census that enumerated paupers on a state-by-state basis in a special schedule. However, the Department of Commerce and Labor, Bureau of the Census, issued a report four years later that signaled a return to the level of interest in the condition of pauperism that had been reflected in the studies springing from the 1890 census. The special report was limited to paupers in almshouses, which made it of limited usefulness in enumerating and analyzing the pauper population in general, since it excluded the large numbers of paupers on outdoor relief. Furthermore, as the report pointed out, the reasons for the relative numbers of institutionalized paupers from county to county and state to state were various and not readily quantifiable. However, as the report's authors pointed out, "In general, the number of paupers in a state who are supported in almshouses bears close relation to the laws governing the indoor care of the poor as well as to the manner of their administration." In addition, the methods of almshouse administration had an impact on the numbers of paupers in almshouses, and the authors asserted that strict rules about admission and discharge usually resulted in a morestable population throughout the year, whereas "lax and inviting" rules usually resulted in a population that grew quickly and "fluctuate[d] violently from season to season." Another factor was the character of outdoor relief which, if plentiful and permanent, made care in the almshouse less appealing (U.S., Department of Commerce and Labor, Bureau of the Census 1906).

A review of the chief points in the numerous special provisions within laws throughout the United States as presented in the government study of paupers in almshouses revealed that, when compared to those of other states, the laws of Texas were brief, general, and per- missive. At the time of the study, the general provisions of the law were encompassed in just four sentences, surpassed in brevity only by those of Louisiana. As with the great majority of the states, Texas law in 1904 assigned to county commissioners the management of almshouses. It also assigned them the duties to provide for paupers who were actual residents of the counties and unable to care for themselves, to send the indigent sick to county hospitals where they existed, and to bury dead paupers. Commissioners were empowered to encumber a county for sums necessary to support paupers and to employ doctors for their care (U.S. Department of Commerce and Labor, Bureau of the Census 1906:48). Left unaddressed in the Texas law were issues such as responsibility of relatives to care for the poor, management of poorhouses, state supervision of charitable institutions, and other topics. Indeed, 36 other states required residency or the ownership of property before applying for aid, support by relatives if any were able, or work. Texas required none of those. Only 6 states, other than Texas, were silent on issues of legal settlement, responsibility of relatives, responsibility of paupers to work, and recordkeeping requirements (U.S. Department of Commerce and Labor, Bureau of the Census 1906:41-49).

As the 1904 report pointed out, permissiveness in state law often resulted in an extraordinarily fluctuating pauper population in almshouses. Statistics for Texas in the same report (U.S. Department of Commerce and Labor, Bureau of the Census 1906:88) reflected such movements: there were 913 paupers in Texas almshouses on December 31, 1903 (706 white and 221 colored). A total of 901 paupers was admitted to almshouses during 1904 (785 white and 116 colored), and 851 were discharged, died, or transferred during the year ( 749 white and 102 colored). The statistics, then, show an approximately 90 percent turnover in the population during the sampling period.

The number of Texas counties having almshouses continued to grow, reaching 62 by the time of the 1903-1904 study (Figure 10). At least one county, Bowie, took note of the federal study and included a copy of it in the minutes of the commissioners' court. Soon thereafter, the commissioners issued rules and regulations governing the poor farm, but none of the 


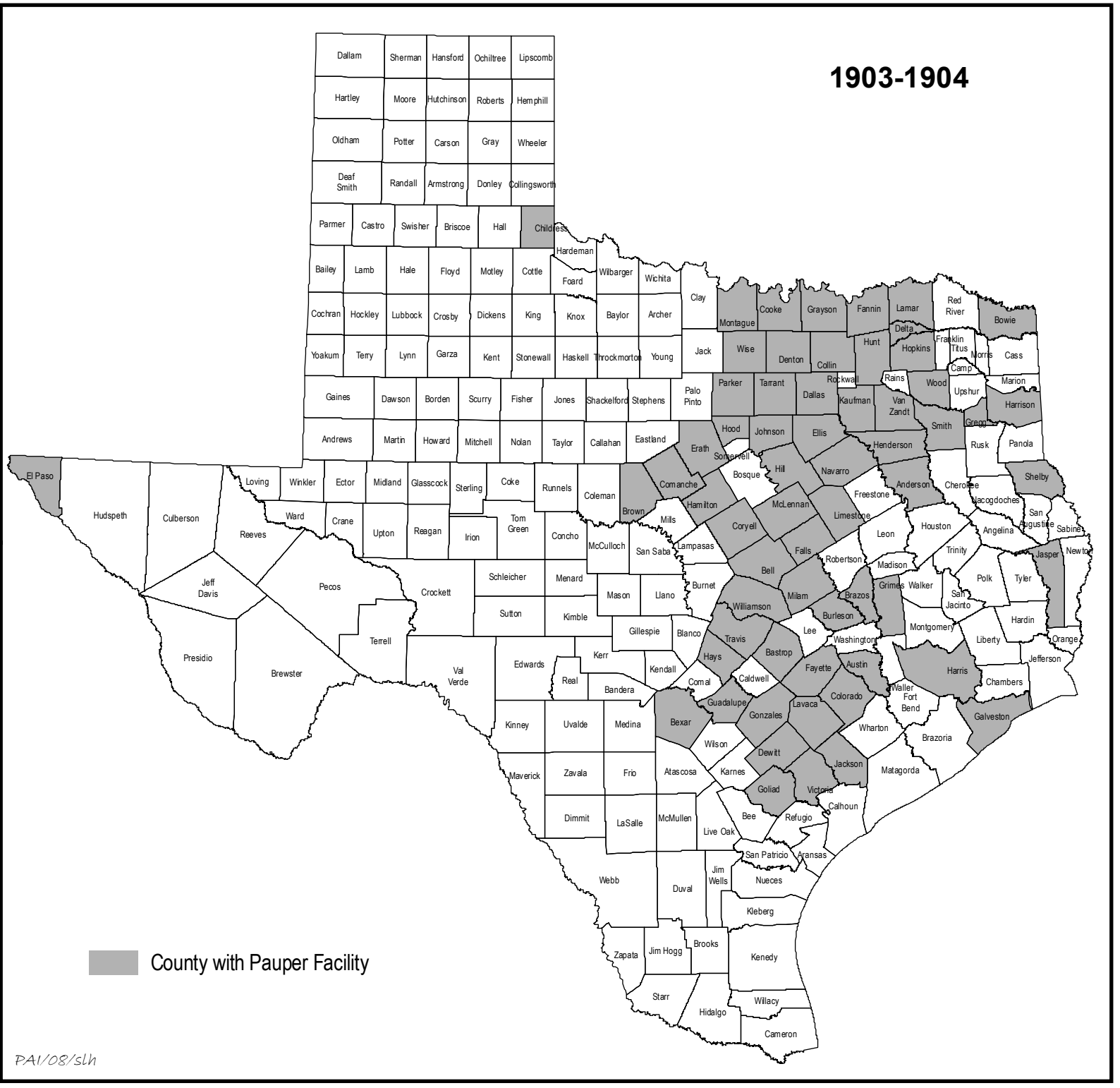

Figure 10. Counties having a county poorhouse, city poorhouse, almshouse, or pauper farm, 1903-1904. Data source is U.S. Department of Commerce and Labor (1906).

rules reflected the less-permissive regulations then current in other states. Rather, they reiterated the superintendent's obligations to care for the paupers in a humane fashion and to report expenses associated with the poor farm to the county commissioners (Brett n.d.). Such care also was reflected in the actions of the Travis County Poor Farm superintendent, who labored in 1903-1904 to improve conditions at the institution by replacing unusable items and hiring a Negro cook to prepare three meals a day. The superintendent lived in a one-story, five-room building with two large porches, a kitchen, and an adjoining storeroom. Pauper inmates had a washroom, dining room, and a dozen two-room cottages. A large barn was on site, and a separate guarded house held prisoners. Typical paupers were elderly, blind, or epileptic; those who could kept their own rooms clean and assisted with chores. The pauper population included a former lawyer and a surgeon who had lost his savings in an unsuccessful business venture. The prisoners, who included a Swiss doctor who was a drug addict, a gambler, and "six small colored boys who had been fined for stealing chickens," helped 


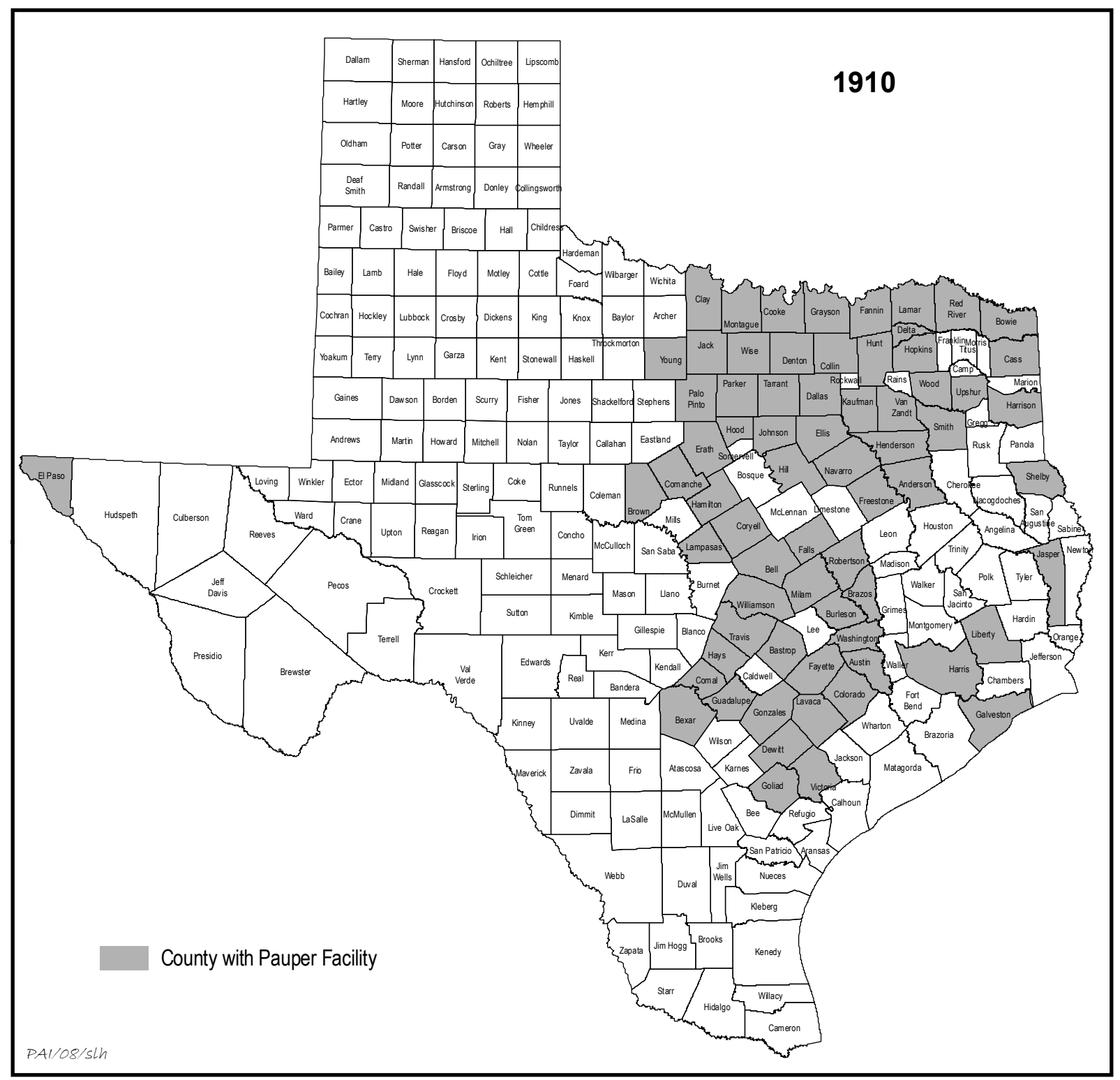

Figure 11. Counties having poor farms or other institutions for housing paupers, 1910. Total Texas population 3,896,542. Data source is U.S. Department of Commerce, Bureau of the Census (1915).

support the poor farm by raising vegetables and crops such as wheat, oats, corn, and cotton (Carpenter 1960:119-125, 131).

The number of Texas counties having almshouses and poor farms increased again from 62 in 1903-1905 to 69 in 1910 (Figure 11) The population of inmates became increasingly white $(75$ percent of the poorhouse population in 1903 versus 77 percent in 1910), although the percentage admitted remained relatively constant. Trends noted by the Department of Commerce, which provided the statistics, reiterated the decline in the ratio of paupers in the United States. This trend was reflected in the statistics for Texas that not only showed a decrease in the ratio, but a decrease in the total number of paupers. National trends also saw a percentage decrease in the numbers of paupers in almshouses who were less than 50 years old, a statistic that pointed to a poorhouse population that was increasingly elderly. In addition, the almshouse population was becoming increasingly male, and immigrant paupers continued to represent a significantly large part of the population, although not the overwhelmingly large numbers that some 
had feared. In Texas, this foreign-born population predominated in counties with large urban populations (Bexar and Harris) and counties with large immigrant populations (Bexar, Brazos, Comal, Guadalupe, Harris, and Lavaca). Single people were disproportionately represented as were the illiterate, unskilled laborers, those who were not able-bodied, and those who were physically or mentally defective. In keeping with the general character of almshouse paupers as being "an unstable, rapidly shifting, group," Texas paupers appear to have been similarly mobile: with a total population enumerated as 861 on January 1, 1910, and 1,046 admitted in 1910, 700 were transferred and discharged; 313 died during the year (U.S. Department of Commerce, Bureau of the Census 1915:9-12, 76-77).

Texas was different from many other states in the degree to which its laws were permissive, and that generally lenient approach persisted despite the passage of laws by the state legislature prior to World War I. In 1911, for example, the legislature had passed an act authorizing county commissioners to raise money for the "establishment of county poor houses and farms" so that they could provide "proper facilities for caring for their poor..." (Gammel 1911:204), and another law provided for "the support of paupers and such idiots and lunatics as cannot be admitted into the lunatic asylum, residents of their county, who are unable to support themselves" (Gammel 1911:236-237). However, according to a study published by the U.S. Department of Commerce that summarized state laws relating to dependent classes, Texas in 1913 still had no general state supervision of charities, no requirement for legal settlement before receiving assistance, and no requirement that relatives be responsible for dependent family members. Indeed, Texas, 7 other states, and the District of Columbia were the only entities that did not have a residency requirement and 1 of 13 states in which relatives were not liable for the costs of a family member's care. Instead, the statutes supported the historic legal structure in which commissioners' courts were responsible for providing support for residents of the counties and for idiots and lunatics who could not be admitted to the state asylum, for providing pauper burials, and for providing and maintaining necessary public buildings and sending sick paupers to a hospital (U.S. Department of Commerce, Bureau of the Census 1914:271272, 312-346).

Nor was Texas in the mainstream of a national trend identified in the federal report to centralize care under state as opposed to local authorities. In one other particular, however, a new group of social reformers in Texas shared important ideas then current elsewhere in the United States. As early as 1905, Dr. M. L. Graves, Superintendent of the Southwestern Insane Asylum at San Antonio, made a plea for the more humane treatment of insane individuals who were "confined in jails, poorhouses and private homes of Texas," for the improvement of the state's hospitals for the insane, for changes in the lunacy laws, and for recognition of the role heredity played in insanity, criminality, and moral perversion. Finally, Graves pointed to the burden that the insane imposed on taxpayers (Graves 1905).

Graves' work was followed a decade later by C. S. Yoakum's study of the care received by the feebleminded and insane in Texas, which drew new attention to this particular population of paupers and introduced mainstream reform ideas about eugenics, the classification of "undesirable citizens," their cost to the public, and the lack of control the state then exerted over the population (Yoakum 1914:1112). ${ }^{15}$ Unable to find the county-level statistics he needed in the federal census, Yoakum sent a questionnaire to county judges in Texas to which all but four counties responded (Figure 12). Of the total, Yoakum provided some degree of detail about six county facilities (Bell, Bexar, Collin, Dallas, Grayson, and Hill). At the Bell County farm, Yoakum found 3 "distinctly insane persons," an old woman who "made life a burden for all the others by her desire to steal everything she could find and hid it in her trunk," an epileptic, and a man who had recently "failed in an apparent attempt at suicide by cutting his

15 In 1916 , the care of the insane by counties drew the attention of Dr. Thomas W. Salmon, who described conditions in a wealthy, but otherwise unidentified, Texas county. He noted that the paralytics, epileptics, and elderly housed at the poor farm had humble but comfortable accommodations. The insane, who were housed in a separate brick building, however, were cared for in such a way that they were degraded. The attendant was well-intended, but untrained, and the facilities and lack of care testified to what Salmon referred to as "ignorant conception of the nature of mental disease. .." (Gilbertson 1917:266-271). 
wrist with a razor." He found the "cottages" at the "poor house" to be "woefully overcrowded" (Yoakum 1914:110). The Bexar County poor farm was under the charge of "one untrained woman" who was solely responsible for 22 insane, senile, or idiotic women. The population also included 2 idiotic children and 2 "dope fiends." There was a total of 120 at the poorhouse under the care of 1 superintendent. Yoakum found the wards "floored with rough boards, showing broken places and impossible of sanitary cleansing." He commented, however, that the county had plans to build "a modern building on a large farm south of town, where the inmates will be given greater freedom and be put to work as far as they are able" (Yoakum 1914:112-113). According to The San Antonio Light (July 27, 1913), the commissioners' court had already bought 100 acres for the farm, and they planned to raise money for "an institution for the poor that will not be surpassed anywhere in the South" by selling the old poor farm on Jones Avenue in the city. An essential first step in the sale of the old farm was the removal of the associated "unsightly burial ground," an action that would make the property more desirable to potential buyers. Plans included reinterment of identified pauper burials in City Cemetery No. 7, reinterment of the unknown in a common grave at the new poor farm, and leveling of all evidence of the old burial ground after removal of the bodies.

In Collin County, Yoakum found 4 insane at the county farm, where appropriate treatment and expert care were not available, but in Dallas County, he found a poor farm that "was kept clean and wholesome," despite its "antiquated buildings." Here, he found "the first hospital building on a poor farm." It was "well equipped for its simple purposes" and had five beds. About 10 insane and 12 idiotic individuals were at the Grayson County farm, where conditions were "very bad." Some individuals were kept in unclean and untidy cells, and Yoakum noted that a number of the poor farms had "miniature jails." On the other hand, he found the rooms in the main building for the paupers and imbeciles at the Grayson County facility to be "clean and pleasant." Finally, he found 6 feebleminded individuals at the Hill County farm where the buildings had "long since outlived their usefulness," and 1 employee had referred to them as "bat cages"' (Yoakum 1914:114, 119, 122).

Yoakum's focus was on the insane and feebleminded population in public institutions, including poor farms (Figure 12), and so his comments reflected a bias about the quality of care available and the institutions in which it occurred. In counterpoint to Yoakum's descriptions of degraded conditions, a photograph of the Cass County farm in 1914 (Stow 1974:22-23) depicted an apparently well-maintained complex. The superintendent's house and paupers' dining room was a turn-of-the-century, one-story frame, gableroofed structure with a full front porch and stone chimney on a gable end. Close by was the paupers' house, a one-story frame, gableroofed structure with a full front porch and two chimney flues. Each room in the building had an entrance to the porch. A county commissioners' report found the rooms "neat as a pin." During a typical day, and if the weather was cold, the superintendent built a fire in each of the rooms and fixed breakfast for the inmates with the help of his family members. In hot weather, his concern for the convicts, who worked on the farm raising crops, led him to leave the jail doors open so they wouldn't suffocate. He solved the potential problem of flight risk by gathering the convicts' clothes and taking them with him (Stow 1974:22-23, 63-64).

Like many of his contemporaries, Yoakum advocated the removal of certain classes of defectives and dependents to specialized state institutions, where they could receive care and their behavior could be controlled for the benefit of general society. He advocated the establishment of permanent state agencies to study and solve "these intricate social problems," and he warned that, if Texas did not take its responsibilities to the "weaker classes" (in this study, the feebleminded and insane, some of whom were paupers), the future burden on society would be as great as it was in the eastern United States. Because he believed heredity to be the prime factor in a variety of neuroses that led inevitably to insanity, idiocy, crime, and, eventually, pauperism, Yoakum reiterated his generation's commitment to eugenics as a solution to the defectives in society. He strongly recommended the development of farm colonies for the segregation, management, and care of those elements of society unable to care for themselves, 


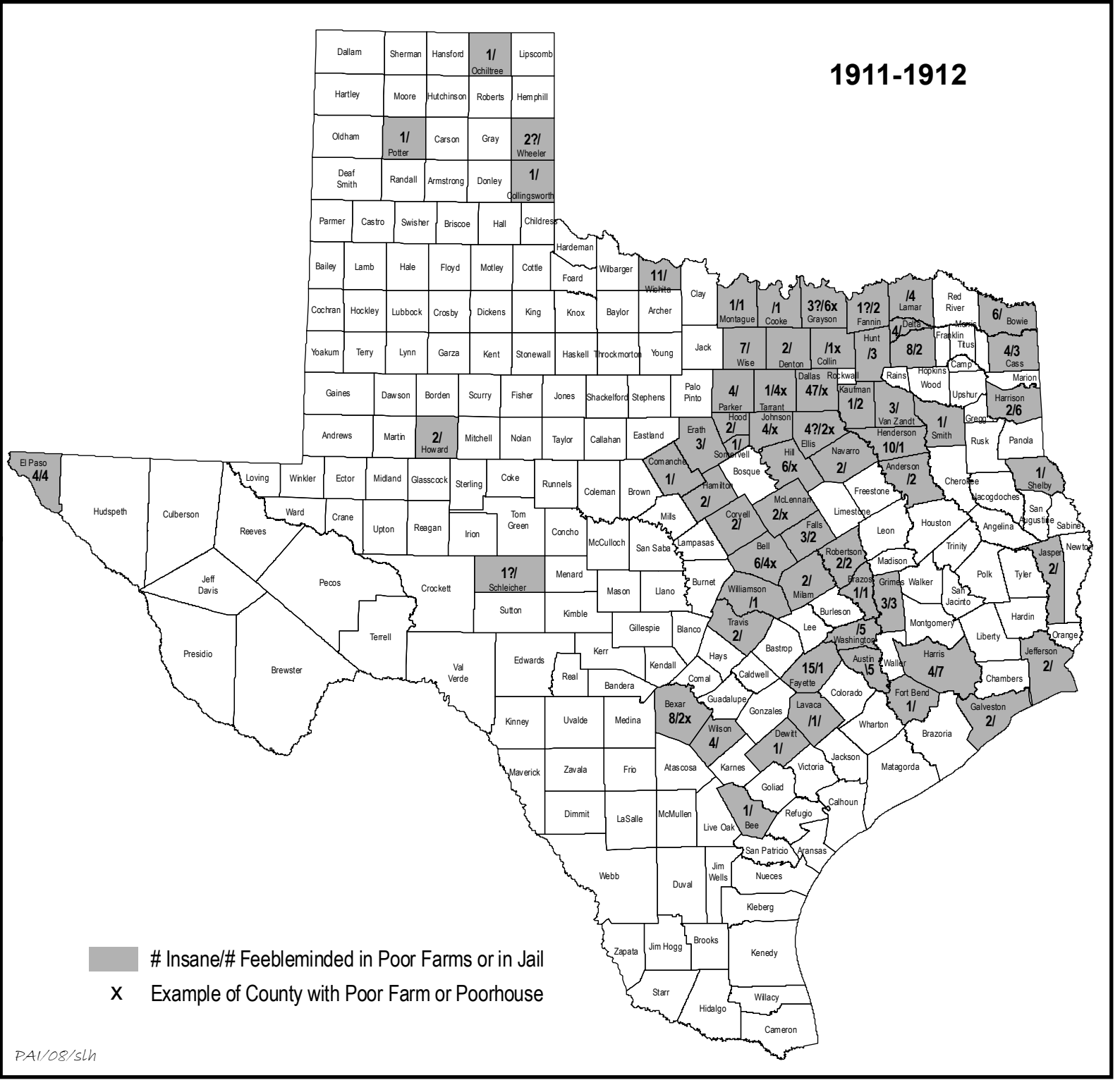

Figure 12. Counties having poor farms or poorhouses, numbers of insane on poor farms, and numbers of feebleminded in jail and on poor farms, 1911-1912. Data source is Yoakum 1914.

and he believed that their line of descent should be terminated (Yoakum 1914:12, 17, 24, $66,74-77)$.

In 1911, the American Breeders' Association's eugenics section had unanimously adopted a resolution that authorized the association chair to appoint a committee. The purpose of the committee was "to study and report on the best practical means for cutting off the defective germ-plasm in the American population." Yoakum pointed out that solutions such as euthanasia and natural selection were "repugnant to present-day ideals of religion and humanity." But two relatively acceptable solutions were sterilization and segregation, and Texas legislators were sufficiently alarmed by the information that social scientists and others provided them to submit three bills at a session about the time Yoakum was completing his work (Yoakum 1914:82, 82n). One of these, introduced in the senate in 1913, authorized sterilization of some criminals, of lunatics and epileptics, and of people being hereditary carriers of congenital diseases of mind and body who either were confined to eleemosynary or penal institutions or might be. The bill was reported 
out favorably but failed (Nelson 1926:124) In the meantime, there remained almost 500 insane individuals in Texas county jails or poor farms (Yoakum 1914:108).

Available literature does not indicate that there was an administrative response to Yoakum's study. Indeed, the legislative record appears to have been silent until the early 1920s, when Governor Pat Neff, who was something of a crusader and moralist with interests in education, prisons, public health, law enforcement, and taxation (Turner 1996:4:970), delivered a speech in 1923 that criticized what he called the "dead weights" (the crippled, permanently sick, women, dissipated and indolent individuals, and drug addicts in institutions), whom he characterized as consumers rather than producers. While his critical comments targeted inmates in the Texas prison system, who he believed should be put to work (Neff 1923:44), his characterizations echoed earlier ones made about residents of poor farms.

Neff's comments appeared about the same time as the national study Paupers in Almshouses, 1923, which found an increase in the numbers of paupers between 1880 and 1923 in the West South Central region of the country (U.S. Department of Commerce, Bureau of the Census 1925). Within Texas, the pauper population in almshouses had increased by ca. 25 percent, but it seemed to have escaped notice that the total number in 1923 was still very small, 1,073 being enumerated in the special census. Furthermore, the number of paupers in almshouses per 100,000 population had remained constant, while the total number of paupers admitted to almshouses had decreased by 32 percent between 1910 and 1923 (U.S. Department of Commerce, Bureau of the Census 1925:7-8). Estelle Stewart's study, published the same year, examined statistics from institutions throughout the United States, including 54 in Texas that had 657 male and 294 female occupants, and a total of 8,682 associated acres. Of these, 4,645 acres were in cultivation. The majority (28) of the Texas poorhouses or poor farms housed 1-10 inmates (3.67 inmates per employee and supported at a cost of $\$ 464.67$ per inmate per year), 14 housed 11-25 inmates (10.68 inmates per employee and supported at a cost of $\$ 332.36$ per inmate), 2 housed 26-50 inmates (7.5 inmates per employee and supported at a cost of $\$ 321.07$ per inmate), 1 housed 51-100 inmates (14 inmates per employee and supported at a cost of $\$ 124.99$ per inmate), and 3 housed 101-200 inmates (7.88 inmates per employee and supported at a cost of $\$ 271.39$ per inmate). There were no larger institutions in Texas. Interestingly, 6 of the state's poor farms comprised of 607 acres had no inmates at all (Stewart 1925:17-20, 26).

In summarizing state laws pertaining to poorhouses and poor farms, Stewart found that Texas was 1 of 28 states (out of 48 states and the District of Columbia) where control of almshouses was vested in a board of county commissioners (Stewart 1925:53-54). This total number probably reflected the early results of a national shift from local to state control that had begun occurring in the late nineteenth century and eventually became a dominant pattern throughout the United States. Reflecting a change from the pre-World War I pattern, Texas required legal residence to receive assistance, although exceptions still could be made. Texas and 3 other states did not enumerate who could be committed to an almshouse; and with 28 other states, it did not address in its laws the subject of contracting for the care of the indigent. Texas, 35 other states, and the District of Columbia made provision "for the removal of mental defectives in almshouses to an asylum for defective persons," but it was 1 of 18 states that did not make relatives "liable to the support of poor persons committed to almshouses." Texas and 11 other states did not require paupers who were able to work to be employed, and it was 1 of 30 states that had not made provision for almshouse consolidation, an activity some states had undertaken because of a belief that consolidation resulted in financial savings.

While some authors have assumed that Texas was intolerant and punitive in its posture towards paupers (Cottrell 1989:172; Crannell 2003), the data in Stewart argue otherwise: there was a generally tolerant and lenient attitude about work, the financial liability of relatives, and residency. At the same time, the state recognized, even if it did not provide adequate local or state support for, one of the core values of late nineteenth- and early twentieth-century progressive social policy: that "mental defectives" were more appropriately cared for in asylums than in poorhouses and poor farms. 
Stewart concluded that almshouses throughout the United States were characterized by dilapidation, inadequacy, and even "indecency," and she asserted, quoting the North Carolina State Board of Charities, that the county home was "a failure" (Stewart 1925:41, 49). Her conclusions were affirmed by the findings of the Texas Eleemosynary Commission. Called together by Governor Neff in November 1923 , but provided with no funds by the legislature, the commission raised money and hired mental health experts to help them find "better and more economical methods of conducting the State's eleemosynary institutions and, especially...seeking out means of preventing in future, as far as possible, dependency and delinquency." The commission focused on the insane and feebleminded but, because a number of those classes were housed in poorhouses and at poor farms, the commission's report described general conditions at county poor farms and almshouses. The experts studied a total of 148 individuals at 11 poor farms and 1 "old-ladies' home" and found 53.4 percent to be mentally ill or deteriorated (insane), 22.3 percent mentally defective (feebleminded), and 1.4 percent each to be borderline mental defective or suffering from gross personality defects (Texas Eleemosynary Commission 1925:5, 19, 29-30).

Of the facilities, the commission found that two counties had "well constructed buildings," but in most counties, housing consisted of "several small "pauper houses' of frame," each of which had two small rooms, each room being occupied by 1 or 2 people. Most of the 11 poor farms had no dining room. The inmates received food in the kitchen and consumed it in their rooms. Conditions were generally dirty, and clothing, bedding, and rooms were in need of soap and water. Concerning inmate demography, the commissioners found 111 male inmates and 37 females. There were 121 whites, 27 Negroes, and no Mexicans. Children were found at 2 of the poor farms, and the greatest number of the residents (100) fell between the ages of 50 and 89. Single people (66 of 148) and widowed individuals (50) predominated.

A total of 85 of the inmates were sufficiently educated to read and write, and 9 of them had some high school training or had been to college; however, 97 of them had not passed beyond the third grade. A total of 19 had some level of skilled training; the remaining 129 had none. Although the commission found that the great majority of inmates were what they called mentally diseased or deteriorated, the fact that 56 suffered from arteriosclerosis and another 24 of cardio-related diseases (Texas Eleemosynary Commission 1925:31-33), suggests that advanced age may have been the most significant contributor to their mental condition.

Projecting to the state as a whole, the commission estimated that 933 individuals were housed on Texas' poor farms where all classes of people were mixed together, just as they had been since the nineteenth century. They concluded that poor farms were performing "no useful service whatever, unless it be considered useful to temporarily hide from our sight the aged, the insane, the feeble-minded, the syphilitic, and the tuberculous and mix them in one house with no proper care of either class, no treatment likely to rehabilitate them, or even to ease their pains efficiently and protect society from them."The commission concluded with the statement: "Poorhouses are relics of medieval ignorance and largely a waste of money. They should be abolished and their inmates sent to institutions suited to their several needs" (Texas Eleemosynary Commission 1925:8, 33-34).

The attack on poorhouses and poor farms in Texas and the nation continued during the mid-1920s in the form of Harry Evans's study that included 54 Texas poor farms. Evans briefly described conditions at 14 poor farms and provided specific, but only brief, information about improvements at 11 of them. All of the $11 \mathrm{had}$ outdoor privies, well water, and no sewerage. Typically, men and women slept in adjoining rooms. Collin County had three "old, one-story board buildings battened" with whitewashed rooms; a dining room; and a building with cells, an iron door, and iron grated windows. Palo Pinto County had an "old shack of a building," while the Travis County facility looked like an "old logging camp." The Wilson County poor farm was comprised of "two old shacks" (Evans 1926:79-80).

According to Nelson (1926), who reiterated the findings of the Texas Eleemosynary Commission, the chief recommendations of the commission were embodied in a bill and presented to the $39^{\text {th }}$ Legislature in 1925. The main provisions pertained to terminology used to describe certain classes, division of the state 
into hospital districts, changes to the commitment law, establishment of two psychopathic hospitals, and the requirement that persons judged insane could not be held for more than 30 days in any facility other than "an institution for the treatment of the insane" (Nelson 1926:118-119).

Presumably, enforcement of the last provision would have resulted in removal of persons diagnosed as insane from poorhouses and poor farms. However, insufficient information is available to evaluate whether or not poorhouse and poor farm populations changed following the activities of the Texas Eleemosynary Commission. Some authors have remarked on the growing tendency of the residents to be characterized by their elderly status. A greater impact on the institutions probably occurred as a result of the depression of the 1930s, when federal and state programs began to have an effect on funding of relief and use of the poor farms themselves. The Kaufman County Poor Farm, for example, was used simultaneously as a facility for paupers and in a Farm Demonstration Program beginning in 1931. Under that federal program, some of the farm acreage was set aside and placed under the jurisdiction of the county agent (Hunt 2008).

In November 1932, statewide relief began with passage of the Federal Relief Emergency law (Cottrell 1989:181), and constitutional authority for a state welfare system was established in 1933 under Article III, Section 51a, entitled Assistance Grants and Medical Care for Needy Aged, Disabled and Blind Persons, and Needy Children. The framers of the 1933 provisions established very specific eligibility requirements, as did the Social Security Act of 1935, which forbade assistance to residents of public institutions. This act was accompanied by the Texas Old Age Assistance Law of 1935, whose requirements essentially were the same as those of the Social Security Act (Cottrell 1989:182; Whiteside 1973:10).

Theoretically, the federal and state laws passed during the 1930s and the creation of new state agencies such as the Child Welfare Division and Commission for the Blind in 1931, Unemployment Relief Commission in 1934, Old Age Assistance Commission in 1936, and State Board of Public Welfare (Department of Public Welfare) in 1939 (Cathey 1949:110, 112) should have obviated the need for poor homes and poor farms in Texas. And, indeed, some poor farms were shut down, the one operated by Bowie County being advertised for sale in December 1941. Old age assistance entitled the elderly to services that exceeded what poor farms and poor homes had been able to provide. According to Cottrell (1989:182), the availability of federal and state aid spelled an end to these local institutions, and she attributes the ownership of poor farm properties by counties well after the 1930s to the length of time it took for counties to complete sales of the property.

A more likely explanation for the persistence of these historic institutions is that provided by Wagner (2005:132-133), who pointed out that groups such as agricultural and domestic workers and public employees were not covered by the Social Security Act. Social Security pensions required 10 years of contributory payments, and so a very large number of elderly were not eligible to receive Social Security pensions. The disabled, who comprised another large proportion of the indigent population, were not covered by Social Security until 1956, and even then, they also had to have made 10 years of contributions. These and similar requirements of the law help to explain the persistence of poor homes and poor farms in Texas as late as the 1960s.

A review of the history of indigent care in Texas suggests the following:

- While some provisions for indigent care were provided in Spanish and Mexican law, the legal structure of that care became rooted in English poor law following the Texas Revolution and passage of an act establishing what became the county commission system.

- After 1846, county courts were responsible for supporting indigents and burying paupers.

- Concerns about the number of immigrant poor in Texas during the mid-nineteenth century mirrored those of the rest of the United States and persisted into the late nineteenth century.

- Texas was among the first states to establish, fund, and construct state institutions in the 1850s and 1860s for the care of special classes of individuals (insane, deaf, dumb, and blind) who 
typically were cared for at home. However, space at those institutions was inadequate to relieve the burden of care provided by families and, later, local governments.

- While it would be impossible to reconstruct the number of paupers in Texas after 1850 without reviewing all census records for every county, the small numbers recorded in the special censuses of the late nineteenth century suggest that the numbers of indigents relative to the total population were very small.

- The 1876 Constitution provided for the establishment of poorhouses and poor farms; the first poor farm was acquired by a county the same year.

- Prison labor became an essential part of the operation of poor farms by the late nineteenth century. Misdemeanants typically assisted superintendents in the operation of the farms and raising of crops to feed the paupers.

- Typically poor farms were located 1 to 3 miles from a major town, often the county seat, and the economic ties between farm and town were strong. Improvements at the farm usually included a superintendent's house, pauper housing (often two-room frame cottages), a kitchen, barns, a shower or washroom, wells, and outhouses. A typical poor farm headquarters probably closely resembled that of a rural Texas farm. Cemeteries usually were present. If inmate labor was used, a jail might be present.

- Poor home and poor farm populations were racially mixed. A wide variety of types of indigents usually were present as well, and included elderly, blind, insane, and idiotic individuals. Children were not represented in large numbers.

- The numbers of indigents probably increased in response to natural and economic disasters. The numbers of poor farms increased between 1876 and 1910 , but at a steadily decreasing rate.

- The population served by outdoor relief may have exceeded that served by institutions at all times.
- Between 1900 and 1930, Texas social reformers and legislators reflected national trends in the area of eugenics and the identification of poor farms as undesirable spawning places for undesirables.

- When compared to those of other states, Texas laws regarding the care of indigents were permissive. As a result, pauper populations and the extent to which they received care in county institutions tended to fluctuate more than in states with more restrictive laws.

- As elsewhere in the United States, the numbers and percentages of paupers in Texas decreased in the early twentieth century. Thereafter, the pauper population became increasingly elderly, male, and single.

- As elsewhere in the United States, state programs and bureaucracies designed to provide relief and care for certain classes of needy citizens increased dramatically during the 1930s. However, local solutions to care, such as poor homes and poor farms, persisted because a large percentage of indigent citizens failed to qualify for any other form of relief.

\section{PAUPER CARE IN BELL COUNTY, TEXAS, 1850s-1969}

Pauper care in Bell County, Texas, may have begun as early as 1850, when the county was formed; official records document a continuity of care from 1859 (CCM B:191) ${ }^{16}$ until 1969, when the Bell County Home closed and the last six inmates were moved to a Temple nursing home (Gardner 1995). During the intervening 110 years, the county provided outdoor care for the entire time, and indoor care for 90 of those years at four different locations. Between 1879 and 1969, indoor and outdoor relief occurred simultaneously as county officials worked to develop a system that was humane, economically practical, and flexible. The larger world of

16 The designation "CCM" indicates county commissioners' minute books. All such references in this chapter are to Bell County records, as are deed, death, and probate records cited in the text. Note that "deed record" is abbreviated "DR" in the text for the sake of brevity. 
sociological and reform theory seems not have touched those responsible for the care of indigents, except in occasional requirements to keep records. Rather, pauper care in Bell County reflected other broad patterns: the majority of individuals who needed care received a modest stipend from the county that allowed them to remain in their homes; a number who were in greater need, perhaps because of the seriousness of their afflictions, received a county stipend that was administered by a third party, while others were placed at the county farm or home; and the most serious cases were sent by the county to one of several appropriate state institutions. To call pauper care in Bell County a "system" would be a misnomer. Rather, the county's practices, like those of the state as a whole, appear to have been permissive. While county commissioners attempted, from time to time, to exert some degree of oversight and structure, they were generally lenient concerning issues such as family responsibility, length of time indigents were allowed to be dependent on the county, and legal settlement.

Bell County records suggest that some form of pauper care existed by the $1850 \mathrm{~s},{ }^{17}$ and that care consisted exclusively of outdoor relief until 1879. As early as November 1859, Bell County paid for the burial of a Mrs. Yarbrough at an undisclosed location (CCM B:191), and after the Civil War, the county commissioners' minutes frequently listed sums paid and services rendered for a variety of forms of assistance. A typical arrangement involved several steps. First, the person needing assistance was identified, either by themselves or by others who knew of their plight. Notes in the minutes for October 1865 said that "old man" Wade Hampton was a pauper and "really needed assistance from the county" (CCM C:28); in another case, an impoverished father with a large family had a pauper daughter who was a lunatic for whom he was unable to care $(\mathrm{CCM}$ C:31). In 1866, "freed boy Henry" was identi-

\footnotetext{
17 The author identified data in the county commissioners' minutes by using the index to the minutes. However, it became apparent that the index was not complete, and certainly not exhaustive, because a random review of pages not listed under the subjects "pauper" or "poor" in the indexes resulted in the identification of numerous records other than those that were indexed. The absence of references to paupers during the Civil War was particularly noteworthy, since most counties would have had requests from or on behalf of indigents during that time.
}

fied as a diseased person who was suffering, and two years later, help was sought to keep a Mrs. Griffin and her two children from suffering (CCM C:58, 175-176).

The next step involved the identification of an individual who was willing to take responsibility for the pauper, receive money from the county, and account for the funds. If the pauper was ill, a medical doctor might be selected (CCM C:44). Otherwise, the responsible party could be a member of the general community or a relative: Benjamin Ellis was given money for the costs involved with keeping his insane daughter (CCM C:65), and T.K. Young kept and supported "the old pauper woman of color" (CCM C:176). A caretaker was not named for the money appropriated for the support of an old Negro woman who had been the slave of Parson Crawford and now was a pauper (CCM C:175), but presumably, a third party would have been identified to receive the $\$ 10$ per month that was appropriated for that use.

According to one record, the recipient of the funds was required to present his accounts, justifying the expenses of care, to the court (CCM $\mathrm{C}: 44)$. The tone of the court records, whether pertaining to monetary or personal responsibility, was not punitive but, rather, solicitous. The court understood that an impoverished father who was trying to care for a large family would need assistance for his lunatic daughter in the forms of money and adult care. It used language that urged responsible parties to "prevent suffering" and provide for the paupers' "support and comfort" (CCM C:31, 58, 175-176). Furthermore, the stipends appear to have been generous, ranging from $\$ 10.00$ per month to $\$ 162 / 3$ per month, and they could be used for medical attention, lodging, food, clothing, coffins and graves, and transportation of individuals to the Lunatic Asylum in Austin.

In 1868, court records suggest changes in funding sources and an early attempt to bring some centralized organization to the disbursement of funds. Unlike other counties that imposed a tax for pauper care, Bell County sold lots in the vicinity of Belton and stated that the money raised was to be used for that purpose (CCM C:183). Within months of the sale, the court ordered the appointment of J. M. Kiser, who was directed "to take charge of the indigents in Bell County and to make such arrangements for their Support 
and Comfort as may be really necessary" (CCM C:194). This nascent structure appears to have remained in place during July 1868, when the court directed an agent to furnish food (meal and meat) to each pauper recognized by the court and to draw reimbursement for the cost of the items from the county fund (CCM C:200). However, less-directly regulated care activities continued, as well. During 1868-1869 and 1876-1879, individuals were paid for boarding, feeding, clothing, and otherwise supporting paupers. In other cases, the paupers themselves received the county funds, and by 1877 , there were 9 individuals ( 7 males, 2 females) who drew monthly appropriations that ranged from $\$ 6.00$ to $\$ 12.00$ from the county (CCM E:178). By May 1878, that number had doubled to 18 (14 men, 4 women); in August 1878, there were 15 (11 men, 4 women); in November 1878 , there were 14 individuals ( 11 men, 4 women); in November 1878, there were 14 individuals (11 men, 3 women); and by May 1879, there were 10 individuals (CCM E:263, 272, 291, 342).

While the number of county-supported paupers was relatively few (ca. 13.2 average between 1877 and 1878) when compared to the county population (9,771 in 1870 and 20,517 in 1880) (Connor and Odintz 1996:1:474), the commissioners' court made a decision to purchase a poor farm tract approximately 5.5 miles northwest of Belton from R. H. and Ella B. Turner. The purchase of the tract, which was unusually distant from the county seat, ${ }^{18}$ was consummated on January 16, 1879 (DR Y:236). Presumably, the county constructed the appropriate improvements on the property, and on September 1, 1879, Lucinda Shirley was sent to the poor farm (CCM E:360). There, she would have been greeted by the superintendent, George W. Raney, a white, 40-year-old farmer whose household included a 35-year-old wife, five children between the ages of 1 month and 13 years, and a 46-year-old English helper, who was a farmer (U.S. Bureau of the Census 1880).

The Bell County population statistics for

18 A sample of other farms, such as those in Cass, Bowie, Navarro, and Kaufman Counties, showed that county farms typically were no more than 1 to 2 miles distant from the county seat or some other population center. The benefits of proximity to urban centers were addressed by Alexander Johnson in 1911, when he recommended placing poor farms in the country, but proximate to population centers.
1880 indicated that the poor farm housed 10 pauper individuals ( 5 males, 5 females). Of the 10, 6 were adults and 4 were children. The 3 adult males included a single 44-year-old male who was maimed, crippled, or bedridden; a widowed 71-year-old male who was a carpenter; and a 76-year-old male who was a widowed preacher. The adult females included a mother and daughter (a 72-year-old widow and her 42year-old single daughter) and a mother who had 4 children who were 5 years old or younger. The special census made the same year enumerated 2 paupers who were being supported by the county outside of the poor farm: one suffered from heart disease and the second, who was classified as habitually intemperate, had cancer in his face. The 13 individuals at the poor farm (most of them enumerated in the population schedule) included the Wheat family (5 members), who suffered no disabilities. Other individuals suffered from old age or a combination of old age, paralysis, and other ailments (3); were crippled or crippled and epileptic (2); were paralyzed and idiotic from dropsy of the brain (1), or were paralyzed and epileptic (1). The only able-bodied individual male had no disabilities. None were habitually intemperate, and none were criminal.

George Raney remained the poor farm manager from 1879 to 1886 , successfully rebidding for the position each year. Typically, he agreed to feed the paupers for $\$ 5.00$ each per month. Sometimes he provided washing and mending services and supplied tobacco for an additional sum per head; he also offered to go for a physician, haul wood, and help the sick "in ordinary cases" for an additional $\$ 50.00$ per year. He promised to bury the dead on the poor farm and to furnish coffins at $\$ 10.00$ each (CCM G:311).

Despite the opening of the poor farm in 1879 and the improvements that were made to it, including construction of a cistern measuring 10 by 16 feet (CCM E:398) and providing furniture (CCM F:322), outdoor care continued at a robust pace. Paupers supported outside of the farm included blind individuals (CCM E:380; F:166, 322), lunatics (CCM E:398), idiots (CCM F:322), crippled individuals (CCM F:161, 312 ), and a number in "actual want" (CCM E:406). Pauper funds also were used to provide medical care to the paupers. A contract with Dr. S. N. Nunn in 1884 called for Nunn to be paid 
$\$ 250.00$ per year. In return, he was to supply medical attention and all medicines and drugs to the paupers on the poor farm, in the corporate limits of Belton, or confined in the Bell County jail (CCM F:287). The contract for 1886 specified that the county physician also was to examine applicants to the poor farm after the court decided that each was "a fit subject for admittance...so far as financial ability and character is concerned," and to ascertain whether or not the applicant was able to "make a livelihood" (CCM F:411).

In January 1886, Bell County agreed to sell the 125-acre poor farm on the Bowers Survey to George Raney, the superintendent (CCM F:409; DR 50:442-443). The same month, the commissioners accepted the offer of E. Brunet to sell the county 5.5 acres on the Leon River "near the Bridge and known as the Ice house property" for $\$ 950.00$. The new poor farm site was on the Connell Survey in northeast Belton, and the acreage was paid for out of funds received from the sale of the first poor farm (CCM F: 411, 412; DR 54:113).

The county improved the new poor farm on the Leon River with a two-story home and other buildings. Alterations and additions to the buildings occurred during the next decade and included the addition of a gallery on one side of the superintendent's house and the boxing in of another gallery (CCM G:365). The commissioners' court also authorized the addition of a room to "the house on the poor farm" for two of the female paupers (CCM G:432). In November 1894, the commissioners decided to construct an entirely new house because the paupers were not properly accommodated, and the sexes and races were not separated. The new paupers house would be two 14-foot-square rooms 10 feet high, with a single roof. It would be "box and stripped and ceiled overhead." Each room would have a stove flue. The two rooms would be connected by a door and there would be two outside doors and two windows to each room. The foundation would be cedar blocks and the cornice would be "plain box" (CCM H:154).

As in the past, a series of superintendents provided care to the paupers at the Leon River location. These included J. Brister (1888-1890), J. W. Ogletree (1890-1893), D. B. Birchfield (1893-1896), and W. B. Coburn (1896-?). Contracts were negotiated yearly between the commissioner's court and appli- cants for the position, and they laid out the rights and responsibilities of the superintendent. In November 1888, for example, the county furnished J. Brister the 5-acre poor farm with improvements, the use of two mules and harness, and all farming implements on hand: one cotton and corn planter combine, one turning plow, one stock and two sweeps, three shovels, one mattock (an implement for digging and grubbing), two picks, and three hoes. He also was granted the privilege of cutting and hauling wood he needed at the poor farm free of charge from a tract of land the county had purchased (CCM G:137). ${ }^{19}$

The county committed to pay Brister $\$ 6.00$ per head at the end of each month for each pauper at the poorhouse. Brister agreed to furnish the paupers with "good and sufficient food and to take care of, nurse and look after the same, to the best of his skill and ability." The county was to give the paupers the clothing, medicine, and medical attention they needed. In case of death, the county would furnish clothing and a coffin for the corpse, and Brister would dig the grave. Brister would receive his payment at the end of each month after filing a "verified account" that showed "the number of paupers on hand, the date of the entering or discharge of any pauper and the total amount due for the month just ended..." (CCM G:137).

The language of the agreement between the county and the poor farm manager set the terms for a relationship between manager and paupers that was intended to be solicitous, and entries in the commissioners' court minutes suggest that Brister, in particular, fulfilled that expectation. In 1890, for example, he apparently had approached the commissioners' court about a lunatic and an epileptic who were being kept in the county jail. The court gave Brister permission to take the two men from the jail to the pauper farm and attempt to care for them there (CCM G:217-224). In addition, the court was not without its own charitable behavior: in June 1892, the commissioners ordered the "graves at the poor farm fenced in and to included about one-fourth (1/4) of an acre of land" (CCM G:391). About five months later, the county authorized the marking of graves at

\footnotetext{
19 In February 1887, the county acquired 18 acres of timber land out of the J. J. Simmons Survey from D. W. McGlassen for $\$ 150.00$. Timber on the land was for the use of the poor farm (CCM G:29-30).
} 
the poor farm "with head boards \& names of dead" (CCM G:419).

While the official county posture towards paupers appears to have been solicitous, that of the community was not always. By 1887 , the concerns of Belton's citizens focused on the burial of pauper dead, and late in the year, some of them petitioned the court to purchase a piece of land other than the one-quarter acre that would be used as a burying ground for paupers (CCM G:77). A committee looked at a number of sites, and on January 2,1888 , members recommended acquisition of a 5-acre tract belonging to W. H. Edwards (CCM G:79). Soon after, the president of the Ladies South Belton Cemetery Association, Mrs. Lydia Alexander, petitioned the court to deed the South Belton Cemetery to her and her successors and to pass an order prohibiting the "further burying of paupers or negroes on said ground" (CCM G:93). This petition revealed that some pauper burials between 1886 and 1888 had been in the South Belton Cemetery as well as at the poor farm on the Leon River. The court signed a quitclaim deed to Alexander and proceeded with its plans to acquire the 5 -acre pauper cemetery site from Edwards. However, citizens living near the Edwards tract objected, and the court gave them the option of purchasing the property from the county (CCM G:93). It is unlikely that any burials occurred on the Edwards tract because of citizen objection and the short amount of time during which the county owned the 5 acres.

In the meantime, the county continued to practice a dual system of indoor and outdoor relief. Even incomplete lists of those receiving care by direct county grants or through thirdparty warrants suggest that the numbers identified with outdoor relief probably surpassed those receiving institutional care at the farm: in February 1887, the 13 paupers supported monthly by the county outside of the farm included 9 whites and 4 blacks of whom 8 were men and 5 women. Of those who suffered disabilities, 2 were idiots, 2 cripples, 2 blind, 1 infirm, and 5 aged (CCM G:33). In February 1888, the 16 paupers included 11 men and 5 women (CCM G:87), and in February 1890, there were 11 male and 10 female paupers (CCM G:226). A year later, the court enumerated 18 paupers (11 males, 7 females) (CCM G:303). In February 1892, the pauper list included 18 (10 males and
8 females) (CCM G:362), and by February 1893, the total had more than doubled to 42 , again primarily male (CCM G:438, 452). The number remained relatively high in February 1894 (26 total; 13 males, 13 females) (CCM H:173, 292). Paupers were predominantly white, and the next largest group was African-American; on occasion, a Hispanic appeared on the rolls. Typically, each pauper was provided $\$ 5.00$ to $\$ 10.00$ per month in the form of warrants that were given to third parties who were responsible for the care of the pauper. Medical attention for all paupers, whether in the Bell County jail, at the county poor farm, or in the city of Belton was provided by a series of doctors, who applied for the position just as the poor farm superintendents did for theirs.

Throughout the $1890 \mathrm{~s}$, the Bell County Commissioners Court wrestled with the question of whether indoor or outdoor relief was more economical. In February 1897, for example, the court instructed each commissioner to personally examine all paupers in their beats for the purpose of reporting on their conditions and their eligibility for designation as paupers so that the county could revise its pauper list, if necessary. In November, the court ordered an individual placed at the poor farm for "safe keeping" and receipt of "proper care." But the order was changed shortly thereafter to one providing for outdoor relief instead, because the commissioners believed that it would be more economical (CCM I:15, 77).

Finally, in early 1898 , the county commissioners met and reviewed the county's situation vis-à-vis its indigent population. The members stated on January 3 that for a number of years there had been about 40 paupers who had been drawing on the monetary resources of the county to the extent of about $\$ 300.00$ per month (outdoor relief) and another number at the county poor farm whose care was costing about $\$ 100.00$ per month. ${ }^{20}$ They concluded that the county should buy a larger farm that would be self-supporting, thereby lessening the fiscal burden on the county. The commissioners, having looked at several farms, settled on

20 The commissioners' statistic of approximately 40 paupers drawing outdoor relief in 1898 and an average from the population schedules for 1880 and 1900 of about 16 paupers at the poor farm at any given time shows the very small number of individuals who were indigent when compared to the total 1880 Bell County population of 20,517 and 1900 population of 45,535 . 
13 acres belonging to Miss J. Carothers and a farm belonging to $\mathrm{S}$. O. Wilson whose 200 acres were on the Leon River about 2 miles northeast of Belton. Wilson agreed to sell his property, and a deal was struck on January 10, 1898. Wilson's parcel was composed of four separate tracts and included land that would become the location of Bell County's third poor farm and a new paupers' cemetery at Pepper Creek (CCM I:99-100; DR 119:261-263). It lay east of the Gulf Colorado \& Santa Fe Railroad rightof-way and north of the river, and it was transected on the north end by Pepper Creek, which meandered through the property before emptying into the river. Access to the property was deeded to the county by W. M. and Mattie A. Sherrod on March 21, 1898, when the Sherrods sold 1.3 acres out of their property in the Nancy Chance League so that the county could build a road from the Belton and Temple Road to the new poor farm (DR 120:412-413). ${ }^{21}$

The Southwestern Telephone Company placed a line at the farm in early 1898 and, presumably, the county moved ahead with building improvements there to house the paupers and superintendent (CCM I:103). In March, the county noted a need to take out insurance, and the commissioners asked an agent to prepare policies that would cover $\$ 2,150.00$ worth of investment (CCM I:130). Paupers at the old farm were ordered to the new, and the county clerk was ordered to cease payments to all individuals on the paupers' roll in Bell County, with one exception (CCM I:100). The hopedfor result was that cessation of payments for outdoor relief would encourage all indigents in the county to move to the farm.

The new poor farm was located on more than 200 acres of prime farmland (an amount that increased with the purchase of additional acreage in October 1903), and so convict labor soon became an important component in its operation. By August 1899, the court had ordered the sheriff to take all male county convicts who owed fines and costs to the county and deliver them to superintendent W. B. Coburn. The next year, the convict gang who had been working on the Belton Little River Road was

${ }^{21}$ The road appears to have entered the property in the future vicinity of a pest house that was established in late 1900 in the north part of the farm near the railroad right-of-way. About the same time, a smallpox detention camp was authorized at an unidentified location on the farm (CCM I:377, 378). ordered to the poor farm with their tools, tents, and teams (CCM I:252, 357). There, Coburn took charge of them, presumably to provide necessary supplemental labor. They were a presence at the poor farm in both the 1900 and 1910 censuses (U.S. Bureau of the Census $1900,1910)$. In 1900 , the county convict population (also identified as day laborers) at the farm totaled eight of whom seven were black and one white, seven male and one female. In 1910 , there were six convicts and two convict guards. Convicts included two blacks, two mulattos, and two whites; of these five were male and one female. Presumably, the convicts assisted the farm superintendent with farm duties, including work on a special project in 1905 , when the county commissioners' court ordered the superintendent to set aside 10 acres of the farm and follow the directions and rules of the "Agriculture Department" in a cotton-raising experiment. The department would furnish the seed free of cost and fertilizer at cost. The superintendent then was to fertilize 5 acres and leave the balance unfertilized, and use identical seed and cultivation methods in each tract (CCM J:358).

Apparently in an effort to bring structure to the poor farm system, the county commissioners made an inventory of all Bell County property at the poor farm and filed the record with the county clerk (CCM J:348). They also required the superintendent to keep a set of books in which he recorded money received from the sale of farm products, the convict labor, sales of livestock, and all forms of income. He was to record all expenses incurred in farm maintenance, convict and pauper support, and all other expenses. The books would include lists of all paupers and convicts received, and dates of reception and discharge (CCM J:347-348).

The resulting records for the operation of the Bell County Poor Farm on the Leon River are missing from county archives. Consequently, for the 14 years during which the farm was located on the Leon River, only two federal censuses (1900 and 1910) provided profiles of the pauper population on the farm, and the 1900 census included incomplete information because portions of it were indecipherable. In 1900, the farm included 23 paupers, of whom at least 13 were white, 14 female, and 13 either widowed or single. One mother was present with her two young daughters; in another case, 
an adult mother and daughter were present. Otherwise, all inmates appear to have been unrelated. The household of the superintendent, William Coburn (40 years old), included his wife (37 years old), 5 children ranging in age from 5 to 18, and Coburn's mother, who was 79. In 1910, the superintendent was William J. Kennedy (50 years old), and his household included a wife (32 years old) and 5 children ranging in age from 1 to 16 . The 17 paupers included 9 females and 8 males of whom only 1 was married. Nine paupers were widowed and 7 single. There were 13 whites and 4 blacks, and 7 of the individuals were 60 years old or older.

One purpose of the Leon River poor farm had been to lessen the financial burden on Bell County that was associated with a dual support system in which the cost of outdoor care was three times that of care at the poor farm. ${ }^{22}$ It was for that reason that the commissioners had stated in 1898 that allowances paid to Bell County paupers would cease (CCM I:99-100). But it took only a few years for the dual system to resume in the county. In early 1905, receivers were appointed for each of three sets of paupers, who were allowed $\$ 5.00$ per month support (CCM J:283). Thereafter, the commissioners' court minutes made frequent references to paupers on the pension roll, on allowance from the county, or allowed groceries. In other cases, paupers received payments directly from the county. These activities were supplemented by care provided to the poor in Temple, where the King's Daughters and the Sisters of Divine Providence provided medical and burial services to paupers (Benoit n.d.:1-3). ${ }^{23}$

The pauper farm on the Leon River never achieved the level of self sufficiency the county had hoped for, despite the purchase of additional property in 1903 (DR 150:191). As early as 1911, the commissioners discussed selling the farm (CCM K:373-374), and it was apparent that they were not satisfied with arrangements to care for Bell County's indigent population.

22 The reasoning of the commissioners is not entirely clear. While the cost of outdoor care was three times that of care on the farm, the number of paupers provided outdoor care at any time was proportionately greater, as well.

23 In 1899, the Bell County Commissioners' Court began to provide $\$ 15.00$ per month to King's Daughters Hospital in Temple for providing medical treatment to Bell County paupers (Benoit n.d.:3).
Commissioners concluded in November 1912 that the facility, which was used as a detention farm for paupers and county convicts, was not "anything like a paying proposition as a farm...." It was a burden on the county taxpayers, and the county judge and commissioners voted to sell it (CCM L:2). The property was offered for sale, and J. P. Hellums offered the winning bid (CCM L:4). The county transferred the property to Hellums in a deed whose calls excluded the 1-acre paupers' cemetery north of Pepper Creek (DR 239:416-418).

Sale of the poor farm in November 1912 was followed in December by the purchase of 5 acres across from the North Belton Cemetery where the county intended to build a superintendent's home and three houses for the indigent population (CCM L:6). Eventually, this fourth county facility, called the County Home, had its own paupers' graveyard (Gardner 1995:9, 10), and county paupers were regularly admitted to the home, which provided care to indigents until it closed in 1969. The practice of outdoor relief continued as well, and county commissioners' minutes record numerous examples of individuals who received county funds, sometimes in the form of warrants amounting to $\$ 3.00$ to $\$ 10.00$ per individual. This practice persisted until at least the late $1960 \mathrm{~s}$.

In the meantime, the old paupers farm that had been purchased by J. P. Hellums in November 1912 (CCM L:4) appears to have retained an agricultural function. The tract was reduced in size in 1913 by the sale of 1 acre in the northwest corner of the property, and then it was sold to Ida Allen in August 1916 (DR 24:123; DR 276:72-73). Within two months, Allen sold the property to F. L. Denison (DR 282:197-198), who increased the size of the tract by purchasing land adjacent to it on the southwest corner (DR 294:142-143).

Denison, who came from a prominent Bell County family (his father was second district attorney for the judicial district that embraced Waco, and Denison helped his mother publish the Belton Reporter), conveyed the property to his wife, Callie, in July 1928 (DR 394:124-125). The next year, Callie sold the old poor farm tract and the land that had been added to it to H. R. Smith (DR 398:541-542).

Smith, who was born in Williamson County in 1885, was married to Minnie Pearl Ruble in 1906; the couple moved to Bell County in 1923 
(The Belton Journal, March 22, 1945:10). They probably moved to the poor farm tract shortly after they acquired it, and Smith became active in local community affairs. He became president of the Belton Farmers Cooperative Gin and Locker Association and served for five years as a member of the Farm Debt Adjustment Committee of Bell County's Farm Security Administration (The Belton Journal, March 22, 1945:3). According to a granddaughter, the Smiths also ran the Allis-Chalmers dealership in downtown Belton (Worley 2008).

A descendant and other relatives believe that the Smiths constructed a one-and-onehalf-story or two-story "colonial style" home on the property, as well as two barns, a garage and workshop, a secondary garage, stone water tank and attached laundry room and garage, sheep shed, storm cellar, and numerous other site improvements, including a cattle weigher and cattle chutes. Site features that may have been present before 1929 included two one-story frame houses, numerous small buildings that housed farm workers when the Smiths owned the property, and what descendants identified as a jail associated with the county convicts who worked on the pauper farm (Miller 2008; Ruble 2008; Worley 2008).

In 1940, the Smiths designated two tracts in the Chance Survey as their homestead. The first was $1601 \frac{1}{2}$ acres that lay along the Leon River and were adjacent to the historic poor farm tract on the west; the second was 39.5 acres in the northwest portion of the farm adjacent to the railroad right-of-way that included their home and the associated improvements (DR 484:242-243).

H. R. Smith died in Temple on March 18, 1945 , and the poor farm and nearby properties went to his widow (Probate File 4002). Their daughter, Elaine Smith Riley, and Riley's husband moved to the farm to help with its management, and the family continued to live on the property in the Smith home until it burned in December 1952. They then built another home adjacent to the original house site using materials from the McCloskey Hospital in Temple in about 1954 (Worley 2008). In 1985, Riley became Smith's guardian. Smith died on December 4, 1988, and her home on the Chance Survey burned the next year (Probate Docket No. 14,300; Temple Daily Telegram, December 6, 1988:6-B).
Minnie Pearl Smith had conveyed her property to the Baptist Foundation of Texas in 1959 with the understanding that she and her daughter had the right to occupy, use, manage, control, and receive benefits from it during their lifetimes (DR 801:437-439). With the deaths of Smith, and then Riley, the foundation obtained complete control of the property, and on September 6, 2005, it sold the 35.197 acres that included some or all of the improvements constructed by the Smiths and some remnants of the Bell County poor farm to Terrell and Geraldine Timmermann (DR 5826:126).

\section{CONCLUSIONS}

The history of public policy surrounding and scholarly interest in poor care in the United States has focused on topics such as the roots and causes of pauperism, the character of poorhouse and poor farm populations, demographic trends, and the long-term ill effects of pauperism on the poor themselves and on the larger society. While government-sponsored demographic studies have not always supported their conclusions, scholars and reformers after the mid-nineteenth century asserted that pauperism tended to be family-based and self-perpetuating, that specific classes of indigents should not be allowed to propagate, that children were particularly susceptible to the effects of pauperism, that alcohol played a role in indigence, that immigrants represented a disproportionate part of the pauper population, that poorhouses and poor farms exacerbated the worst effects of poverty, and that the intervention of social scientists was necessary to break cycles of dependency. Governmentsponsored studies often found little empirical evidence of multigenerational pauperism and suggested instead that pauper populations, particularly in poorhouses and poor farms, were very fluid, moving in and out of those institutions with frequency. The evidence also pointed to the decreasing numbers of paupers in institutions and the tendency for the institutional population to become increasingly weighted toward the elderly. Reformers and government entities, alike, agreed that certain classes of poor-those suffering from mental illness or mental deficiencies-were best off when segregated in their own state-run special-care institutions. In general, North American pauper 
care was locally based for most of its history, and so funding was local as well. Families were considered to be the primary caregivers, and laws concerning legal settlement and family responsibility were strong in most states.

Pauper care and the institutions designed to facilitate that care in Texas followed broad trends and patterns that were typical of the rest of the United States: local government was given responsibility by the state for funding indigent care, which was administered by a commissioners' court. Both indoor and outdoor care were funded in Texas, so not every county was the location of a pauper institution such as a poorhouse or poor farm. Beginning in the early twentieth century, reformers appeared who stressed the evils of poor farms and the importance of segregating classes of paupers so that individuals who suffered debilitating mental conditions could be housed in one of the state-run facilities. However, local institutions tended to be long-lived, perhaps due in part to their acceptance within the local community, the lack of alternatives for care, and the fact that federal programs failed to provide aid to a significant proportion of an increasingly elderly population until the second half of the twentieth century. In general, Texas pauper care appears to have been permissive, and local government exercised considerable latitude in making decisions about how best to care for county indigent populations. As a result, structure of care tended to change frequently as county officials responded to both an obligation to treat paupers in a humane fashion and a requirement to be responsible stewards of public funds.

Specific information about the architecture of a large sample of Texas poor farms is not available because so few survive. Most were located in close proximity to county seats or large urban centers, and almost all were associated with farms. Poor farm architecture uniformly included a superintendent's house that was sufficiently large to accommodate a family, cottages (usually frame) for inmates, support features such as wells and outhouses, outbuildings normally associated with agricultural activities, and a structure to accommodate county convicts who became part of the poor farm workforce around the turn of the last century. Cemeteries were located at all poor farms and would have been used for the interment of any county indigent, including those who received outdoor care, those housed at poor farms, and convicts.

A study of pauper care in Bell County reflects and reinforces the broader patterns of care in North America and Texas. County-level outdoor care was part of the fabric of indigent care in Bell County from its earliest days, and institutional care in the form of poor farms began shortly after passage of the 1876 state constitution that mandated the creation of county-level institutions. As in other counties, policy about care in Bell County appears to have been permissive, so that all races and age groups were accommodated; indoor and outdoor care coexisted; public and private postures towards paupers, particularly those suffering from disease or mental deficiencies, were solicitous; and local officials seemed little influenced by then-current reform theories about separation of classes of paupers, eugenics, and the innate evils reformers believed to be associated with poor farms and poor homes. Segregation of indigents who suffered debilitating mental conditions was rare in the nineteenth and early twentieth centuries, perhaps because there was insufficient space in state-run institutions to accommodate them.

A study of Bell County pauper care also reveals a number of interesting facts that may have a bearing on studies of other county-level indigent care facilities in Texas. First, while scholars generally discuss single institutions within a county, implying that the county poor farm occupied a single location, the Bell County example reveals that county commissioners were not averse to moving those institutions when practical considerations warranted it. As a result, Bell County was the location of no fewer than four county homes or poor farms between 1879 and 1969. Each of those institutions was the location of significant improvements that were associated with the history of pauper care in the county. Second, only a percentage of the indigent population of Bell County was accommodated in county institutions. Indeed, the system of outdoor relief that existed from the 1850 s to the 1960 s was, if anything, more vigorous and better-funded than that associated with indoor, or institutional, relief. As a result, any study purporting to inventory and analyze the extent and character of a county's pauper population cannot do so on the basis of federal population schedules and poor farm 
or poorhouse records alone. To do so would be to exclude the largest part of the indigent population. Finally, for all the attention paid to indigent populations, their size relative to the general population was extraordinarily small. Concerns about the effects of paupers on the genetics and economics of the larger, non-indigent population appear to have been unfounded through the mid-twentieth century, and their numbers did not warrant the expressions of alarm within the ranks of professional reformers that eventually dominated discussions about poor farms between 1900 and 1930 . The insufficiency of the arguments, together with the persistent need and local commitment to assist the indigent, may have been overriding factors in the persistence of what reformers considered to be an archaic mechanism for delivering care.

Poor care in Texas actually touched very few lives relative to the general population between the 1820s and 1960s. However, the institutions associated with the delivery of that care on a county level remain landmarks within a larger cultural landscape. Their relative rarity as property types and lack of archival documentation lend additional significance to the few remnants that still exist and to the records of their operation that survive.

\section{PRELIMINARY INVENTORY AND ASSESSMENT OF THE 1898-1912 BELL COUNTY POOR FARM}

The Bell County Pauper Cemetery on Pepper Creek, documented as archeological site 41BL1201, is but one component of the 1898-1912 Bell County Poor Farm. Located immediately east of IH 35 , the cemetery was at the far northern end of the old poor farm property and became isolated from the rest of the poor farm when IH 35 was constructed (Figure 13). During the previous phases of investigation that focused on the cemetery (see Table 1), it became apparent that a cluster of buildings and features west of Interstate Highway 35 , and about $1,500 \mathrm{ft}$ west-southwest of the cemetery, was on the poor farm property. Subsequent inquiries revealed that some of the structures at this location might have been associated with the poor farm. Following up on this information as part of the current project, the author and principal investigator obtained permission to visit the property from the current landowners, Terrell and Geraldine Timmermann, and the leasee, Burt Cummings. They visited the site to examine the historic resources on two occasions. The first visit was in August 2007 with Mr. Cummings, and the second visit was in January 2008 with Carl and Joy Riley Worley. The onsite interviews (Cummings 2007; Worley 2008) were informative and provided important information relating to the history of the property and individual buildings and features on it. Notably, H. R. and Minnie Pearl Smith purchased and moved to the property in the late $1920 \mathrm{~s}$, and Mrs. Worley, their granddaughter, was a young girl there in the late 1940s. While Mr. Cummings' knowledge of the historic resources was primarily second hand (i.e., stories he had heard from many different sources), Mrs. Worley had more intimate knowledge of the resources from having grown up on the property. She remembered many secondhand stories about the older resources that were on the property when she was a little girl or that existed when her grandparents acquired the land. She also provided many firsthand recollections about buildings and features that were built by her family or modified while they owned the property.

During the site visits, a detailed inventory was made of all buildings and features within the main farm-ranch complex west of the highway that were either visible or were pointed out by Mrs. Worley. Digital photographs also were taken to document each building and feature within this portion of the property. Each resource was assigned a unique number and plotted on large-scale prints of modern aerial photographs. UTM coordinates also were obtained for each resource using a handheld, recreation-grade GPS unit. These locations were then plotted on the aerial photographs to create a detailed map of historic resources (Figure 14), with the locations being accurate within about $5 \mathrm{~m}$. Observations and historical notes were tabulated to create an inventory of the historic resources (Table 2) keyed to the location map.

The inventory includes two kinds of historic resources: (1) resources that have physical evidence remaining (i.e., standing structures and features, as well as rubble and artifact concentrations where structures or features once 


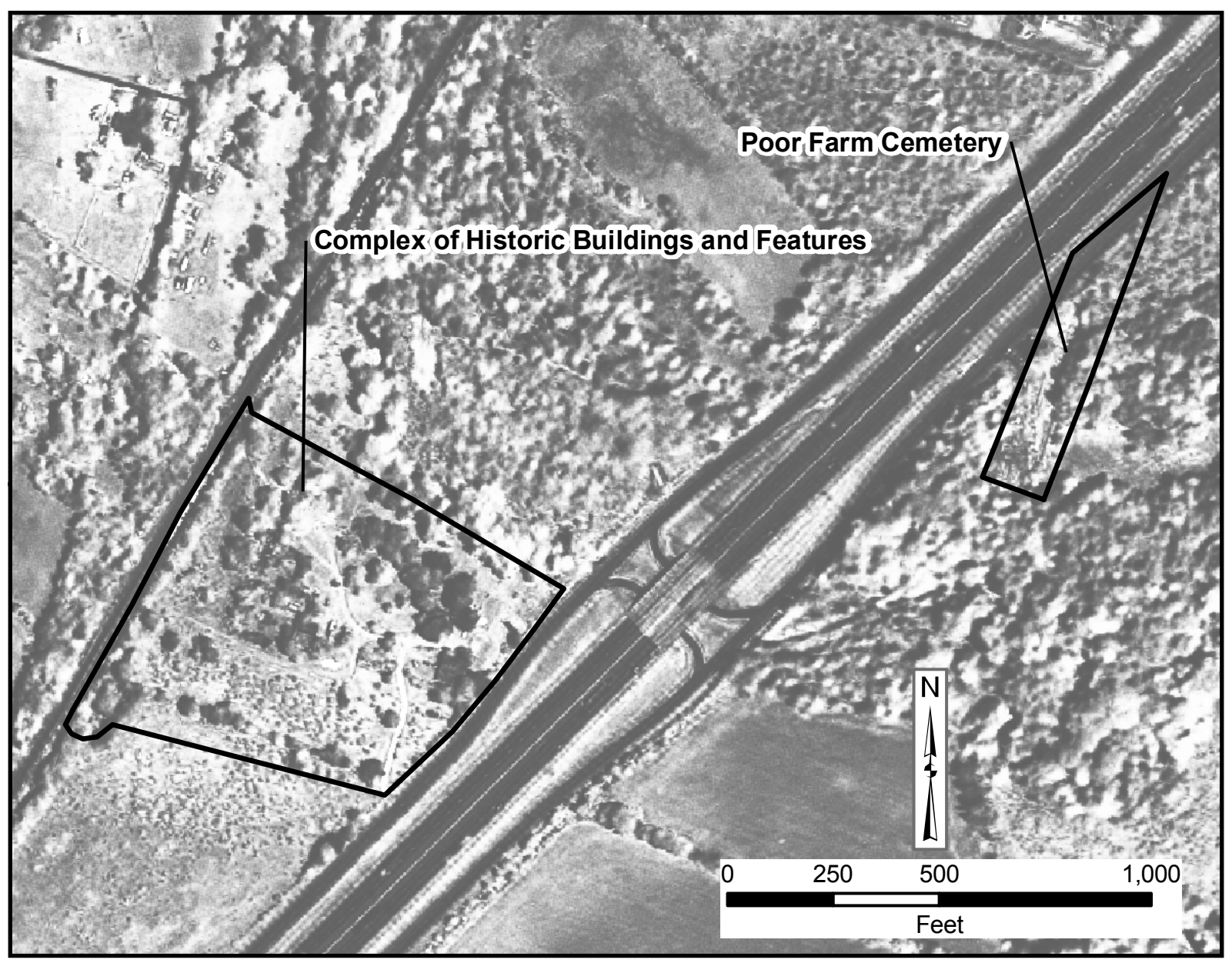

Figure 13. Modern aerial photograph showing Interstate Highway 35, the Bell County Pauper Cemetery on Pepper Creek, and the complex of historic buildings and features on the 1898-1912 Bell County Poor Farm property. Base image August 8, 2004, aerial photograph from the U.S. Department of Agriculture, National Agricultural Imagery Program, Aerial Photography Field Office, Salt Lake City, Utah (available from the Texas Natural Resources Information System online at http://www.tnris. state.tx.us).

existed), and (2) resource locations that were remembered by informants but have little or no physical evidence remaining. It includes 24 existing historic resources as well as 8 possible resource locations. Of the existing resources, only 3 were definitely associated with the 1898-1912 poor farm. Structure No. 1 is a wood frame building that was a Bell County jail used to house inmates sent to work on the poor farm. Structures 6 and 11 are wood frame houses that may have been used as housing for indigent people being cared for by the county or perhaps by the poor farm superintendents and their families. While all three of these structures were certainly used for other purposes after 1912, the buildings are in relatively good condition and do not appear to have been seriously modified. Besides these structures, at least 10 other buildings, features, or locations are identified as being of unknown age or possibly being associated with the poor farm (see Table 2).

Presenting a complete and well-supported evaluation of the resources, relative to National Register eligibility criteria, is beyond the scope of this study. However, three facts are notable and indicate that the 1898-1912 Bell County Poor Farm may well be eligible for listing on the National Register of Historic Places. First, the historic contextual framework presented in this report reveals that poor farms played an important role in the history of indigent care 
in Texas. Second, poor farms that have original standing structures, features, and associated cemeteries are very rare in Texas. And third, the Bell County property appears to contain some relatively intact components associated with the turn-of-the-century poor farm and therefore is an good example of this property type. In conclusion, the historic resources on the Bell County Poor Farm property warrant additional consideration if there will be any impacts to the location associated with the proposed improvements to the Interstate Highway 35 corridor. If the property will be impacted, it is recommended that the following tasks are appropriate and warranted: (1) additional archival and oral history research focused in particular on the improvements made at the poor farm in the 1898-1912 period, (2) more thorough onsite investigations of existing historic buildings and features, and (3) archeological investigations of selected locations and suspected resource areas. The goals of this additional work would be:

- to more fully document the history of the poor farm

- to provide a better inventory and assessment of the existing resources on the poor farm property (broadening the survey to include the entire poor farm property)

- to investigate and identify the suspected resource areas on the poor farm property

- to identify and evaluate all resources that were associated with (built or used by) the Bell County Poor Farm from 1898 to 1912 . 


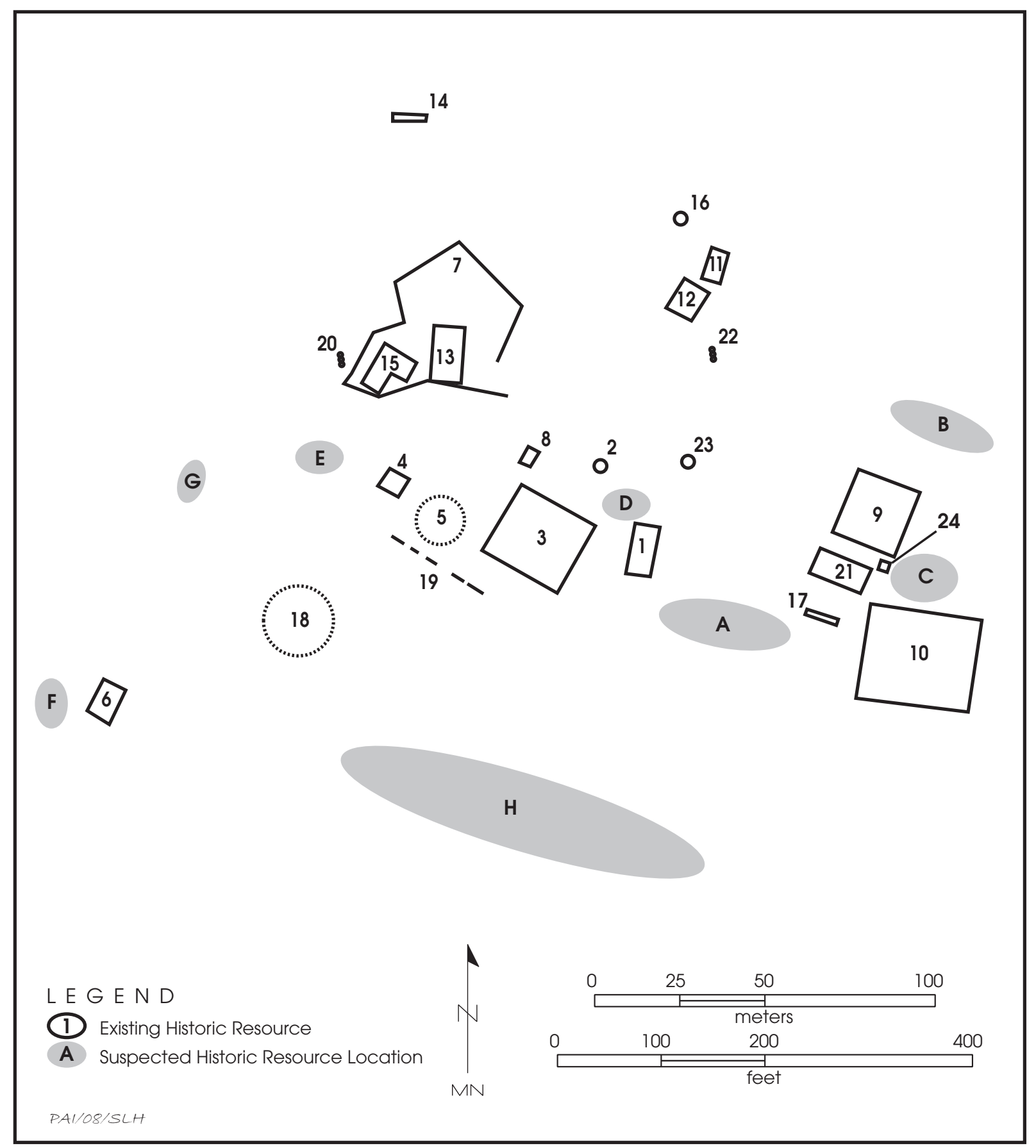

Figure 14. Map of historic resources located on the 1898-1912 Bell County Poor Farm property west of Interstate Highway 35. 


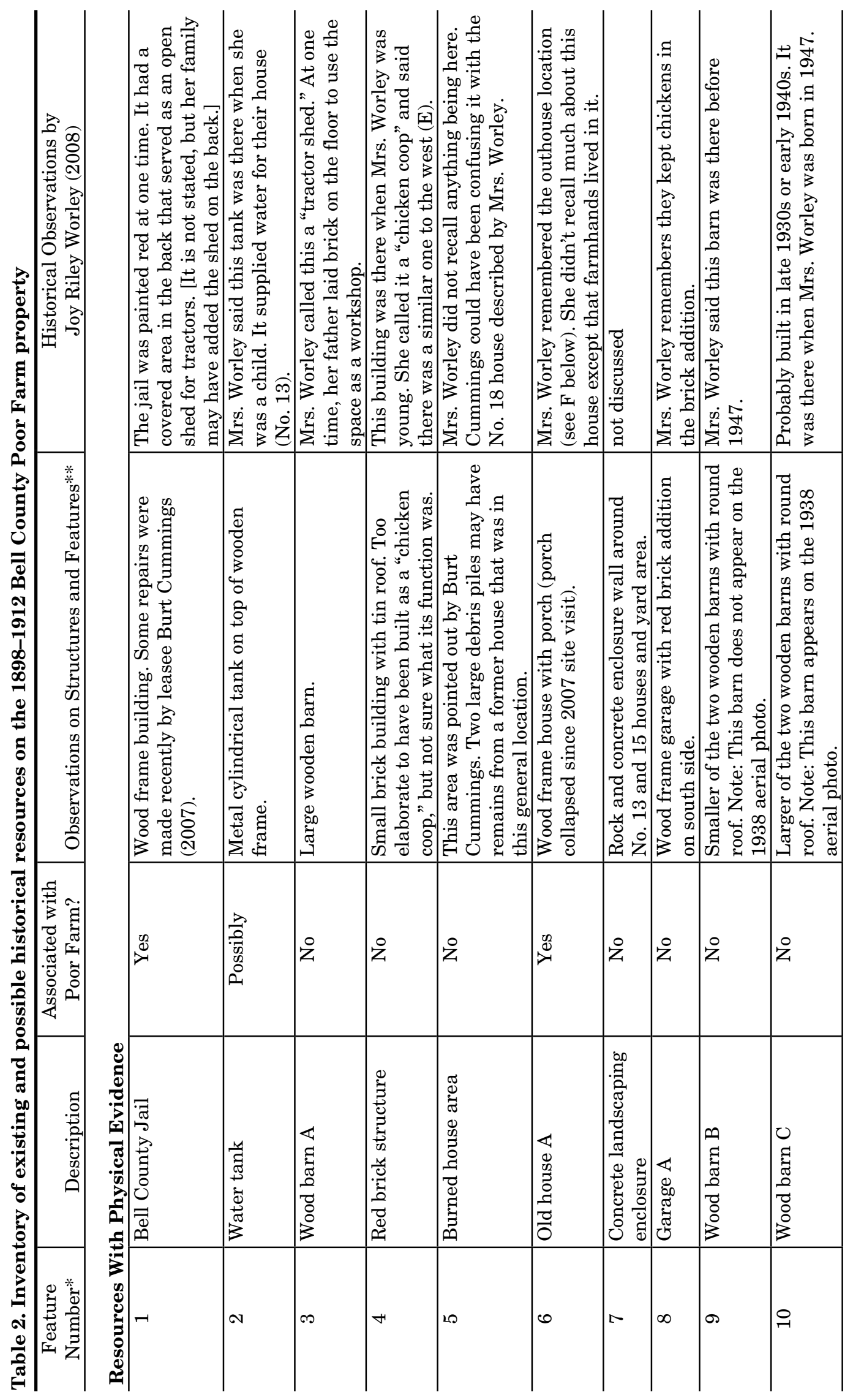




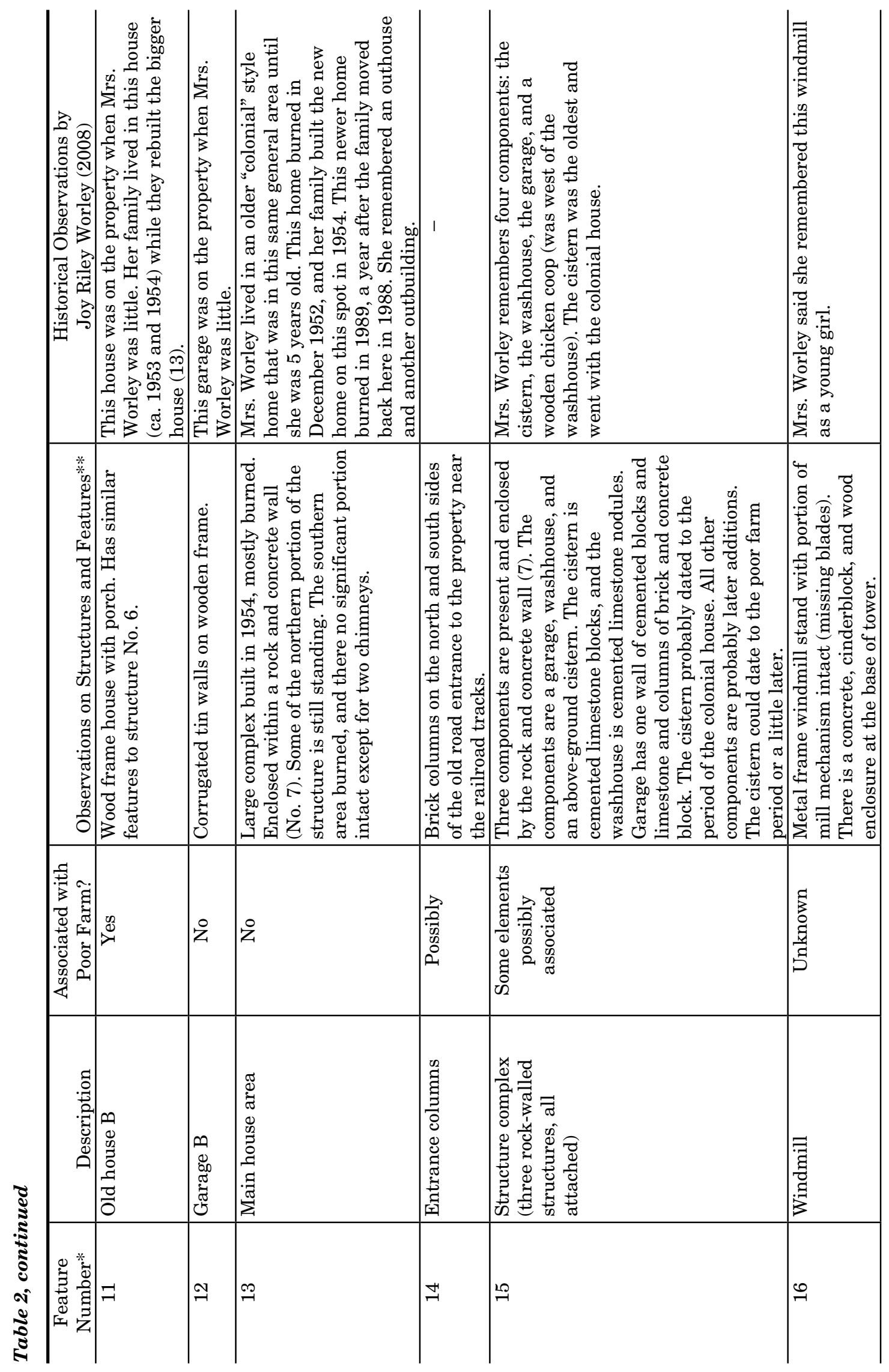




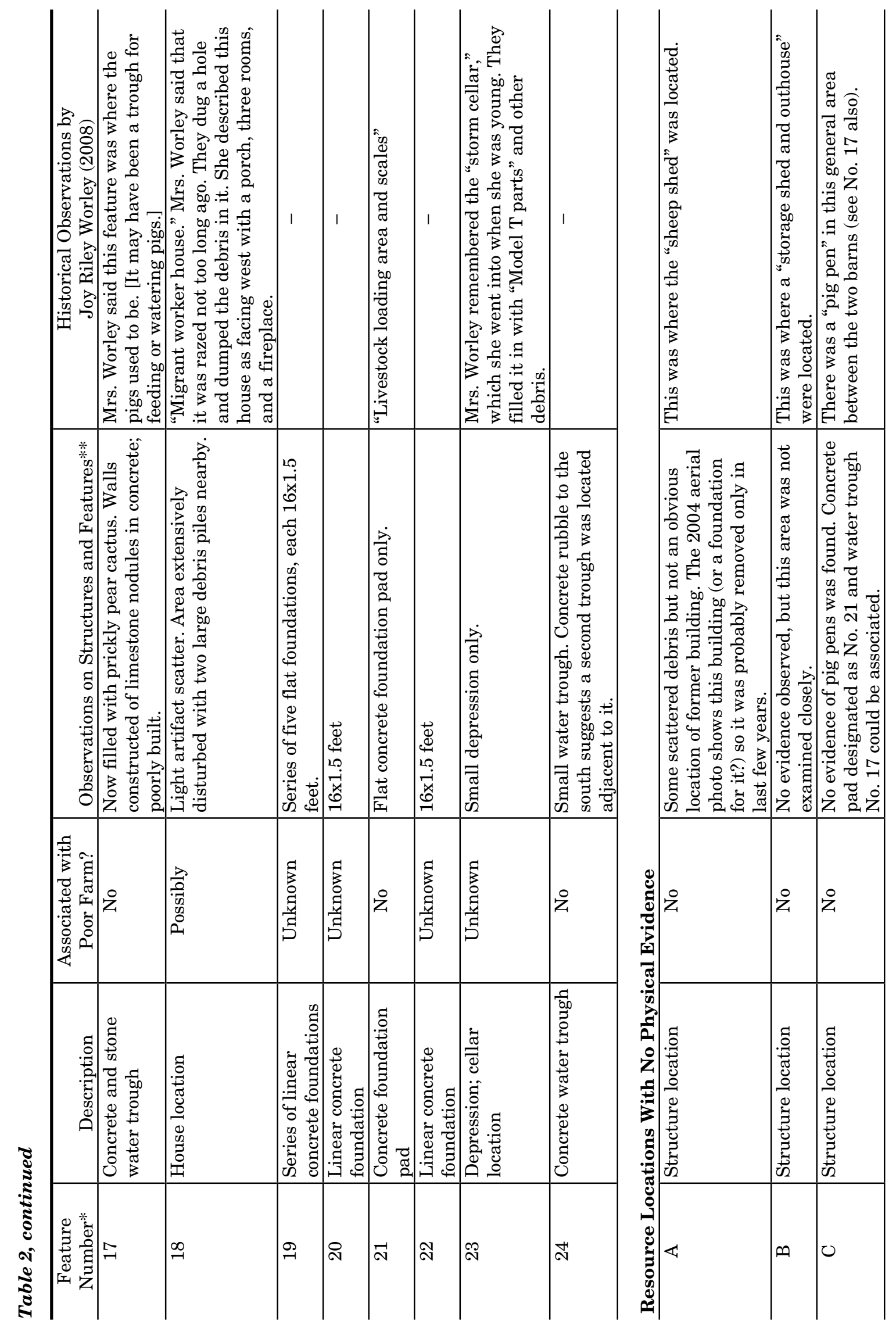




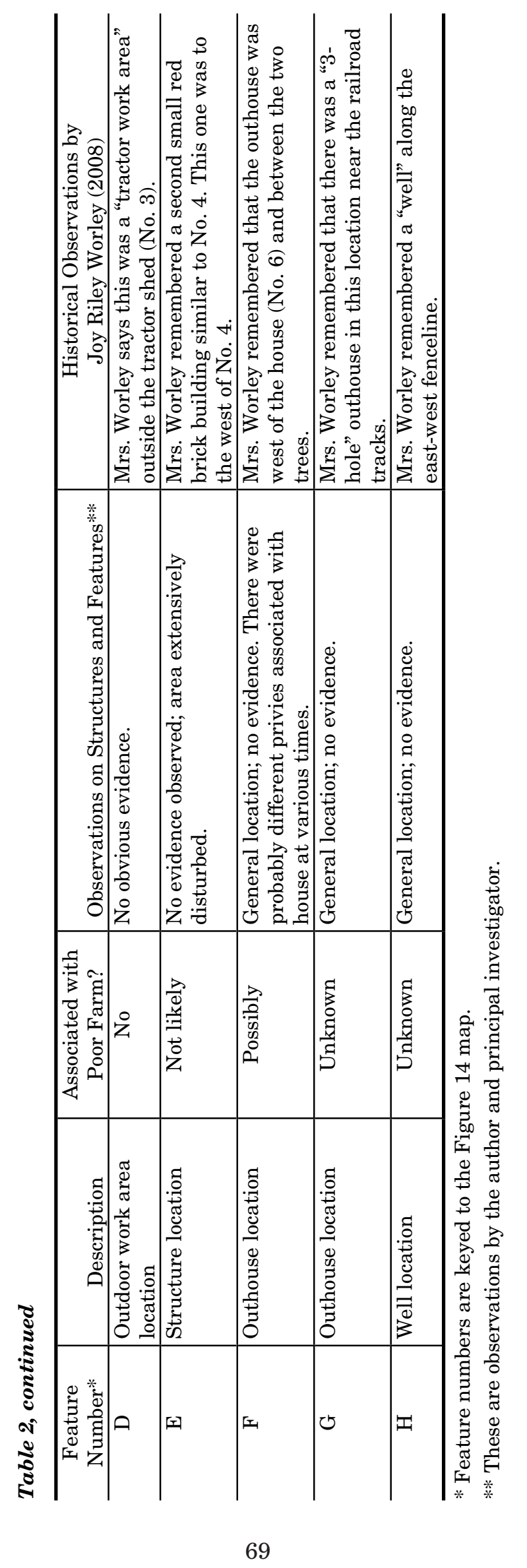




\section{REFERENCES CITED}

Bell County, Texas

County Commissioners Minutes

Deed Records

Probate Dockets

Probate Files

Belton Journal, The

Belton Reporter

Benoit, Patricia K.

n.d. Brief Time Line of Bell County Medicine. The author, Temple, Texas.

Bland, Jeanette

1994 Some Early Charity Cases in Collin County, Texas. Collin Chronicles. Spring 1993/4.

Borah, Woodrow

1966 Social Welfare and Social Obligation in New Spain: A Tentative Assessment. Center for Latin American Studies, Institute of International Studies, University of California, Berkeley.

Brett, Anna

n.d. Bowie County Poor Farm. Available from http://www. rootsweb.com/txkusa/poorfarm/ bowiecountypoorfarm.htm [accessed May 11, 2007].

Brown, Roy M.

1928 Public Poor Relief in North Carolina. The University of North Carolina Press, Chapel Hill.

Bruce, Benjamin

2007 The Parker County Poor Farm: Rich in History and Nature. Available from http:// poorfarm.benjaminbruce.com/aboutweb. html [accessed May 27, 2008].

\section{Carpenter, Edna Turley}

1960 Tales from the Manchaca Hills. Edited and recorded by Jane and Bill Hogan. The Hauser Press, New Orleans, Louisiana.
Cathey, Velma Lee

1949 History of Public Welfare Legislation in Texas. M.A. thesis, North Texas State College, Denton.

Chipman, Samuel

1834 Report of an Examination of Poor-Houses, Jails, \&c. in the State of New-York and in the Counties of Berkshire, Massachusetts; Litchfield, Connecticut; and Bennington, Vermont. The American Quarterly Temperance Magazine II (May).

Clement, Priscilla Ferguson

1985 Welfare and the Poor in the NineteenthCentury City. Philadelphia, 1800-1854. Associated University Presses, Inc., Cranbury, New Jersey.

Connor, Seymour V., and Mark Odintz

1996 Bell County. In The New Handbook of Texas. Volume I. The Texas State Historical Association, Austin.

Cottrell, Debbie Mauldin

1989 The County Poor Farm System in Texas. Southwestern Historical Quarterly 93 (October):169-190.

Crannell, Linda M.

2003 Poverty vs. The American Dream: A Clash of Reality on the Frontier (or How Poor Relief was Different in the West). Available from http://www.poorhousestory.com/ PovertyAmerDream.htm [accessed September 2, 2003].

Cray, Robert E., Jr.

1988 Paupers and Poor Relief in New York City and Its Rural Environs, 1700-1930. Temple University Press, Philadelphia, Pennsylvania.

Cummings, Burt

2007 Interview with Burt Cummings at the Bell County Poor Farm Site, August 8, 2007. Photographs and interview notes by Martha Doty Freeman and Douglas K. Boyd. 
Dallas Morning News, The

De la Teja, Jesus F., and John Wheat

1985 Bexar: Profile of a Tejano Community, 1820-1832. Southwestern Historical Quarterly 89 (July):7-34.

Devine, Edward T.

1916 Pauperism:An Analysis. Studies in Social Work, Number 9. The New York School of Philanthropy, New York, New York.

Evans, Harry C.

1926 The American Poorfarm and Its Inmates. The Loyal Order of Moose, The Brotherhood of American Yeomen, the Maccabees, The Supreme Tribe of Ben Hur, and The American Insurance Union. N.p., n.p.

Foster, L. L.

2001 Forgotten Texas Census: First Annual Report of the Agricultural Bureau of the Department of Agriculture, Insurance, Statistics, and History, 1887-88. Texas State Historical Association, Austin.

Gammel, Hans Peter Mareus Neilsen, compiler and arranger

1898a The Laws of Texas, 1822-1897. Volume I. The Gammel Book Company, Austin, Texas.

1898b The Laws of Texas, 1822-1897. Volume II. The Gammel Book Company, Austin, Texas.

1898c The Laws of Texas, 1822-1897. Volume IV. The Gammel Book Company, Austin, Texas.

1898d The Laws of Texas, 1822-1897. Volume V. The Gammel Book Company, Austin, Texas.

1898e The Laws of Texas, 1822-1897. Volume VI. The Gammel Book Company, Austin, Texas.

1898f The Laws of Texas, 1822-1897, Volume VII. The Gammel Book Company, Austin, Texas.

1898g The Laws of Texas, 1822-1897. Volume VIII. The Gammel Book Company, Austin, Texas. 1898h The Laws of Texas, 1822-1897. Volume IX. The Gammel Book Company, Austin, Texas.

1911 The Laws of Texas. Volume XV. Gammel's Book Store, Austin, Texas.

Gardner, Janet Clayton, compiler

1995 Record of Inmates of County Home, Bell County, Texas, 1913-1969. The author, Huntsville, Texas.

Gilbertson, H. S.

1917 The County: The "Dark Continent" of American Politics. The National Short Ballot Organization, New York.

Graves, Dr. M. L.

1905 The Care of the Insane. Bulletin of The University of Texas No. 63. The University of Texas, Austin.

Green, Elna C., editor

1999 Before the New Deal: Social Welfare in the South, 1830-1930. The University of Georgia Press, Athens, Georgia.

Harris, Wm. J.

1915 Paupers in Almshouses, 1910. Department of Commerce, Bureau of the Census. U.S. Government Printing Office, Washington, D.C.

Hazard, Thomas R.

1851 Report on the Poor and Insane in RhodeIsland; Made to the General Assembly at its January Session, 1851. Joseph Knowles, State Printer, Providence, Rhode Island.

Hoffman, Frederick L.

1919 Pauper Burials and the Interment of the Dead in Large Cities. Prudential Press, Newark, New Jersey.

Hunt, Kathey Kelley

2008 Kaufman County Poor Farm, Kaufman County, Texas. Available from http:// www.poorhousestory.com/TX [accessed February 7, 2008].

James, Arthur W.

1926 The Disappearance of the County Almshouse in Virginia: Back from "Over the Hill." Davis Bottom, Superintendent of Public Printing, Richmond, Virginia. 
Johnson, Alexander

1911 The Almshouse, Construction and Management. Charities Publication Committee, New York.

Jones, Anson

1859 Memoranda and Official Correspondence Relating to the Republic of Texas, Its History and Annexation. D. Appleton and Co., New York.

Kansas Board of Control

1908 Second Biennial Report of the Board of Control of the State Charitable Institutions of Kansas, for the Two Years Ending June 30, 1908. State Printing Office, Topeka, Kansas.

Kansas Emergency Relief Committee

1935 A Study of Kansas Poor Farms. Bulletin KERC No. 307. The Kansas Emergency Relief Committee, Topeka, Kansas.

Katz, Michael B.

1986 In the Shadow of the Poorhouse: A Social History of Welfare in America. Basic Books, New York.

Kaufman County Historical Commission

2007 Kaufman Poor Farm Project. Available from http:www.kaufmantx.com/history. html [accessed May 11, 2007].

Kennedy, William

1841 Texas: The Rise, Progress, and Prospects of the Republic of Texas, Vol. I. R. Hastings, London, England.

Lowe, Robert C., and Staff

1937 Digest of Public Welfare Provisions Under the Laws of the State of Kansas. Works Progress Administration, Washington, D.C.

McClure, Ethel

1968 More Than a Roof: The Development of Minnesota Poor Farms and Homes for the Aged. Minnesota Historical Society, St. Paul.

McKay, S. S.

1996 Constitution of 1869. In The New Handbook of Texas. Volume 2. The Texas State Historical Association, Austin.

Miller, Joanne Ruble

2008 Telephone conversation with Joanne Ruble Miller, Centerville, Texas, January 11, 2008, by Martha Doty Freeman.
Murchie, R. W.

1933 Land Settlement as a Relief Measure. The University of Minnesota Press, Minneapolis.

Neff, Pat M.

1923 Speeches Delivered by Pat M. Neff, Governor of Texas, Discussing Certain Phases of Contemplated Legislation. Von Boeckman-Jones Co., Printers, Austin, Texas.

Nelson, Mary McKenney

1926 A History of the Care of Defectives in Texas. M.A. thesis, The University of Texas, Austin.

Olmsted, Frederick Law

1857 Journey Through Texas, Or, A SaddleTrip on the Southwestern Frontier. Dix, Edwards \& Co., New York.

Philadelphia Board of Guardians

1827 Report of the Committee Appointed by the Board of Guardians of the Poor of the City and Districts of Philadelphia, to Visit the Cities of Baltimore, New-York, Providence, Boston, and Salem. Samuel Parker, Philadelphia, Pennsylvania.

Poynter, J. R.

1969 Society and Pauperism: English Ideas on Poor Relief, 1795-1834. Routledge \& Kegan Paul, London.

Ruble, Charles

2008 Interview with Charles Ruble, San Antonio, Texas, by Martha Doty Freeman, January 11, 2008.

San Antonio Light, The

Sedgwick, Theodore

1844 Thoughts on the Proposed Annexation of Texas to the United States. D. Fanshaw, New York.

Smith, Mary Roberts

1896 Almshouse Women: A Study of Two Hundred and Twenty-Eight Women in the City and County Almshouse of San Francisco. Stanford University, Palo Alto, California.

Stafford, Paul Tutt

1941 Government and the Needy: A Study of Public Assistance in New Jersey. Princeton University Press, Princeton, New Jersey. 
Stewart, Estelle M.

1925 The Cost of American Almshouses. Bulletin of the United States Bureau of Labor Statistics No. 386. Government Printing Office, Washington, D.C.

Stow, Jean Howe

1974 Cass County Poor Farm. Frontier Times 48 (December-January):22-23, 63-64.

Temple Daily Telegram

Texas Eleemosynary Commission

1925 Report of the Texas Eleemosynary Commission to the Governor and the Members of the Thirty-Ninth Legislature of Texas. House of Representatives of Texas, Austin.

Texas Historical Commission

Historical Markers: Anderson County Poor Farm

Galveston County Poor Farm

Kaufman County Poor Farm

Parker County Poor Farm

Smith-McCrery Home

Wise County Poor Farm

Thomann, G.

1884 Real and Imaginary Effects of Intemperance: A Statistical Sketch, Containing Letters and Statements from the Superintendents of Eighty American Insane Asylums, the History of Five Hundred Inebriates, the History of Six Hundred and Seventy-one Paupers, and Statistics of Drunkenness; Together with a Review of the Operations of Prohibitory and Restrictive Laws, and the Gothenburg System. The United States Brewers' Association, New York.

Thrall, Homer S.

1879 A Pictorial History of Texas. N. D. Thompson \& Co., St. Louis, Missouri.

Turner, Thomas E.

1996 Pat Morris Neff. The New Handbook of Texas. Volume 4. The Texas State Historical Association, Austin.

Tuten, James H.

1999 Regulating the Poor in Alabama: The Jefferson County Poor Farm, 1885-1945. In Before the New Deal: Social Welfare in the South, 1830-1930, edited by Elna C. Green. The University of Georgia Press, Athens.
United States Bureau of the Census

1880 Bell County

1900 Bell County

1910 Bell County

United States Department of Commerce, Bureau of the Census

1914 Summary of State Laws Relating to the Dependent Classes 1913. Government Printing Office, Washington, D.C.

1915 Paupers in Almshouses, 1910. Government Printing Office, Washington, D.C.

1925 Paupers in Almshouses, 1923. Government Printing Office, Washington, D.C.

United States Department of Commerce and Labor, Bureau of the Census

1906 Special Reports: Paupers in Almshouses, 1904. Government Printing Office, Washington, D.C.

United States Department of the Interior, Census Office

1895 Report on Crime, Pauperism, and Benevolence in the United States at the Eleventh Census: 1890. Part II. Government Printing Office, Washington, D.C.

1896 Report on Crime, Pauperism, and Benevolence in the United States at the Eleventh Census: 1890. Part I. Analysis. Government Printing Office, Washington, D.C.

Wagner, David

2005 The Poorhouse: America's Forgotten Institution. Rowman \& Littlefield Publishers, Inc., New York.

Warfield, George A.

1915 Outdoor Relief in Missouri, a Study of its Administration by County Officials. Survey Associates, Inc., New York.

Webb, Sidney and Beatrice, editors

1909 The Break-Up of the Poor Law: Being Part One of the Minority Report of the Poor Law Commission. Longmans, Green and Co., 39 Paternoster Row, London.

Whiteside, Ruth A.

1973 The Impact of the Texas Constitution on Public Welfare. N.p., Houston, Texas. 
Worley, Joy Riley

2008 Interview with Joy Riley Worley at the Bell County Poor Farm Site, January 4, 2008. Site map, photographs, and interview notes by Martha Doty Freeman and Douglas K. Boyd.

\section{Writers' Program}

1942 Houston, A History and Guide. Anson Jones Press, Houston, Texas.

Yancy, Hon. Wm. Lowndes

1845 Speech of Hon. Wm. Lowndes Yancey, of Alabama, on the Annexation of Texas to the United States. Harris \& Heart, "Constitution" Office, n.p.
Yates, John

1971 Report of the Secretary of State in 1824 on the Relief and Settlement of the Poor. In Thirty-Fourth Annual Report of the New York State Board of Charities. Reprinted in The Almshouse Experience, Collected Reports. Arno Press \& The New York Times, New York.

Yoakum, C. S.

1914 Care of the Feeble-minded and Insane in Texas. Bulletin of The University of Texas No. 369. The University of Texas, Austin. 
